\title{
The pathophysiology of stress urinary incontinence: a systematic review and meta-analysis
}

\author{
Kobra Falah-Hassani ${ }^{1} \cdot$ Joanna Reeves $^{1} \cdot$ Rahman Shiri $^{2} \cdot$ Duane Hickling $^{3,4} \cdot$ Linda McLean $^{1}$ (D)
}

Received: 8 October 2020 / Accepted: 16 November 2020 / Published online: 8 January 2021

(C) The Author(s) 2021, corrected publication 2021

\begin{abstract}
Introduction and hypothesis To evaluate the evidence for pathologies underlying stress urinary incontinence (SUI) in women. Methods For the data sources, a structured search of the peer-reviewed literature (English language; 1960-April 2020) was conducted using predefined key terms in PubMed and Embase. Google Scholar was also searched. Peer-reviewed manuscripts that reported on anatomical, physiological or functional differences between females with signs and/or symptoms consistent with SUI and a concurrently recruited control group of continent females without any substantive urogynecological symptoms. Of 4629 publications screened, 84 met the inclusion criteria and were retained, among which 24 were included in meta-analyses. Results Selection bias was moderate to high; $<25 \%$ of studies controlled for major confounding variables for SUI (e.g., age, BMI and parity). There was a lack of standardization of methods among studies, and several measurement issues were identified. Results were synthesized qualitatively, and, where possible, random-effects meta-analyses were conducted. Deficits in urethral and bladder neck structure and support, neuromuscular and mechanical function of the striated urethral sphincter (SUS) and levator ani muscles all appear to be associated with SUI. Meta-analyses showed that observed bladder neck dilation and lower functional urethral length, bladder neck support and maximum urethral closure pressures are strong characteristic signs of SUI. Conclusion The pathology of SUI is multifactorial, with strong evidence pointing to bladder neck and urethral incompetence. While there is also evidence of impaired urethral support and levator ani function, standardized approaches to measurement are needed to generate higher levels of evidence.
\end{abstract}

Keywords Stress urinary incontinence $\cdot$ Females $\cdot$ Ultrasound $\cdot$ Magnetic resonance imaging $\cdot$ Electromyography $\cdot$ Dynamometry

\section{Introduction}

Urinary incontinence has a prevalence of up to $28 \%$, with stress urinary incontinence (SUI) being the most common form [1]. SUI is defined by involuntary loss of urine during tasks (e.g., coughing) in which bladder pressure exceeds the pressure at which the urethra has the capacity to remain closed [2]. Diagnosis of SUI and subsequent management decisions appear to be best evaluated by subjective report [3]; however,

Linda McLean

linda.mclean@uottawa.ca

Faculty of Health Sciences, University of Ottawa, Ottawa, Canada

2 Finnish Institute of Occupational Health, Helsinki, Finland

3 Ottawa Hospital Research Institute, Ottawa, Canada

4 Department of Surgery, Division of Urology, The Ottawa Hospital, Ottawa, Canada subjective measures do not offer any information about contributing pathology and do not inform any potential opportunity to personalize interventions.

Objective, summative measures of continence function, such as abdominal leak point pressure (ALPP) or Valsalva leak point pressure (VLPP), determined through urodynamic assessment, are used to confirm SUI, but do not reflect symptom severity or predict treatment outcome [4]. ALPP is defined as the intravesical pressure at which urine leakage occurs in the absence of a detrusor contraction. Yet there is currently no standard application of ALPP and no consensus on its utility in guiding management decisions [5]. While not validated through empirical data, McGuire et al. suggested that, among women with SUI, ALPP $<60 \mathrm{cmH}_{2} \mathrm{O}$ is related to intrinsic sphincter deficiency while ALPP $>90 \mathrm{cmH}_{2} \mathrm{O}$ is related to urethral hypermobility [6].

Maximum urethral closure pressure (MUCP) is another summative urodynamic measure used to confirm SUI. While MUCP does not capture true fluid pressure but rather an artifact of the total urethral closure force [7], and outcomes 
depend on the technology used (microtip catheter transducers, water perfusion catheters, air-charged balloon catheters [8]), it may have utility in terms of understanding the pathophysiology of SUI. Schick et al. suggested that MUCP is impacted by both urethral hypermobility [9] and intrinsic sphincter insufficiency [10], yet there are many continent women with low MUCP and there are women with SUI who demonstrate high MUCP [5]; as such, compensatory strategies, such as levator ani muscle (LAM) contraction, may also be important.

Prevailing theory suggests a combination of disruption in the supportive connective tissues of the bladder and urethra [11] and weakening of the muscular structures of the pelvic floor, bladder neck and urethral sphincters [12] all lead to reduced urethral closure pressure [13] and lower ALPP [5], functionally resulting in SUI $[14,15]$.

Support of the urethra depends on its fascial attachment to the arcus tendinous fasciae pelvis and connective tissue attachments to the pubis [16]. Impaired anatomical support of the bladder neck and proximal urethra is associated with urethral hypermobility, which is thought to impede the transfer of loads induced by the descending pelvic structures to the urethra, resulting in less extrinsic closure force, and ultimately with urine leakage. The mobility of the urethra can be detected visually [17] and through palpation and can be measured using magnetic resonance imaging (MRI) or ultrasound scanning (USS) [18]. However, detection may be biased when women are asked to perform tasks that may result in urine leakage; women may limit their effort [19] or co-contract the levator ani muscles (LAMs) [20] to avoid the embarrassment of leakage.

The pelvic floor muscles (PFMs), including the LAMs, coccygeus, perineal muscles, striated urethral sphincter (SUS) and external anal sphincter, form the base of the abdomino-pelvic cavity and contribute to the support of the pelvic contents and continence control [21]. The LAMs are considered a functional unit which provides support to the pelvic organs in the transverse plane (lifting) and compresses the urethra against the anterior vagina in the mid-sagittal plane (squeezing). Damage to or dysfunction of the LAMs is thought to be a contributor to SUI [22-25].

LAM structure and function can be evaluated through many different approaches (Table 1) [55, 56]. USS and MRI can identify gross damage to the LAMs such as avulsion [57], and strain (microtrauma) can be inferred through the size of the levator hiatus [58]. Manual palpation can be used to detect levator avulsion [59]; yet, while it is commonly used in clinic to assess LAM strength [60], there are limitations around reliability and precision [51]. Intravaginal dynamometry is recommended as the best approach to directly measure LAM force-generating capacity [61]; yet, as with manometry, only force contributions in a single plane are recorded, and measures may be contaminated by intra-abdominal pressure [48].

While electromyography (EMG) amplitude does not translate directly to force output [62], when applied correctly, kinesiological EMG recordings from the LAMs can be useful to determine the extent and timing of LAM activation during functional tasks, i.e., motor control. However, surface EMG recordings of the LAMs can carry a high risk to external validity and detection bias due to a number of measurement issues (Table 1), for example, concurrent activity recorded from nearby muscles is inseparable from that of the LAMs (crosstalk) [45]. Dynamic USS and MRI have identified urogenital landmark motion, through which LAM activation has been inferred [63] (e.g., anterior and cranial motion of the anorectal angle), an approach that has recently been validated [64].

Distinct from kinesiological EMG, clinical EMG involves the recording of evoked potentials and motor unit potentials, the latter normally studied using needle electrodes. Clinical EMG findings can be used to infer myopathic and neuropathic processes. While studies have been few, results have suggested that damage to the pelvic and/or pudendal nerves may be implicated in SUI [65]. While the external anal sphincter is part of the PFM complex, it is not thought to contribute to urinary continence function, but is an accessible muscle through which pudendal nerve integrity can be evaluated.

The SUS is considered part of the PFM complex, and it appears to be a major contributor to urinary continence control [66], alongwith thesmoothmusclesurroundingtheurethraand bladder neck [67]. Contraction of the SUS, achieved through voluntary or automatic control, provides a direct closure force atthemid-urethra[68]. Additionally, intrinsicurethralclosure forces are generated through longitudinal and circular smooth musclesoftheurethralsphincter. KinesiologicalEMGrecordedfromtheSUSmayprovidevaluableinformationaboutreflex and motor control; however, it is not commonly measured, as the sphincter muscles are not accessible without invasive methods. To supplement sphincteric closure forces, passive (bulk) forces are generated by perfusion of the urethral blood vessels and a hermetic seal is produced by mucoid secretions from the urethral epithelium [69].

In light of the complex interactions among tissue morphology, mechanical properties, perfusion, innervation and motor control, several factors may contribute to the pathophysiology of SUI, yet the evidence for many of these factors has not been systematically evaluated, and their relative importance is largely unknown. The aim of this systematic review and meta-analysis was to synthesize the evidence for the different morphological and pathophysiological mechanisms associated with SUI.

\section{Methods}

\section{Search strategy}

We used the Preferred Reporting Items for Systematic Reviews and Meta-Analyses (PRISMA) guideline [70] to 
Table 1 Measurement and methodological issues associated used in the included studies

Assessment method Measurement issue

Electromyography (EMG)

- Data susceptible to crosstalk, the recording of activity from nearby muscle groups that cannot be distinguished from true pelvic floor muscle activity

- Valid comparisons not possible between groups without normalization because of differences in impedance, muscle depth and muscle fiber orientation

- Normalization challenging because of possible difficulties in being able to perform voluntary maximum pelvic floor contractions

- Normalizing PFM EMG data using MVCs reported to have the smallest standard error of measurement and minimal detectable difference compared to a cough, Valsalva and abdominal crunch maneuvers; however, the participants in the study did not have any form of PFM dysfunction and results may differ in a population with SUI [26]

- Artifact from probe movement

- Variety of devices used: Periform ${ }^{\mathrm{TM}}$ (NEEN Mobilis Healthcare Group, UK) [27-29]; Lifecare PR-02 (Everyway Medical Instruments Co., Taiwan) [30, 31]; VET-A (Nanjing Vishee Medical Technology, Ltd.) [32]; Femiscan ${ }^{\mathrm{TM}}$ (Mega Electronics Ltd., Kuopio, Finland) [33, 34]; STIMPONTM (Innocept Biobedded System $\mathrm{GmbH}$ ) [35-39], a custom probe [25] and unspecified [40] as well as disposable surface electrodes (Mediwatch, UK or Medtronic, Minneapolis, MN) attached to a sponge $[41,42]$

- While the Periform ${ }^{\mathrm{TM}}$ and Femiscan ${ }^{\mathrm{TM}}$ have demonstrated poor between-day reliability [43], large coefficients of variation [44] and large standard error of measurement [29], to the authors' knowledge, the reliability of the STIMPON, Lifecare PR-02 and VET-A probes have not been published in a peer-reviewed journal. The cylindrical tripolar electrode design of the STIMPON would be particularly prone to motion artifact, especially when used during dynamic tasks such as running and jumping [45]

- Allegedly good reliability of PFM EMG variables in running across 10 steps in one session based on high ICCs; however, minimal detectable differences were very large $87 \%$ of MVC for maximum activity [46]), and high reliability does not reflect validity (i.e., crosstalk contamination), especially as high activity of hip external rotator muscles has been shown while running [47]

Ultrasound imaging (USI) and magnetic resonance imaging (MRI)

- Affected by bladder volume and the multiplanar orientation of the pelvic flor

- Affected by posture

- Lack of standardized procedures, positions, outcome measures and terminology

Manometry, dynamometry and perineometry

- Embarrassment about leakage might prevent women with SUI straining as directed, especially when assessors not blinded

- Difficult to establish whether a true maximum was performed

- Intra-abdominal pressure can be misinterpreted as forces having been generated through PFM action $[48,49]$

- Confounding effect of intra-abdominal pressure greater with perineometry (where air- or fluid-filled chambers inserted into the vagina record pressure changes within the chamber resulting from the sum of the forces acting on all surfaces of the chamber, including forces generated by the descent of the pelvic organs) than with dynamometry [50]

- Measures of maximum force-generating capacity may be confounded by poor motor control [33]

Digital palpation

- Subjective and poor reliability [51]

- Lacks the sensitivity to gauge small changes in pressure) [52]

Terminology

- Task nomenclature is not standardized

- Straining sometimes referred to as during cough or Valsalva maneuver, yet not specified

- Tendency for straining and Valsalva to be used interchangeably when they have been shown not to be equivalent [53]:

The correct instructions suggested for a Valsalva have been described as: "take a breath, then close the mouth, pinch the nostrils with the thumb and the index finger, then blow air forcefully toward the blocked mouth and nostrils and direct the increasing pressure into the ears" while for straining: "take a breath, then contract the abdominal muscles and strain downwards with the intention to evacuate stool or urine" [53]. Using these instructions, with the Valsalva there was diaphragm and pelvic floor elevation, while with straining there was pelvic floor descent [53]. Another study showed that bladder neck displacement was similar in a cough and Valsalva in incontinent women, but was lower during the cough than Valsalva in both parous and nulliparous controls [54], despite greater abdominal pressures recorded during the cough than during the Valsalva across groups

- Furthermore, it has also been shown that the Valsalva maneuver can be accompanied by co-contraction of the levator ani in nulliparous women, affecting measurement of bladder neck descent [20] 
develop the study protocol registered in PROSPERO (CRD42020180715). We conducted literature searches in PubMed (Table 2) and Embase from 1960 until April 2020 using predefined key terms. We limited the searches to adult females. We also searched Google Scholar and manually searched the reference lists of eligible articles for publications not identified in the initial search.

\section{Study eligibility}

Studies were deemed eligible if they: (1) were reported as full text in English; (2) reported the results of peerreviewed research based on cross-sectional, case control or cohort studies on women with SUI; (3) included women $>16$ years of age; (4) assessed some aspect of urogenital structure or function related to SUI; (5) concurrently recruited a comparison (control) group of continent women.

Studies were excluded from the review if: (1) the control group reported urogynecological symptoms including urgency incontinence, dyspareunia or pelvic organ prolapse, or were diagnosed with neurological disease/disorder or cancer; (2) in addition to SUI, cases had a concurrent urinary tract abnormality, e.g., fistula, tumor, etc.

\section{Data extraction}

Data were extracted by three independent reviewers (KFH, JR and RS) including year of publication, country, study population, sample size, outcome measures, assessment method and adjustment for covariates.

\section{Quality assessment}

The three reviewers (KFH, JR and RS) independently rated the risk of bias in the included studies using criteria adapted from the Effective Public Health Practice Project Quality Assessment Tool (Table 3) [71]. Studies were rated on selection bias (i.e., response rate and representativeness of the sample), detection bias (i.e., whether the outcome measures were valid and reliable) and confounding variables. Detection bias with respect to the diagnosis of SUI was not assessed because both self-report questionnaires and urodynamic methods have limitations, and there is still no gold standard for diagnosis [72]. Attrition bias was not considered applicable as studies were cross-sectional in nature. Lack of blinding was classified as performance bias (during data collection) and/or detection bias (during analysis) [73]. The authors discussed and resolved disagreements in quality ratings until consensus was reached including, when necessary, the input of the senior author (LM).

\section{Data synthesis}

The results were synthesized qualitatively, and, where possible, meta-analyses were conducted using a random-effects model in R Studio using the METAFOR package [74]. For studies that reported means and standard deviations for subgroups of patients with SUI, we calculated grand means and pooled standard deviations for total cases for meta-analysis. We used raw or standardized mean difference, the latter using Hedges' g to weight group standard deviation by sample size, for continuous outcomes [75] and risk ratios for count data. We assessed heterogeneity across the studies using the $\mathrm{I}^{2}$ statistics [76].

Table 2 PubMed search string

\begin{tabular}{|c|c|c|}
\hline Search & Query & \\
\hline$\# 1$ & 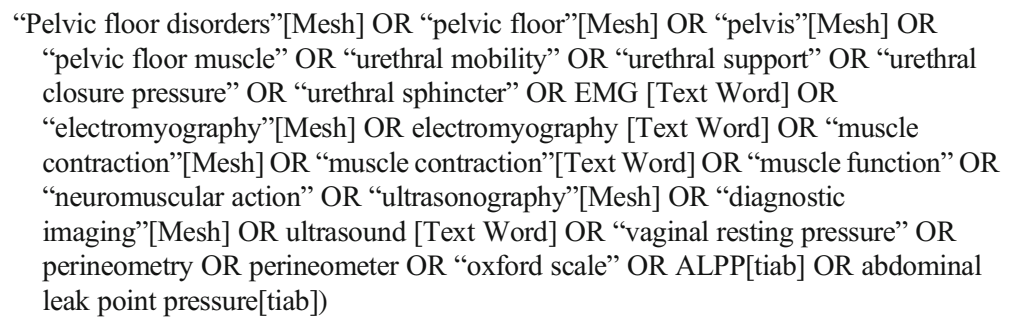 & $2,979,216$ \\
\hline \#2 & $\begin{array}{l}\text { "Urinary incontinence, stress"[Mesh] OR "urinary incontinence"[Mesh] OR "stress } \\
\text { urinary incontinence" OR incontinent [Text Word] }\end{array}$ & 35,419 \\
\hline \#3 & $\begin{array}{l}\text { "Control groups"[Mesh] OR control [Text Word] OR continence [Text Word] OR } \\
\text { continent [Text Word] OR "healthy volunteer" OR asymptomatic [Text Word] OR } \\
\text { without stress incontinence [Text Word] }\end{array}$ & $4,012,744$ \\
\hline \#4 & $\begin{array}{l}\text { Female }[\text { MeSH Terms] OR female [Text Word] OR women [MeSH Terms] OR women } \\
\text { [Text Word] OR woman [Text Word] }\end{array}$ & $8,929,022$ \\
\hline \#5 & $\# 1$ AND \#2 AND \#3 AND \#4 & 2842 \\
\hline Final & \#5 NOT (Clinical Trial[ptyp] OR Review[ptyp]) & $2065 / 2091$ \\
\hline
\end{tabular}


Table 3 Risk of bias assessment

\begin{tabular}{|c|c|c|}
\hline $\begin{array}{l}\text { Type of } \\
\text { domain }\end{array}$ & Criteria definition & Classification (potential for bias) \\
\hline $\begin{array}{l}\text { Selection } \\
\text { bias }\end{array}$ & $\begin{array}{l}\text { Sampling method of the study population, } \\
\text { representativeness (response rate, difference } \\
\text { between responders and non-responders) }\end{array}$ & $\begin{array}{l}\text { Low: Target population defined as representative of the general population or } \\
\text { subgroup of the general population (specific age group, specific geographic area and } \\
\text { specific occupational group) and response rate is } 80 \% \text { or higher } \\
\text { Multicenter study } \\
\text { Moderate: Target population defined as somewhat representative of the general } \\
\text { population, a restricted subgroup of the general population, response rate } 60 \%-79 \% \\
\text { Single-center study } \\
\text { Limited details of the method of recruitment and study population } \\
\text { High: Target population defined as self-referred/ volunteers, or response rate }<60 \% \\
\text { Single-center study } \\
\text { Very limited details of method of recruitment and study population }\end{array}$ \\
\hline $\begin{array}{l}\text { Detection } \\
\text { bias }\end{array}$ & $\begin{array}{l}\text { Valid and reliable assessment } \\
\text { of pelvic floor function }\end{array}$ & $\begin{array}{l}\text { Low: Normalized EMG, ultrasound } \\
\text { Moderate: Vaginal palpation, assessment method prone to some measurement issues } \\
\text { High: EMG reported in } \mu \mathrm{V} \text {, not normalized, assessment method prone to several } \\
\text { measurement issues }\end{array}$ \\
\hline
\end{tabular}

\section{Results}

A total of 4629 abstracts were screened. Of those, 4399 abstracts were excluded on first pass, and 230 relevant studies were identified. Studies with no control group or with a control group that had other significant lower urinary tract symptoms were excluded $(n=150)$. No studies were excluded based on the age of the participants, and all reported on women aged $\geq 18$ years. Two studies were excluded $[77,78]$ because they were considered to be from predatory journals [79]. Ultimately 84 studies were included in the review, and 24 studies were included in the meta-analyses (Fig. 1 and Appendix (Table 4). The majority of studies confirmed SUI through some form of self-report or urodynamics. Selection bias was rated as moderate or high in all cases. Eighteen studies [19, 27, 28, 32, 33, 66, 83, 88, 91, 93, 97, 108, 114, 130, 133, $135,136]$ controlled for all or most major known confounders of urinary incontinence, 43 studies controlled for some confounders, and 23 studies did not match or control for any confounding factor. Over two thirds of the studies $(61 / 84)$ did not report blinding the assessors to any of the outcomes. Detection bias ranged from low to high, with issues around measurement fidelity being associated with most assessment methods (Table 1).

\section{Summative measures of SUI}

\section{Abdominal leak point pressure}

No study using ALPP as an outcome met the inclusion criteria.

\section{Functional urethral closure}

Several studies found that maximal urethral pressure (MUP) measured at rest [14, 83, 96-98, 115, 122] and MUCP (the difference between MUP and bladder pressure using filling cystometry) $[10,14,15,93,96-98,105,115$, 116] were lower in stress-incontinent than in continent women. Urethral closure pressure measured in supine position was negatively associated with greater severity of SUI [95]. Among urethral closure pressure, measures of urethral support and other parameters (e.g., levator hiatus size, urethral axis on LAM contraction, LAM strength, levator defect status) and maximal cough (intravesical) pressure, MUCP was the strongest determinant of SUI ( $n=211$, Cohen's $\mathrm{d}=1.47$ [93]). In other studies, the best predictor of clinically significant SUI was urethral incompetence, defined using residual MUCP, closure pressure measured during a cough [10] or MUCP alone [93]. Minimum urethral closure pressure on coughing was also significantly lower in stress-incontinent women than in continent controls [98], whereby women were instructed to cough forcefully until leakage was observed at the urethral meatus [10].

The meta-analyses of standardized mean difference showed that MUP (the inward pressure exerted by the walls of the urethra) (Hedges' $\mathrm{g}=-0.95,95 \% \mathrm{CI}-1.58$, $-0.32,4$ studies, Fig. 2) was lower in stress-incontinent $(n=1034)$ compared to continent $(n=336)$ women, and MUCP (Hedges' $\mathrm{g}=-1.42$, 95\% CI $-1.93,-0.92$, 8 studies, Fig. 2) was lower in stress-incontinent $(n=1122)$ compared with continent $(n=342)$ women. Similarly, MUP (pooled raw mean difference $=-16.39 \mathrm{~cm} \mathrm{H}_{2} \mathrm{O}$, 95\% CI -5.98 to $-26.80,4$ studies) and MUCP (pooled raw mean difference $=-26.52 \mathrm{~cm} \mathrm{H}_{2} \mathrm{O}, 95 \% \mathrm{CI}-35.63$ to 


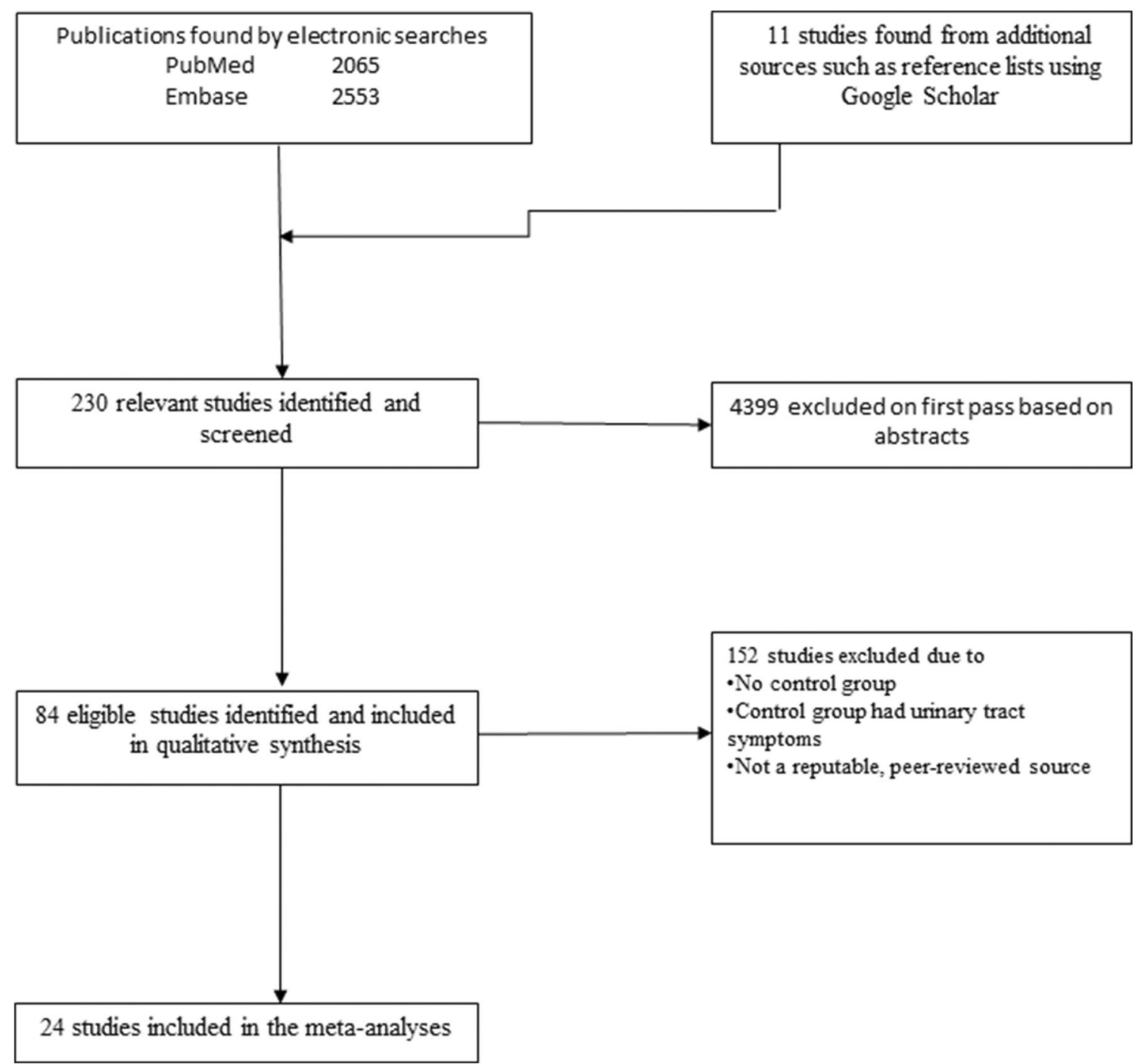

Fig. 1 Flow chart of the search strategy and selection of studies

- 17.41, 8 studies) were significantly lower in women with SUI compared to continent women.

\section{Individual factors contributing to SUI}

\section{Urethra and bladder neck}

\section{Morphology}

Urethral morphology Nine studies reported on urethral morphology, six using USS [88, 97, 102, 104, 106, 136] and three using MRI [101, 110, 111]. Compared to continent women, the thickness of the mid-urethra in women with SUI seen on USS was not significantly different in the lateral aspects of the striated muscle layer [104], the longitudinal and circular smooth muscle layers [104] or more generally [106]. However, using USS, cohorts of stress-incontinent women have demonstrated shorter and more cranial positioning of the urethral sphincter complex at rest [88] and smaller area and circumference of the sphincter muscles compared to continent controls [102], the latter consistent with MRI findings that stressincontinent women had significantly thinner SUSs than continent women [101]. Indeed, MRI is the better measurement for this application due to tissue orientation and boundary conditions that can interfere with tissue resolution on USS [137].

Through transvaginal USS, it was found that women with SUI had a distinct midurethral echogenicity pattern where the loose urethral structures were hypoechoic and the anterior region of the mid-urethra was more echogenic compared to controls after adjustment for confounders [120]. Consistent with this, using shear wave elastography, women with SUI were found to have lower stiffness of the SUS than continent women [136], yet 


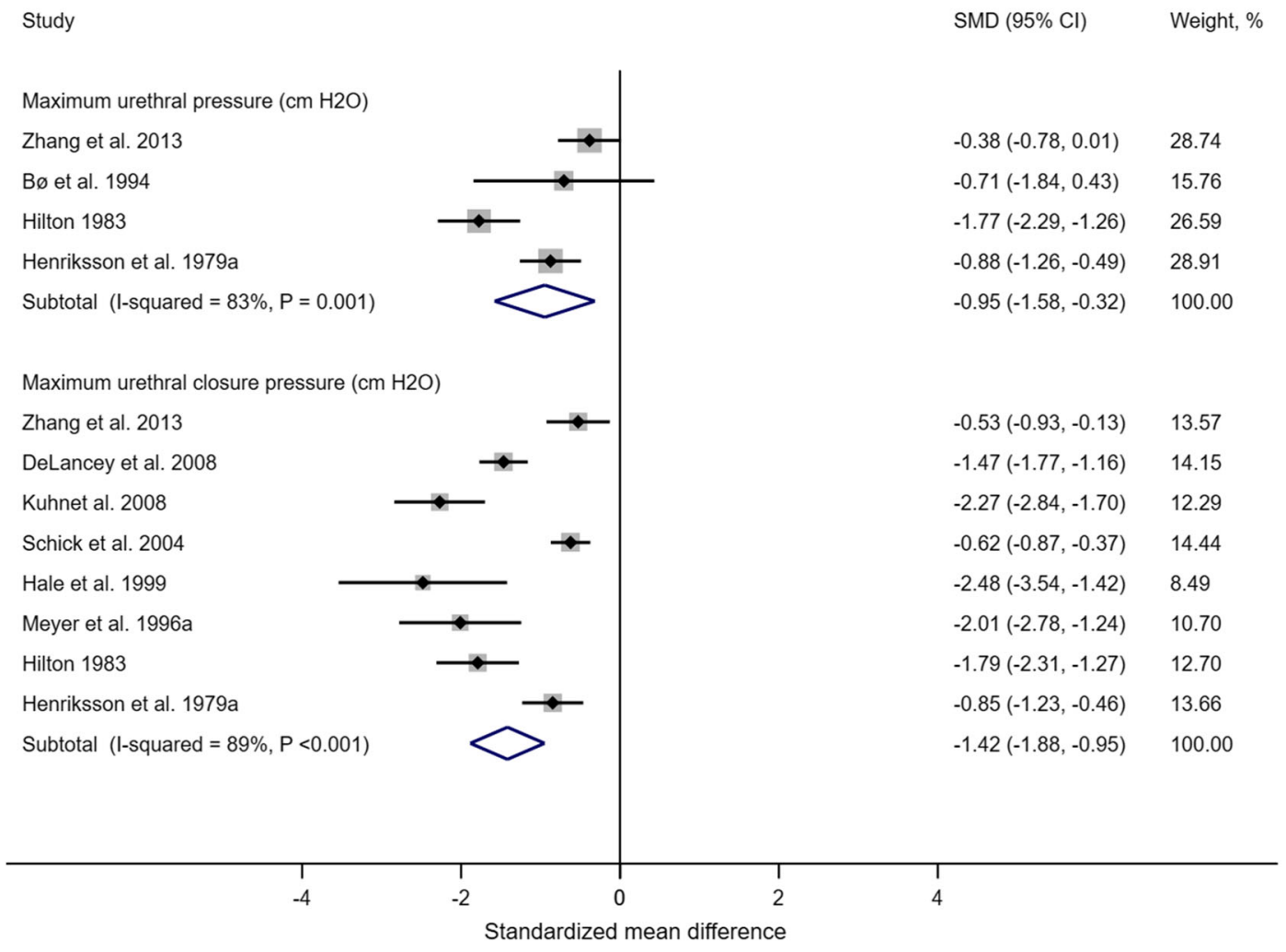

Fig. 2 Standardized mean differences (SMD) in the maximal urethral pressure (MUP) and maximal urethral closure pressure (MUCP) in stress-incontinent women compared with continent women. For studies by Hilton (1983) and Henriksson et al. (1979b), average values across SUI severity and age groups were used respectively. For the study by Meyer et al. (1996a) an average of SUI groups with and without a low

boundary conditions may be an issue with this USS approach.

Urethral length Total urethral length was reported using urethrocystometry [96], microtransducer catheter [98], sonography [119] and MRI [111], and results are inconsistent. Authors reported both shorter [96, 98, 111], longer [119] and no difference [123] in urethral length between stressincontinent and continent women.

Functional urethral length, defined as the length of the urethra along which urethral pressure exceeds intravesical pressure, presumably represents the location of the urethral sphincters. Several studies [14, 96-98, 111, 119], but not all [116] found greater functional urethral length in continent than in stress-incontinent women. Shorter functional urethral length appears to be associated with greater severity of SUI $[95,98]$. Meta-analysis showed that functional urethral length was $3.58 \mathrm{~mm}$ (95\% CI -5.83 to $-1.33 \mathrm{~mm}, 5$ studies) shorter pressure urethra (failure to generate MUCP $>20 \mathrm{cmH}_{2} \mathrm{O}$ ) in supine position was used. For the study by Hale et al. (1999) the MUCP at rest was used. For the study by Kuhn et al. (2008) estimates were made from the published figure (SUI group: $23 \pm 13.5 \mathrm{cmH}_{2} \mathrm{O}$; control group: $55 \pm 20$ $\mathrm{cmH}_{2} \mathrm{O}$ )

in stress-incontinent women $(n=521)$ compared with continent women ( $n=109$, Fig. 3).

Urethral perfusion Using 3D color-Doppler transvaginal USS, fewer periurethral vessels and less periurethral blood flow were found in stress-incontinent than in continent women [112].

Bladder neck funneling Bladder neck funneling (or dilation), measured using USS, MRI or cystourethrography, is described as an observed funnel-shaped opening of the proximal urethra [138], measured dichotomously as present or absent. Bladder neck funneling was studied with women at rest in six studies [19, 87, 114, 123, 133, 134], during straining in five studies $[14,19,99,109,110]$ and during defecation in one study [111]. A meta-analysis of six studies suggests that funneling is five-fold (risk ratio $=5.04,95 \%$ CI 2.12-11.97 at rest and risk ratio $=5.52,95 \%$ CI $0.60-$ 


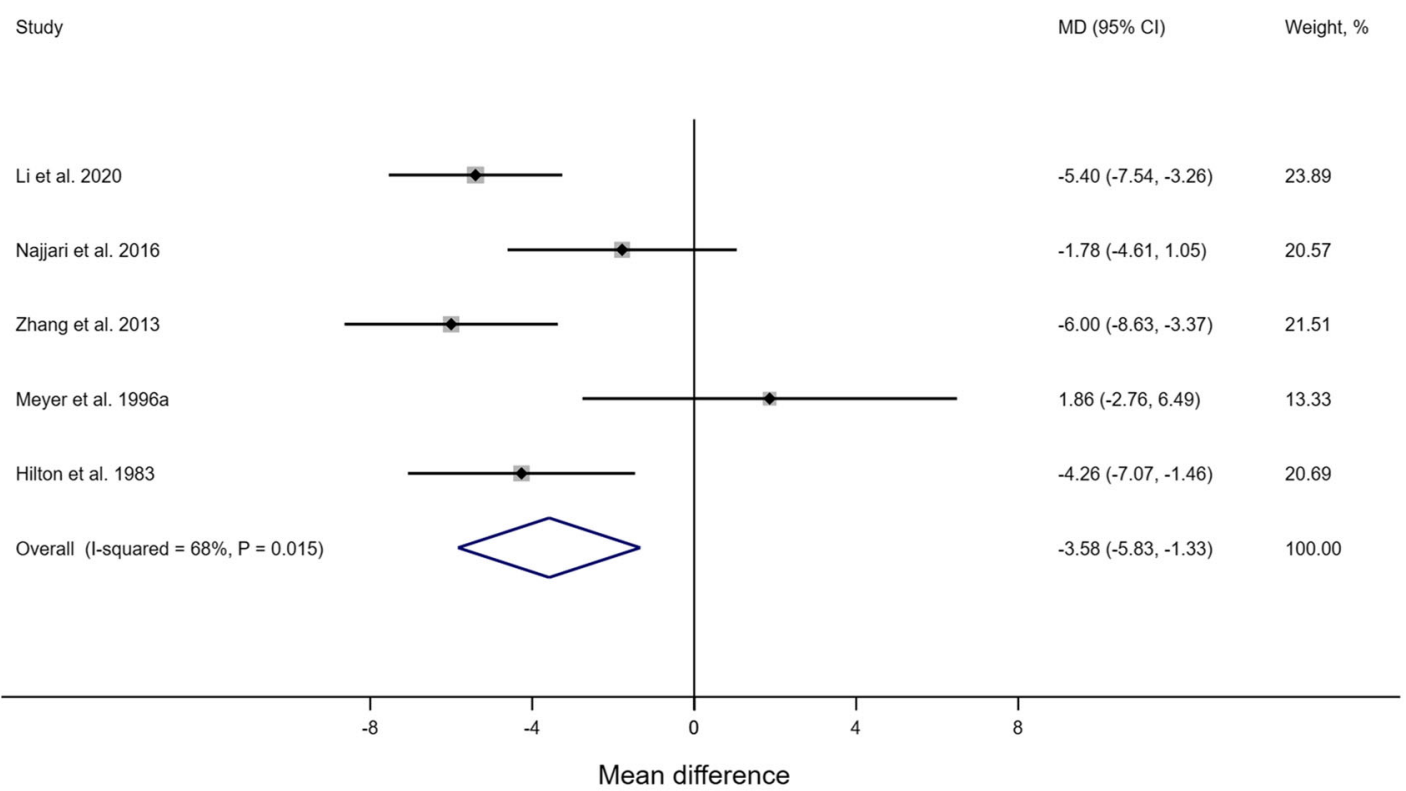

Fig. 3 Mean difference (MD) in functional urethral length in stress-incontinent women compared with continent women. For the study by Li et al. (2020), the perimenopausal control group was used in this analysis

50.54 during straining) more prevalent among stressincontinent ( $n=1195$ and $n=181$ for rest and straining, respectively) than continent women ( $n=775$ and $n=193$ for rest and straining, respectively, Fig. 4). However, most studies did not control for confounding factors such as age, parity and body weight (Fig. 4). In another study, bladder neck incompetence, defined as a widely separated lumen, was found in $42 / 60$ stress-incontinent women, but in none of 14 continent women [106].

\section{Urethral neurophysiology}

Among stress-incontinent women, responsiveness to urethral electrostimulation was lower [91], urethroanal reflex latency was more prolonged [91], neural conduction velocity in the perineal branch of the pudendal nerve (which innervates the SUS) was significantly slowed [126], and dorsal nerve and urethral mucosal electrosensitivity was diminished [129] relative to control groups. However, there were no differences in pudendal nerve terminal motor latency between women with and without SUI in another study [91]. In a larger study $(n=$ 286), signs of neuropathic changes in the urethral sphincter, in the form of longer motor unit potential duration and pudendal nerve terminal motor latencies [116], were observed among women with SUI. Conversely, shorter urethral sphincter motor unit potential duration was found in a stress-incontinent group compared to a continent group [66], and, during bladder filling, the women with SUI demonstrated smaller motor unit potential amplitudes, lower numbers of turns per second and lower turns/amplitude ratios in the SUS [66].

\section{Urethral support}

Para-urethral connective tissues Dense connective tissue arises primarily from the vagina and periurethral tissues and attaches to the pelvic wall laterally at the arcus tendineus fasciae pelvis and to the medial edge of the LAM. ${ }^{1}$ Lesions of the urethral support structures seen on MRI [101] were more prevalent in stress-incontinent than in continent women $[110,111,127]$. For instance, in one study, defects in the periurethral ligament were found in $76 \%$ of stressincontinent women and in $32 \%$ of parous controls $(p<0.001, n=58)$ [111]. While greater pubovaginal distance and periurethral ligament disruption were significantly associated with SUI, in a multivariable model, only periurethral ligament disruption was significantly more common in incontinent than in continent women [114]. Among 31 middle-aged women, periurethral ligament symmetry reduced the odds of

\footnotetext{
${ }^{1}$ These supportive tissues are often referred to as the "pubo-urethral ligaments," although they do not insert exclusively into the pubic bone or attach directly to the urethra [139].
} 


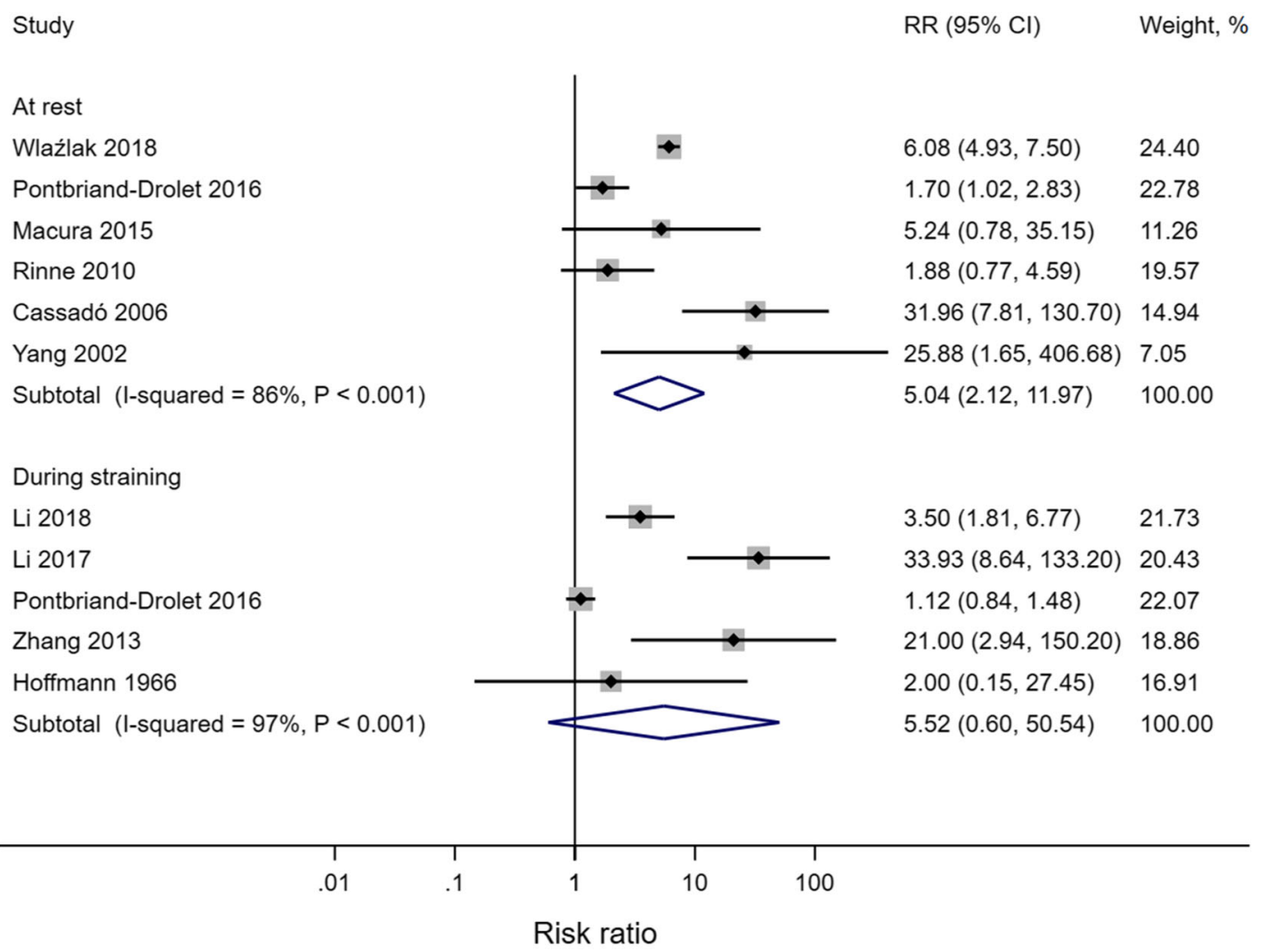

Fig. 4 Risk ratio for bladder neck funneling in stress-incontinent women compared with continent women. For the study by Hoffmann and Ulrich (1966), the SUI group without pelvic organ prolapse was used in this analysis

incontinence by $87 \%$ [114]. The urethropelvic ligaments were significantly thinner in stress-incontinent women [106], but the length of the pubourethral "ligaments" was similar between women with and without SUI $(n=74)$ [106].

Bladder neck position Bladder neck position was reported in several studies using USS [54, 87, 90, 113, 117, 132]. Compared to their continent counterparts, women with SUI demonstrated shorter distances between the bladder neck and the lower margin of the symphysis pubis at rest and during straining [90] and shorter distances from the bladder neck to the central axis of the symphysis pubis in standing, but not in supine position [54, 117]. In women with SUI, a larger distance from the symphysis pubis to the urethra at rest in supine position [87] was observed, and the bladder neck tended to sit in a more posterior and caudal position $[87,132]$ compared to continent women. Another study showed no difference in the resting position of the bladder neck in the horizontal or vertical plane between continent women and those with SUI [113]. It was not possible to conduct a meta-analysis for bladder neck position because of the variation in measurement approaches (e.g., using the central axis of the symphysis pubis [54, 90, 117] vs. a line through the apex [132] and measuring the direct $[90,132]$ vs. perpendicular distance from the bladder neck to symphysis pubis $[54,117])$.

Urethral angular orientation Angular orientation of the urethra has been measured using MRI $[19,101]$ and USS $[14,19,81,89,109,125,134,136]$ employing varying definitions. Compared to continent women, women with SUI had larger rotation $(\alpha)$ angles at rest and during straining, defined as the angle between the axis of the proximal urethra and central axis of the symphysis pubis [81, 134], the angle between a line drawn through the bladder neck parallel to the probe and a line through the apex of the pubic bone [132], or the proximal urethral rotation angle, with a lack of clarity regarding the task [109]. However, when defined as the angle between the vertical axis and the urethral axis (a.k.a. the urethral axis angle), there was no difference in $\alpha$ angles at rest between women with and without SUI $[110,125]$, and, while during Valsalva there was no difference in one study [110], 


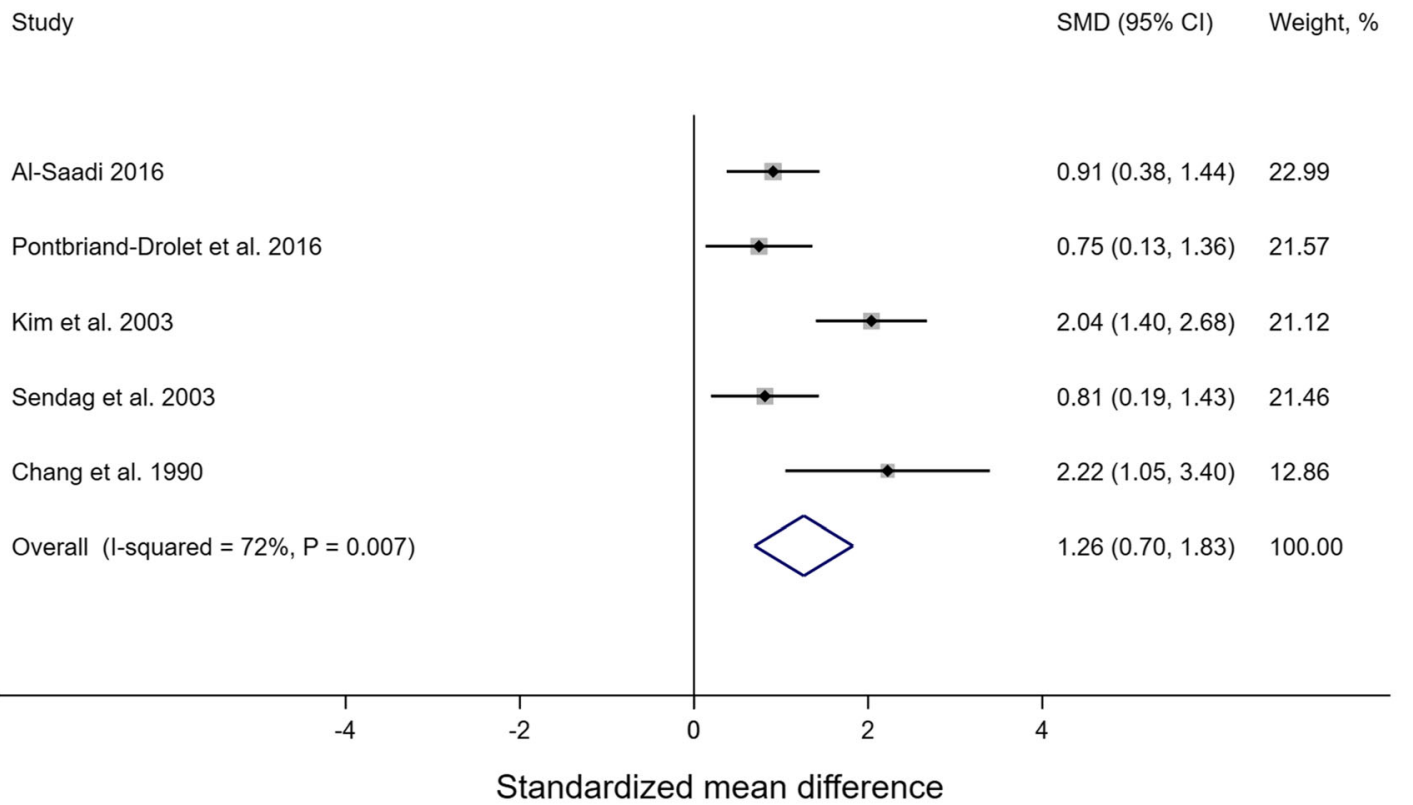

Fig. 5 Standardized mean differences (SMD) of beta angles measured at rest in stress-incontinent women compared with continent women

there were larger $\alpha$ angles in a stress-incontinent group in another study [125]. The $\beta$ angle (also referred to as the posterior urethrovesical angle, posterior vesicourethral angle or retrovesical angle) was measured as the intersection between lines drawn along the urethra and the bladder base $[19,81,89,101,109,125,136]$, the angle from the bladder base to the symphysis pubis [14], the angle from the bladder neck to the vaginal wall [132] or undefined [99, 109]. Regardless of definition, women with SUI typically had larger $\beta$ angles at rest than continent women $[14,19,81,89,101,109,125,132,136]$, with the exception of one study [99]. Meta-analyses showed (Fig. 5) there was a large effect of incontinence on the $\beta$ angle [standardized mean difference: Hedges' $\mathrm{g}=1.26,95 \% \mathrm{CI}$ $0.70,1.83,5$ studies; weighted mean difference $=19.2^{\circ}$ $\left(95 \% \mathrm{CI} 13.3^{\circ}\right.$ to $25.2^{\circ}, 5$ studies)], with larger $\beta$ angles observed among stress incontinent $(n=159)$ than continent $(n=92)$ women. Urethral mobility was assessed clinically using a cotton swab inserted into the distal urethra (Q-tip test) while women remained supine and at rest [93]. Although this test has limited accuracy [140], women with SUI demonstrated larger angular deviations of the cotton swab from horizontal [93] compared to those without SUI. Other findings include that, compared to continent women, women with SUI demonstrated a larger retropubic space [101] and a larger bladder necksymphyseal angle at rest [134], but iliococcygeal angles and levator plate angles [110] did not differ.

\section{Kinematics}

Urethral mobility The mid-urethra was observed through USS to move more caudally during straining in women with SUI compared to continent women [123], and the proximal urethra was also more mobile during coughing [97]. Concurrent with urethral sphincter incompetence, prolapse of the urethra into the anterior vaginal wall during the Valsalva maneuver was more common in women with than without SUI [10].

Bladder neck mobility: i. angular rotation Compared to continent women, women with SUI demonstrated larger rotation angles of the urethrovesical junction, yet definitions varied among studies $^{2}[14,87,90]$. In a multivariable model, bladder neck rotation during straining (referred to as sliding ${ }^{3}$ ) had the highest sensitivity (92\%) and specificity (80\%) to diagnose SUI among 383 women [87]. Larger bladder necksymphyseal angles were described for women with SUI versus continent women during maximal Valsalva maneuver in another study, but differences between the angle at rest and

\footnotetext{
${ }^{2}$ Rotational angle of the bladder neck was defined as the angle between lines from the symphysis pubis to the bladder neck $[14,90]$, as the difference between two angles formed by the intersection of a line from the symphysis pubis to the urethra and the sympysis pubis to the bladder neck [87] at rest and during straining, respectively.

${ }^{3}$ Sliding was described as the difference between the urethra-bladder neck distance (the distance from the crossing point of the symphysis axis with the urethra to the bladder neck) at rest compared to on straining [87].
} 
during Valsalva were not reported [134]. In other studies, there were no differences between women with and without SUI when in angular rotation of the bladder neck was measured during straining [132] or during when the rotation of the long axis of the urethra was measured during a Valsalva maneuver [136].

ii. Linear translation Studies found larger bladder neck linear descent during Valsalva maneuver and/or coughing [54, 90, 109, 117, 136] and straining [82], shorter distance between the bladder neck and the lower margin of the symphysis pubis during straining [90] and more bladder neck mobility in the craniocaudal direction during coughing [132] in stressincontinent women compared with their continent counterparts. Using transrectal USS, stress-incontinent women demonstrated $>1 \mathrm{~cm}$ of caudal motion of their urethrovesical junction during straining, while continent women had $<$ $1 \mathrm{~cm}$ of caudal motion during straining [82]. However, other studies showed no differences between incontinent and continent women in the extent of displacement or descent of the bladder neck during coughing $[113,124]$ or depression of the base of the bladder during straining [99]. It was not possible to conduct a meta-analysis for bladder neck displacement because of the differences in conditions during which it was measured across studies (e.g., during coughing [113, 132], Valsalva $[109,136]$ or straining (either cough or Valsalva) $[87,90]$ and a lack of reporting of means and standard deviations for each group $[53,82,124]$.

\section{Levator ani}

\section{Morphology}

Stress-incontinent women had less skeletal muscle content, fewer muscle fibers in each LAM fascicle [15] and higher connective tissue content $[15,23]$ in their LAMs than were observed in continent women. Asymmetry of the puborectalis muscles was more common in stress incontinent women in one study [101], and, while there were no differences between women with and without SUI in terms of overall levator defects (asymmetry, hypertrophy or disruption) in a subsequent study [111], a significantly greater percentage of pubococcygeal muscle defects was found in stress incontinent women (45-66\%) than in their continent counterparts $(10-28 \%)$ [111, 127]. The thickness of the LAM measured by MRI $[100,127]$ and USS [121] was significantly lower in women with SUI compared with continent women [100, 121, 127]. MRI showed degeneration of the LAM in $45 \%$ of women with SUI [23]. In continent women, a sharp dorsally angulated levator sling was seen in transverse MRI sections [23], yet this angulation was lost in $66 \%$ of stressincontinent women [23].

\section{Neurophysiology}

There were no differences in the presence of caudal-dorsal motion of the clitoris [135] or cranial-ventral movement of the anorectal junction toward the symphysis pubis during coughing between women with and without SUI [135]. Such motion presumably reflects automatic or reflex contraction of the LAMs and/or perineal muscles. In the external anal sphincter, stress-incontinent women had significantly prolonged motor unit potential duration [129], higher tonic activation amplitudes and higher mean numbers of turns/s [80] as well as higher estimates of mean fiber density [80]. However, during maximum voluntary contraction (MVC) there was no difference between groups in the mean amplitude of the EMG interference pattern in the external anal sphincter [80]. There were also no significant differences in the density or mean amplitude of the interference pattern in the puborectalis muscles when women with and without SUI were compared [80].

\section{Passive tissue resistance}

Shear strength of the anterior vaginal wall was significantly lower in stress-incontinent women than in continent women [103], yet using intravaginal dynamometry, the peak resistance to passively stretching the LAMs and paravaginal tissues did not differ between continent and stress-incontinent women [130].

\section{Active force generation}

Strength Stress-incontinent women had weaker LAMs on assessment by palpation using manual muscle testing [24] and other subjective rating [131]. Compared to continent women, women with SUI generated lower intravaginal pressures on maximal effort PFM contraction when measured using perineometry [24] and generated lower forces using intravaginal dynamometry $[22,130]$. The pressures/forces measured at the posterior vaginal wall in stress-incontinent women were significantly lower than in continent women both at rest $[60,84]$ and during maximal effort PFM contraction [60]. Additionally, force was generated more slowly in the women with SUI $[60,85]$, and they were less able to sustain force [84]. Similarly, stress-incontinent women had lower LAM endurance than continent women in one study [24], but not in another [86]. Conversely, among athletes, LAM strength was greater in those with SUI than in those without [94], yet in runners who ran $\geq 20 \mathrm{~km}$ a week, there was no significant difference in LAM strength between the continent and incontinent groups [92].

In other studies there were no significant differences between continent and incontinent women in terms of intravaginal pressure/closure force generated during 
maximal effort LAM contraction when measured using air-filled balloons connected to pressure transducers mounted on the anterior and posterior aspect of an intravaginal probe [34], a microtip sensor [83], unspecified manometry [86] or a multisensor device (MLA-P1, Pliance_System; Novel; Munich, Germany) [84]. Yet external anal sphincter contraction measured using manometry was weaker in stress-incontinent women than in continent women [129].

Using transperineal USS during maximal effort PFM contraction, one study showed greater elevation of the proximal urethra in incontinent women versus continent controls [93], while another showed the opposite [24]. In one study, the midurethra rose higher in women without than with SUI when performing a PFM contraction [123], but in another study there was no difference in bladder neck elevation between groups performing the same task [41]. There was no between-group difference in the change in anorectal angle (lines drawn along the posterior walls of the anus and rectum) from rest to maximal PFM contraction [19].

These conflicting results, as well as the detection bias associated with LAM strength measurement and an overall lack of assessor blinding in studies comparing LAM strength between women with and without SUI, lead us to conclude that there is limited evidence for LAM strength impairment in SUI.

Motor control Of the 16 studies that recorded EMG amplitude [27-37, 40, 41, 80, 108, 118], only 5 normalized EMG amplitude to generate valid comparisons between cases and controls $[28,35-37,118]$.

Tonic activation of the LAMs Three studies reported that EMG tonic activity (activity recorded at rest) of the LAMs was lower in stress-incontinent women than in continent women when they assumed sitting [27], standing [108], lying [108] and unspecified [32] postures. In another study, tonic EMG activity in the LAMs was not different between stress-incontinent and continent women in an unspecified posture, both before and after a fatigue test [40]. However, EMG amplitude was not normalized in any of these studies, putting them at high risk of detection bias [141, 142]. Baseline/resting EMG amplitude of the LAM was similar or lower in women with SUI versus continent women in three studies where statistical comparisons between the groups were not performed because of the nature of the studies (i.e, two training studies that did not compare between groups at baseline [30, 31] and a reliability study that recruited separate groups of women with and without SUI [29].

Phasic activation of the LAMs In some studies women with SUI were reported to have lower EMG activity of the
LAMs during contractions [25, 34, 108] and MVCs [29] versus continent women, although the last study did not make between-group comparisons [29]. Conversely, in other studies there was higher LAM EMG activity in women with SUI during contraction [32], a static hold (although statistical comparisons were not performed) [31] and both prior to and during the postural response associated with unexpected loading [28]. The severity of incontinence experienced by women created a differential effect on LAM EMG activity-women with mild SUI demonstrated higher EMG activation amplitudes than controls $(p<0.05$ and $p=0.07$ for baseline and response, respectively), while women with more severe SUI demonstrated no significant difference in EMG amplitudes than controls [28]. During coughing, there was no effect of SUI or its severity on LAM EMG activity [33]. In another study, maximum EMG amplitude during LAM contraction was inversely related to SUI severity [34]; however, the risk of detection bias was high: EMG signals were not normalized and there was no way of determining whether participants achieved their true maximum activation.

Other studies reported no group differences in EMG activity of the LAM during fast voluntary contractions [35], MVCs [33, 35] or submaximal contractions [41]. Similarly, no differences in EMG variables, normalized to LAM MVC, were found between women with and without SUI during jumping [38] or running [36]. Longer relaxation times during repeated fast voluntary contractions were found in women with SUI versus controls, despite no differences in peak EMG amplitudes between groups [37].

In continent women, the superficial perineal muscles always contracted before the deep PFMs in six positions, while in stress-incontinent women the reverse sequence was observed in three of these positions [42]. No difference was found in the power spectra of intravaginal EMG during treadmill running between stress incontinent women and continent women [39].

\section{Other}

While change in intra-abdominal pressure measured during Valsalva or cough was not different between stress-incontinent and continent women [124], incontinent women generated higher intravesical pressures during cough and Valsalva [93]. In stress-incontinent women, compared to continent women, greater anterior pelvic tilt was found from digitized photographs [108] and greater vertical displacement of a marker on the fifth lumbar vertebrae during running, without any other differences in kinematics [92]. There were no differences in clitoral sensory threshold (measured as the intensity at which the woman was first able to perceive an electrical stimulus) between stressincontinent and continent women [91]. 


\section{Discussion}

Urodynamic measures such as ALPP and MUCP describe the summative result of the many factors that contribute to urinary continence. Indeed, meta-analysis suggests that low MUCP [93] is strongly associated with SUI, and, while low ALPP also appears to reflect the presence of SUI, no studies were found that compared ALPP between women with SUI and a control group of women with no urogynecological disorders. An appropriately controlled study comparing ALPP between women with and without SUI, matched on known confounders (e.g., age, parity, BMI, smoking, activity level) is needed.

While few studies have simultaneously explored multiple factors that contribute to SUI [10, 93], the outcome of this review suggests that SUI is indeed multifactorial [143], with evidence pointing to deficits in urethral and bladder neck structure and support, neuromuscular, vascular and mechanical impairment of the SUS, and defects in but not weakness of the LAMs. Meta-analyses showed that bladder neck dilation at rest and shorter functional urethral length are strong characteristic signs of SUI. Insufficient data were available for meta-analyses related to LAM structure or function.

Among the studies included in this review, few controlled for confounding factors associated with SUI such as age, parity, obesity and menopause. The relative volume of the SUS and blood vessels decreases with age [144] and menopause [145], and this may coincide with an increased prevalence of SUI [19]. The risk of SUI also increases with higher parity [146], obesity [147] and a history of moderate/heavy smoking [148]. Many of the included studies described control groups of continent women who were younger, had fewer children and had lower BMIs than women with SUI and did not report on smoking history. Cumulative loading of the pelvic floor through athletic activities may also be an important confounder [149]. Indeed, observed associations between some of the urethral and bladder neck characteristics and SUI may be attributable to differences between cases and controls in terms of demographic or behavioral risk profiles. Lastly, despite evidence of differences in the prevalence and presentation of SUI by race and ethnicity [150], few studies reported on race/ethnicity [66, 93, 131], whereby only one matched [66] and one adjusted the statistical model based on race [93], however the latter sample was mainly (> 94\%) Caucasian.

The studies in this review measured outcome variables during several different tasks including coughing [113, 132], Valsalva [109, 136] and straining (sometimes described as either during a cough or Valsalva) [87, 90]. Although there was a tendency to use the terms straining and Valsalva (forced expiration or bearing down) interchangeably, these have been shown not to be equivalent (Table 1) [53].

There was high variation in the instruments and outcomes used to measure similar phenomena, and several measurement issues could bias results (Table 1). For example, urethral and bladder neck position and kinematics were measured using the Q-tip test [93, 116], palpation [24], USS [54, 88, 97, 102, 104, $106,117,136]$ and MRI $[101,110,111]$, with many different landmarks and measurement strategies, and differences were found across studies in terms of posture, bladder volume and task.

The presence of SUI itself was often assessed both with self-report questionnaires and urodynamically; however, both methods have limitations. There is no gold standard for diagnosis [72]. While self-report measures and a detailed pelvic floor examination are likely the best way to direct treatment and measure success [3], objective measures such as ALPP and MUCP may be more useful when studying SUI pathophysiology. However, it is well known that different instrumentation and approaches result in different urethral pressure measurements obtained during urodynamics [151]. Furthermore, the lack of blinding in many studies may have led to biased findings, as assessors may vary their instructions during data collection or analyze results differently if they are aware of patient diagnosis. There is a clear need to develop standard terminology [152] protocols and measurements to allow for comparisons among studies and to ultimately improve our understanding of SUI.

Impairments in urethral and bladder neck structure and support, evidenced through ultrasound imaging and MRI, emerged as being strongly associated with SUI in women. Damage to the periurethral, paraurethral and pubo-urethral connective tissues [101] may occur during pregnancy, labor and delivery, through chronic coughing or other repetitive loading, or with obesity and may impact the position of the urethra and bladder neck at rest as well as its mobility during tasks that challenge continence [101, 114]. The wide variation in how these measures are performed is problematic and requires standardization to be useful in clinical investigations.

Bladder neck dilation (or funneling) emerged through meta-analysis as being highly prevalent in women with SUI (risk ratio $=5.23$ at rest and 4.99 during straining). Bladder neck dilation may develop through damage to or denervation of the smooth muscle sphincter around the proximal urethra [124] as well as to the proximal aspects of the longitudinal and circular smooth muscles of the urethra. While bladder neck dilation is observed in 50\% of continent women [124], urinary continence appears to be maintained in those women through the SUS [124] and perhaps the LAMs. As with the limitations of imaging noted above, standardized methods for the quantification of bladder neck funneling are currently lacking. 
Studies included in this review suggest that there is neurophysiological evidence of denervation injury to the SUS in women with SUI $[66,128]$. While a lower turns-amplitude ratio [66] is a non-specific finding [153], increased pudendal nerve terminal motor latency to the striated sphincter [116], longer urethral sphincter motor unit potential durations and fewer turns per second [66] are all suggestive of axonal damage with subsequent re-innervation through axonal sprouting [154]. In a separate multivariate model, however, motor unit potentials recorded from the SUS during bladder filling showed shorter durations, lower amplitudes and larger numbers of phases in stress-incontinent women versus continent women, which may reflect myopathic changes. As such, there may be different presentations that lead to sphincter incompetence. Regardless, neurophysiological findings at the SUS are consistent with morphological findings of reduced crosssectional area in women with SUI. While confirmatory studies are needed, both Heessakkers et al. [155] and Kenton et al. [66] have suggested a role for routine clinical EMG examination in the evaluation of urethral sphincter insufficiency. Myopathic or neurpathic defects in the urethral sphincter may indeed be important predictors of surgical failure [156].

While during MVC there was no difference between women with and without SUI in the amplitude of the EMG interference pattern in the external anal sphincter [80], or in the density or mean amplitude of the interference pattern in the puborectalis muscles [80], motor unit loss needs to be severe [157] before any decrease in EMG amplitude is evident; therefore, these results are inconclusive.

Far more information is available about the role of urethral structure, support and function in SUI than the role of the LAMs. Studies included in this review suggest that the LAMs in women with SUI are more likely to have lesions [110, 111, 127], have fewer muscle fibers [15] and more connective tissue $[15,23]$, have reduced muscle bulk [100, 121, 127] and show evidence of degeneration [23]. These findings are consistent with palpation, dynamometric and imaging findings that suggest that women with SUI sometimes have reduced force generating capacity $[22,130,131]$ and sometimes reduced endurance $[24,84]$ of their LAMs; yet the results are inconclusive, and insufficient data were available for meta-analysis. While there is strong evidence for PFM training as an intervention for SUI [158], the mechanism through which PFM training improves continence symptoms remains unknown and may be compensatory through improved motor control and/or through the concurrent hypertrophy of the SUS [159].

The interpretation of EMG findings from the included studies was particularly limited by issues related to the acquisition and analysis of data. Most recording devices have demonstrated poor between-day (test-retest) reliability [43]. None of the studies that reported on PFM EMG activation during functional activities presented convincing data to rule out the presence of crosstalk or motion artifact contamination. Less than half of the studies reported on normalized EMG amplitudes, which has been identified as a shortcoming in PFM research [160]. Admittedly standardizing a reference contraction of the LAM may be challenging [27, 141, 159], but normalization is required to draw valid conclusions [141].

While mild-to-moderate physical activity may have a protective effect on the PFMs and may decrease the risk of developing SUI, high impact activities may increase the risk of developing SUI [149]. Indeed, in one study, a moderate negative correlation was found between activity level and vaginal resting pressure in the stress incontinent group $(\mathrm{r}=-0.46(p=$ $0.04)$, whereas a weak positive correlation was found in the control group $\mathrm{r}=0.38(p=0.02)$ [86], suggesting different pathological mechanisms between athletes and non-athletes. The four studies comparing LAM activation between women with and without SUI during running [36, 39, 92, 107] were inconclusive, yet data were highly susceptible to detection bias and running durations may not have been long enough [161] to induce observable changes ( $8 \mathrm{~min}$ [92] or unspecified $[36,39])$. Given that running/jogging is the most common high-impact activity to cause leakage [149], this is an important area for future research.

There appears to be much redundancy built onto the urinary continence mechanism in women. Defects in one aspect of continence control, for example, damage to the proximal urethra, may be compensated by another, for example, the SUS. This redundancy suggests that multiple failures may be needed before symptoms of SUI emerge. These multiple failures may occur because of a single event (for example, vaginal delivery) or may emerge after subsequent exposures (deliveries, chronic coughing, high BMI or physical activity, smoking) or with advancing age or the onset of menopause. Sequential insults may explain epidemiological data whereby SUI prevalence rises with age until after the childbearing years, then rises again after around age 70 years [1], often presenting as mixed incontinence in older women [72].

Large cross-sectional studies with concurrent evaluation of morphology, neurophysiology, vascularity and function are needed to understand the relative importance of and the interactions among the different factors associated with SUI. Longitudinal studies are also needed to understand the cause(s) and progression of leakage while considering the impact of age and/or exposure to risk factors. Once we are better able to measure pathological processes, targeted interventions based on predominant underlying pathophysiology could be tested in clinical trials.

\section{Compliance with ethical standards}

Conflicts of interest None. 


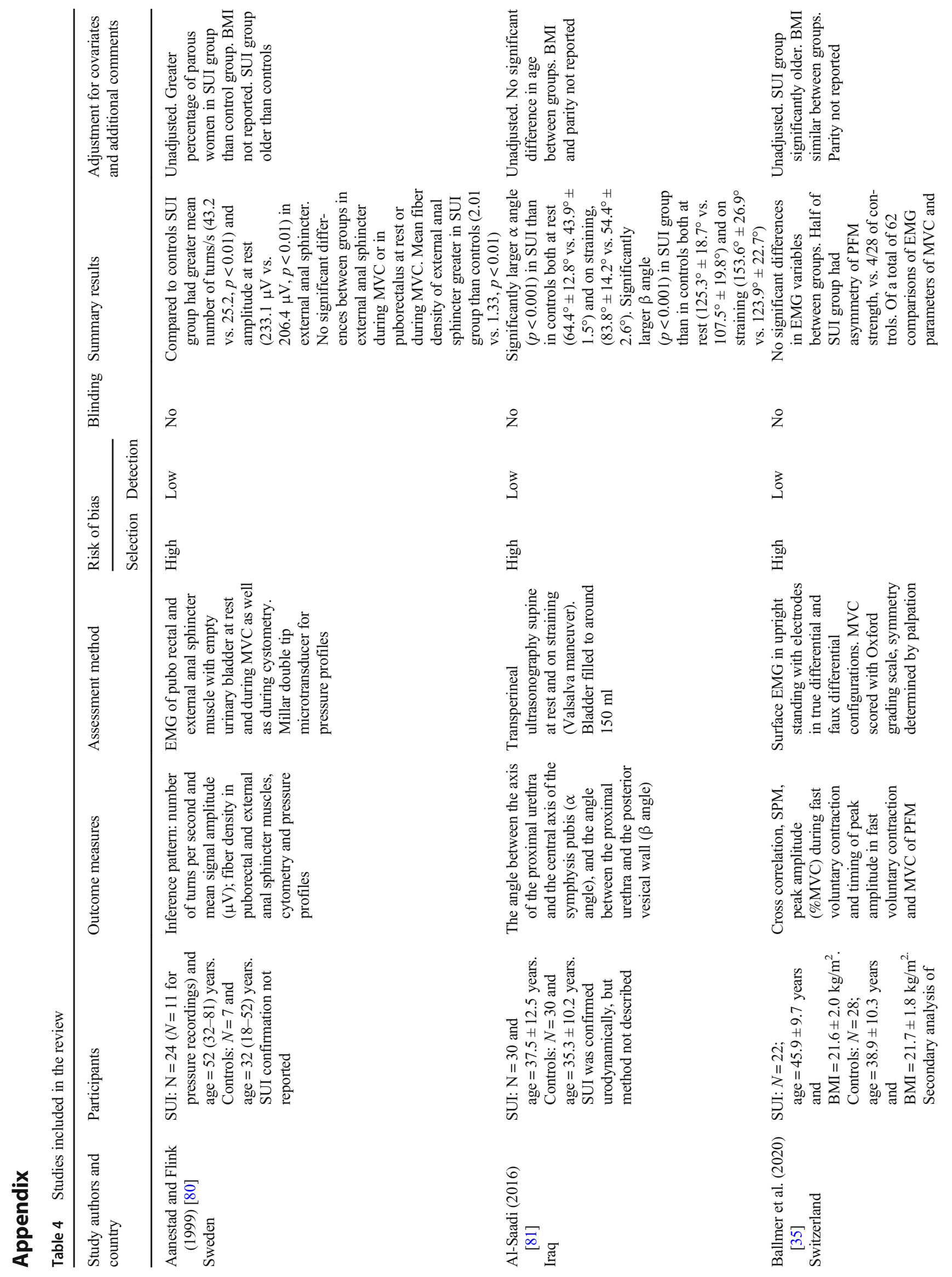




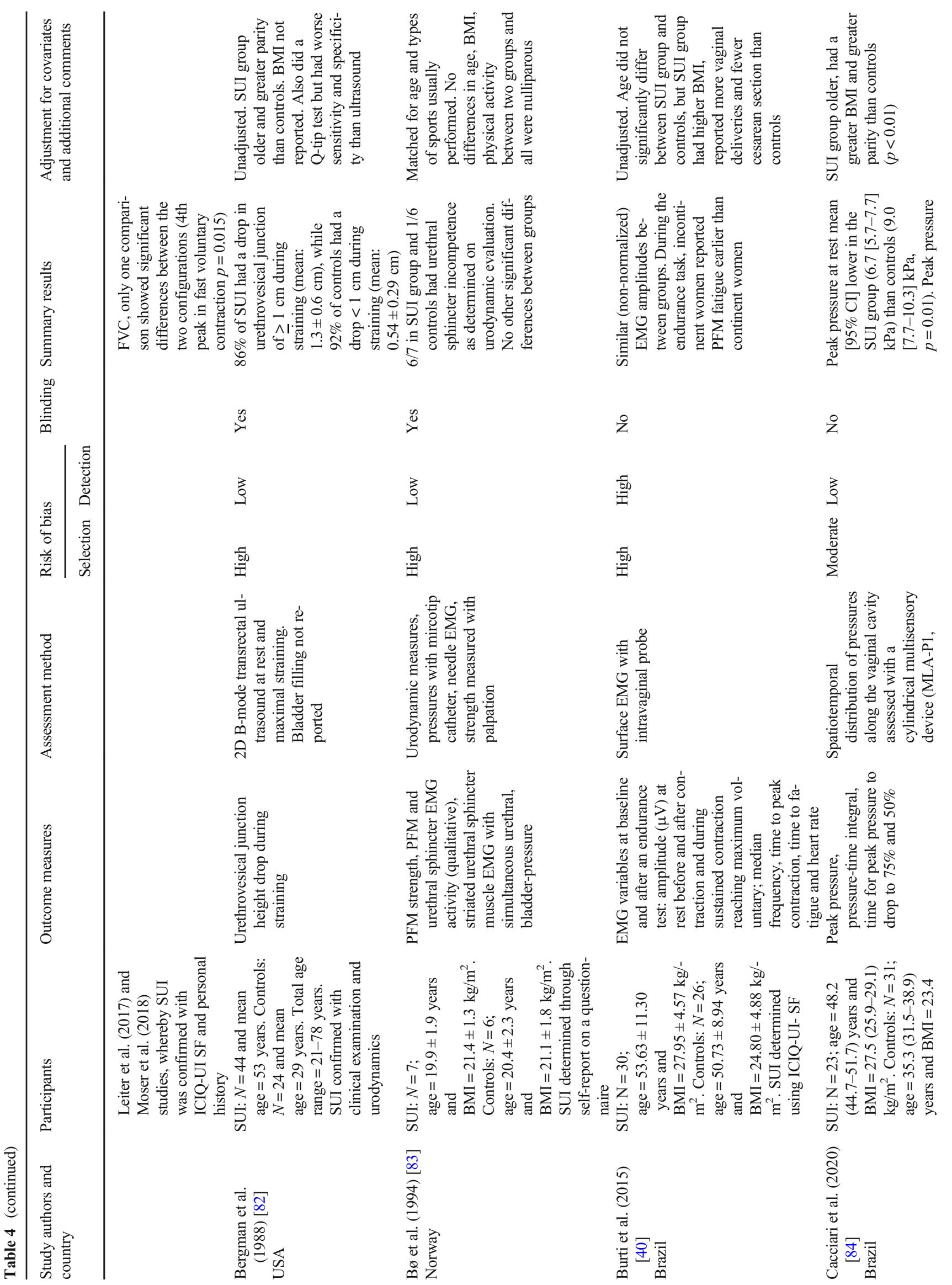




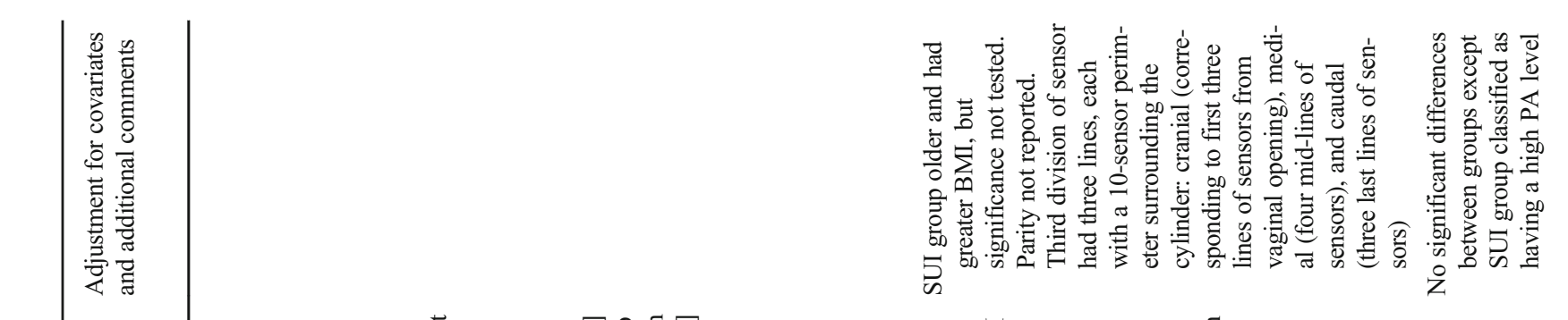

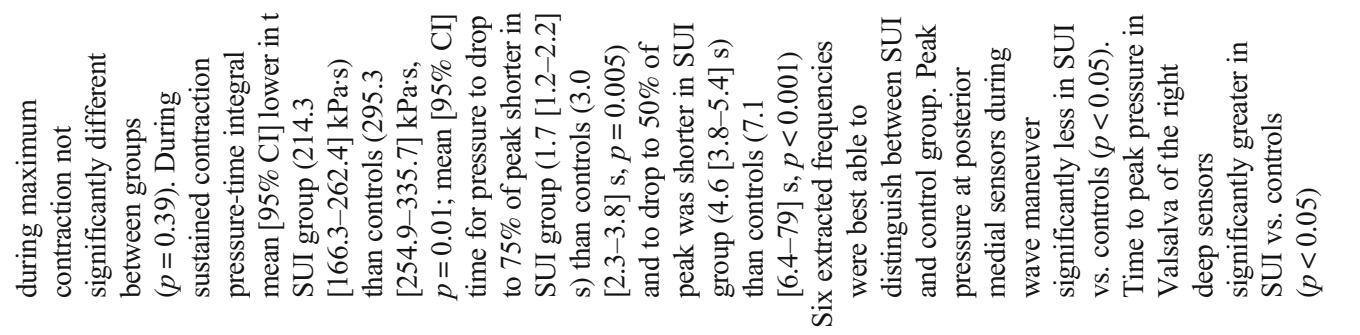

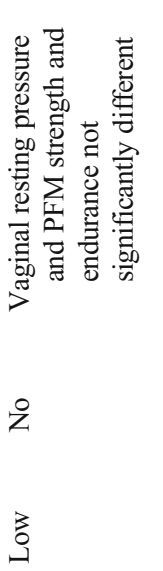

产

혹

总
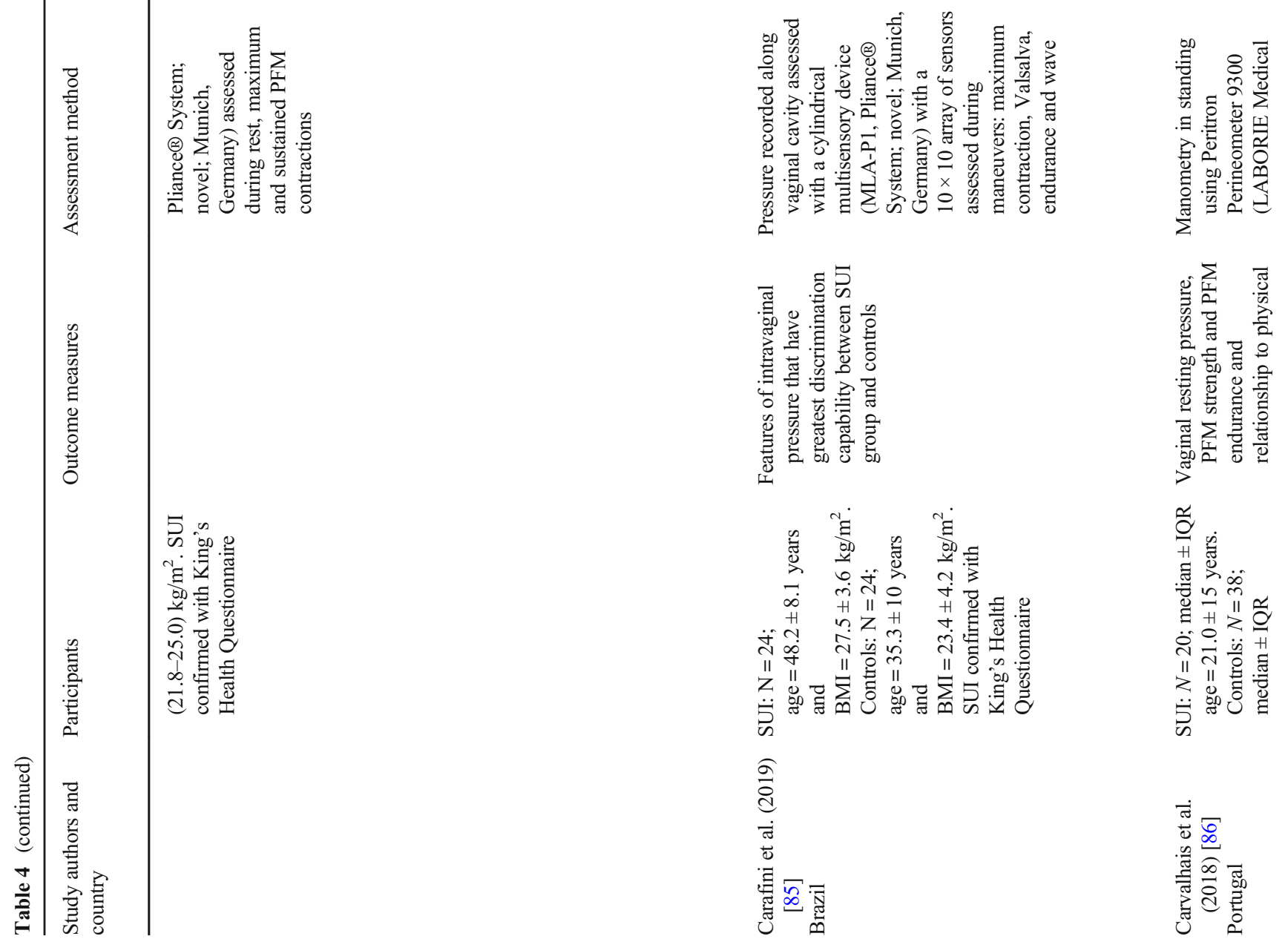

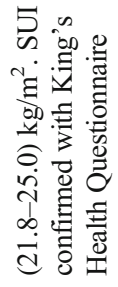
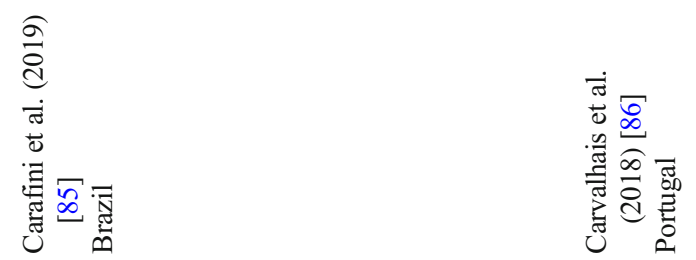


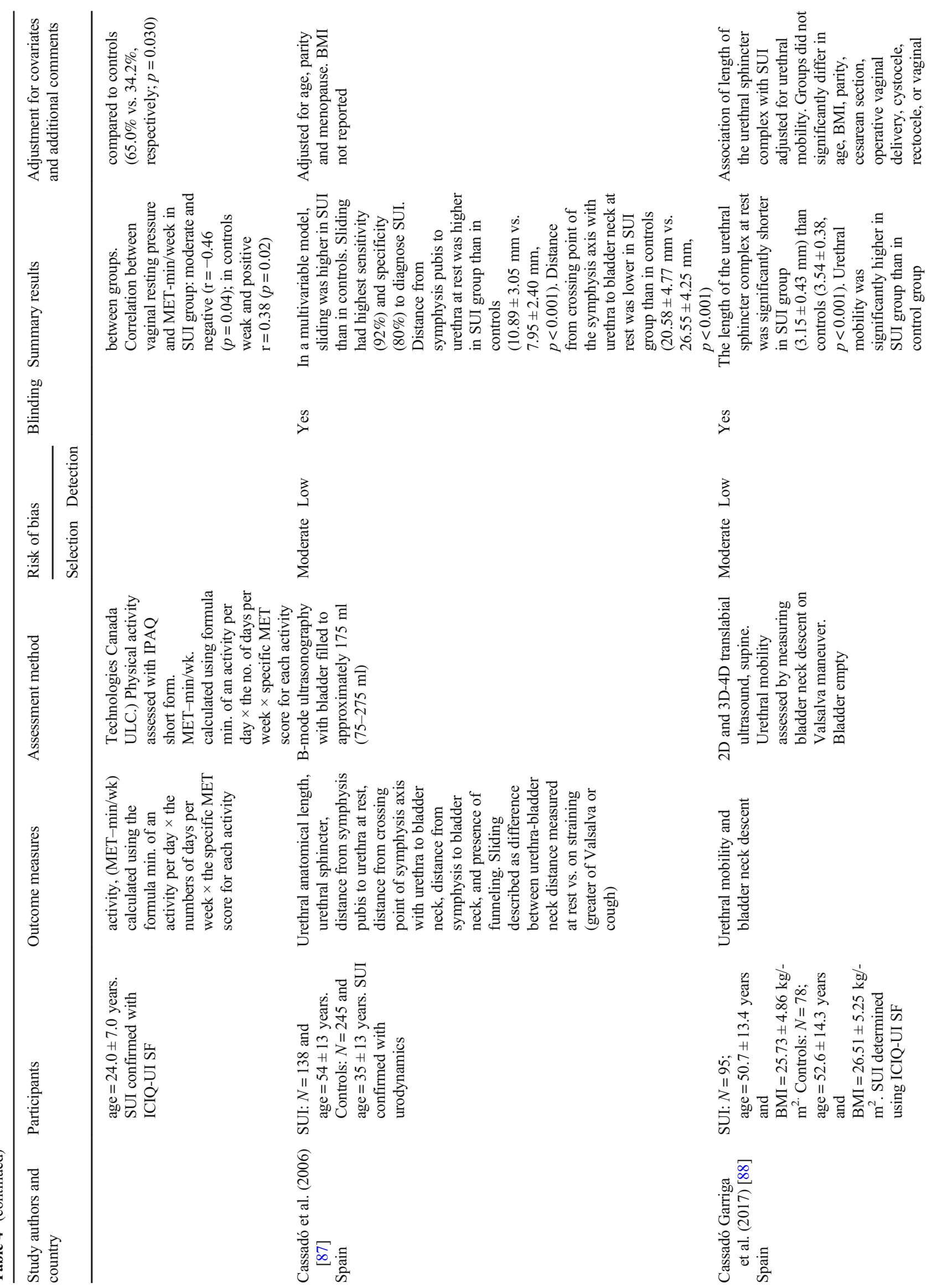




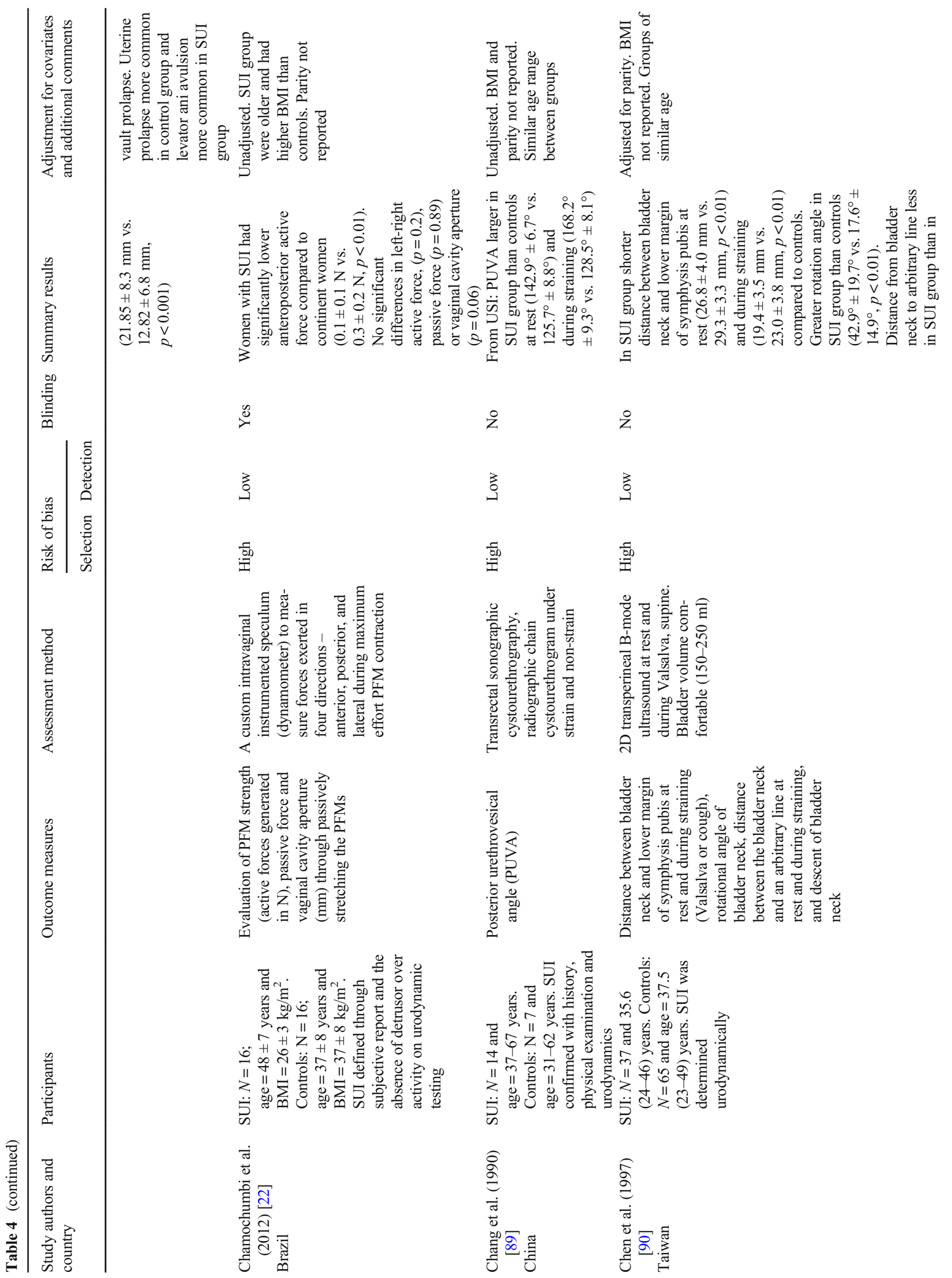




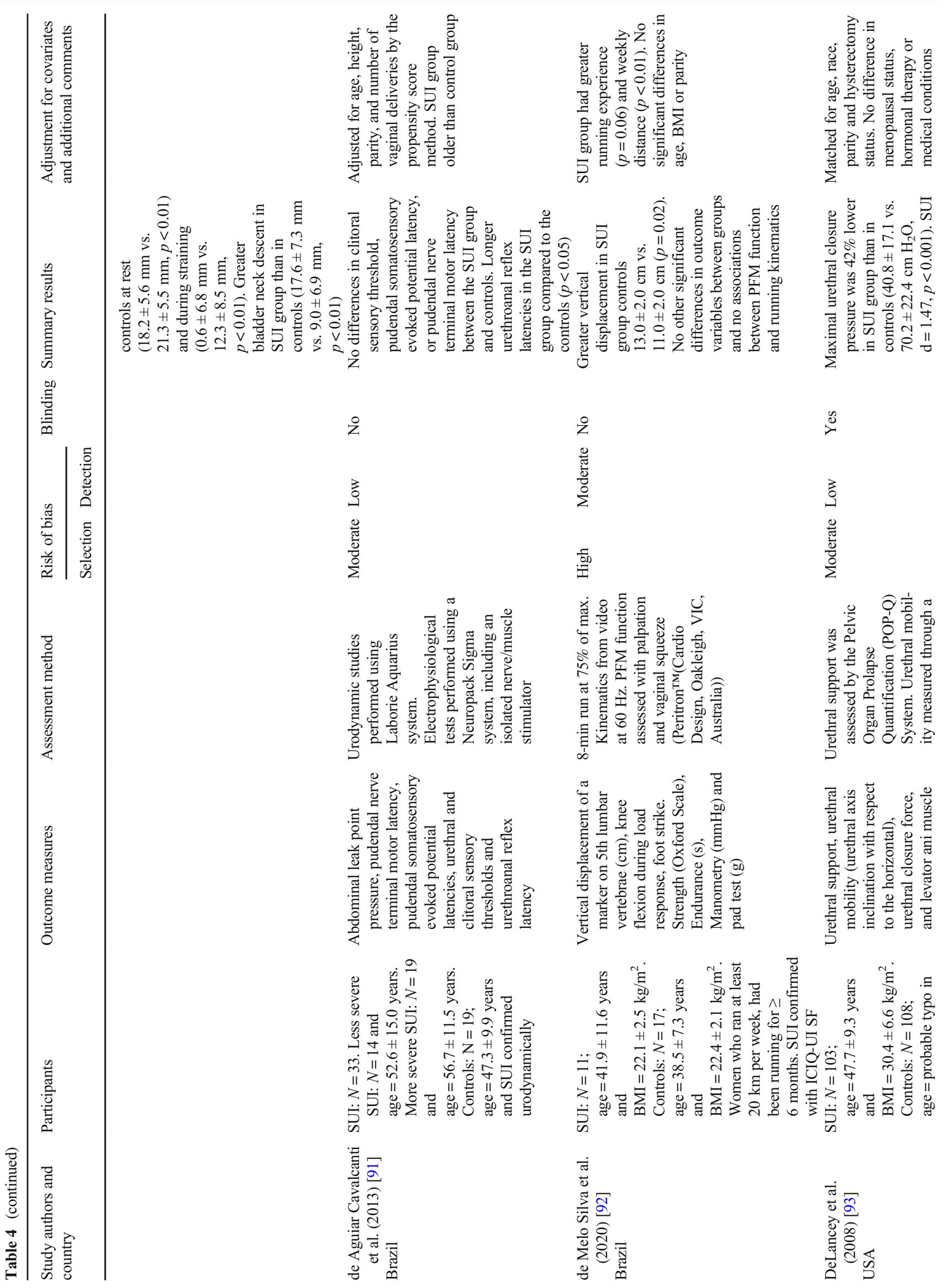




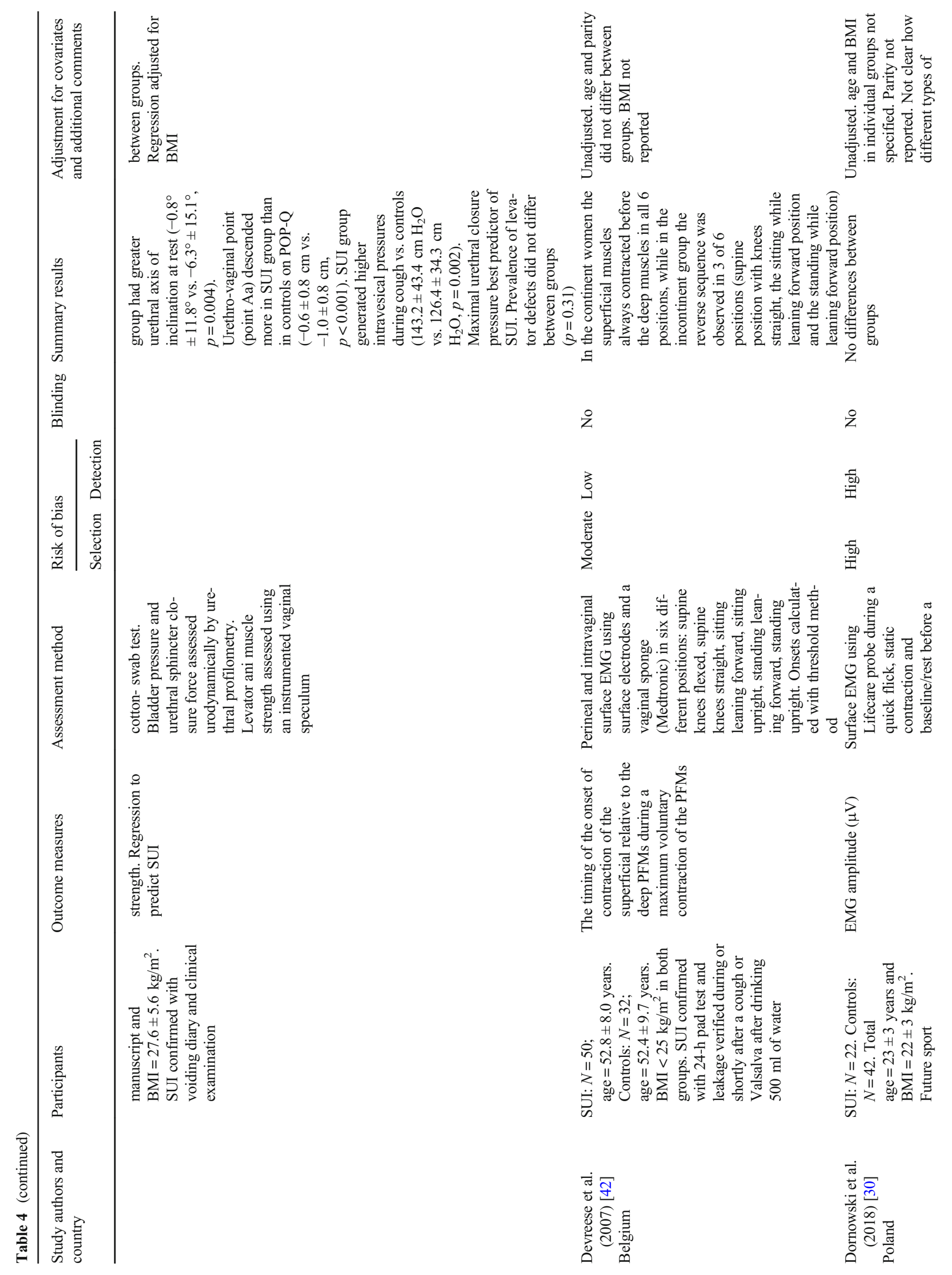




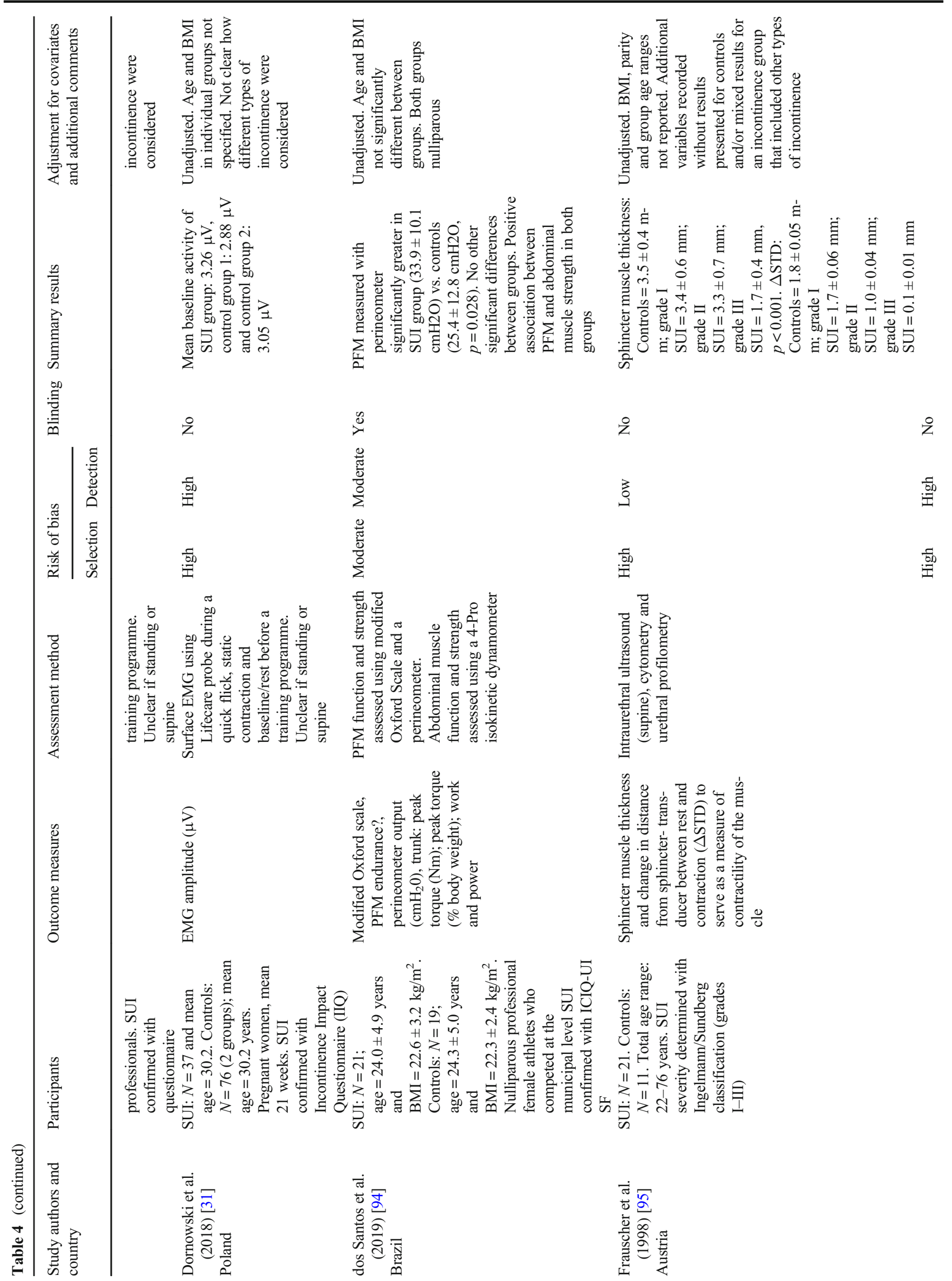




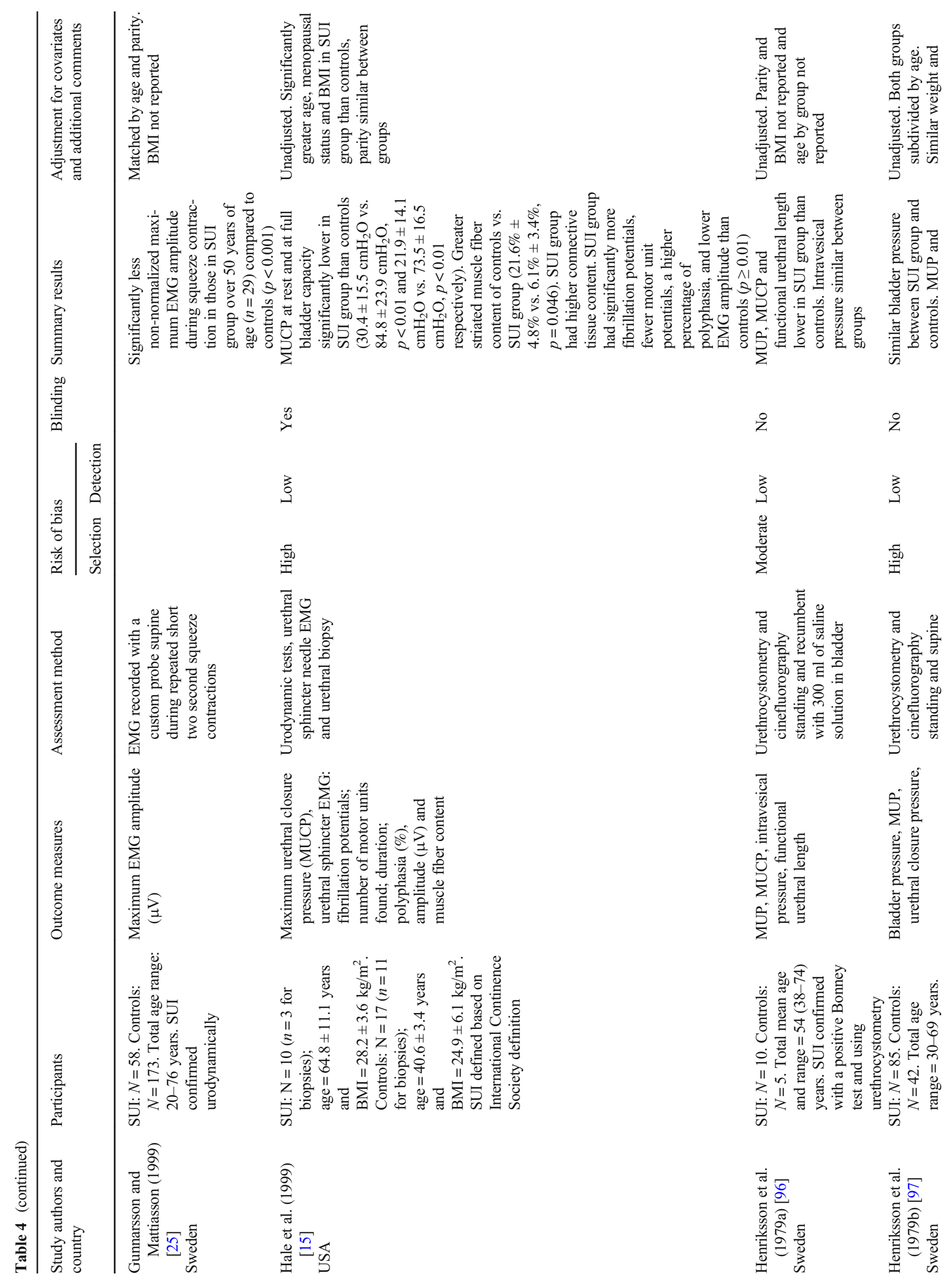




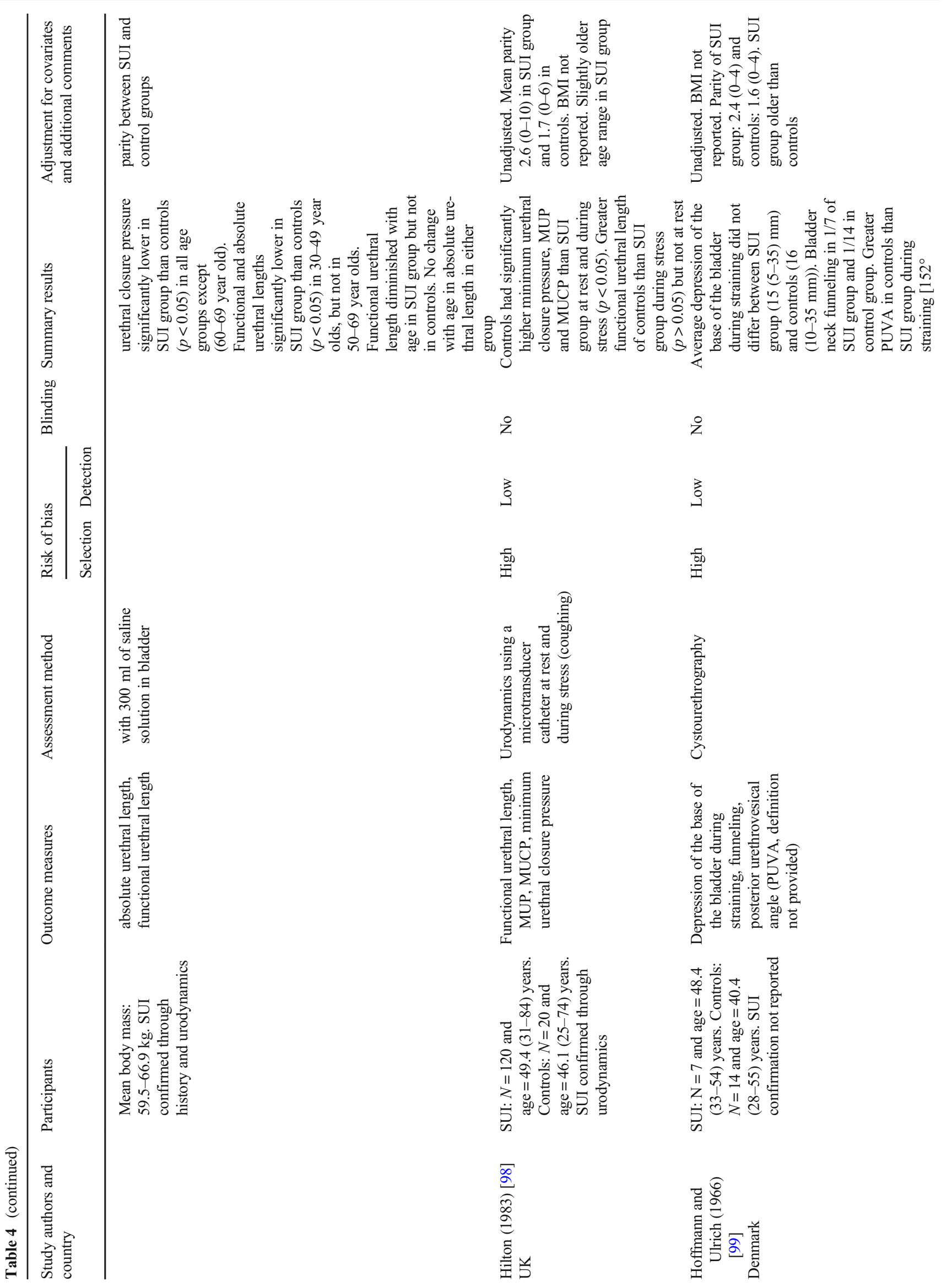




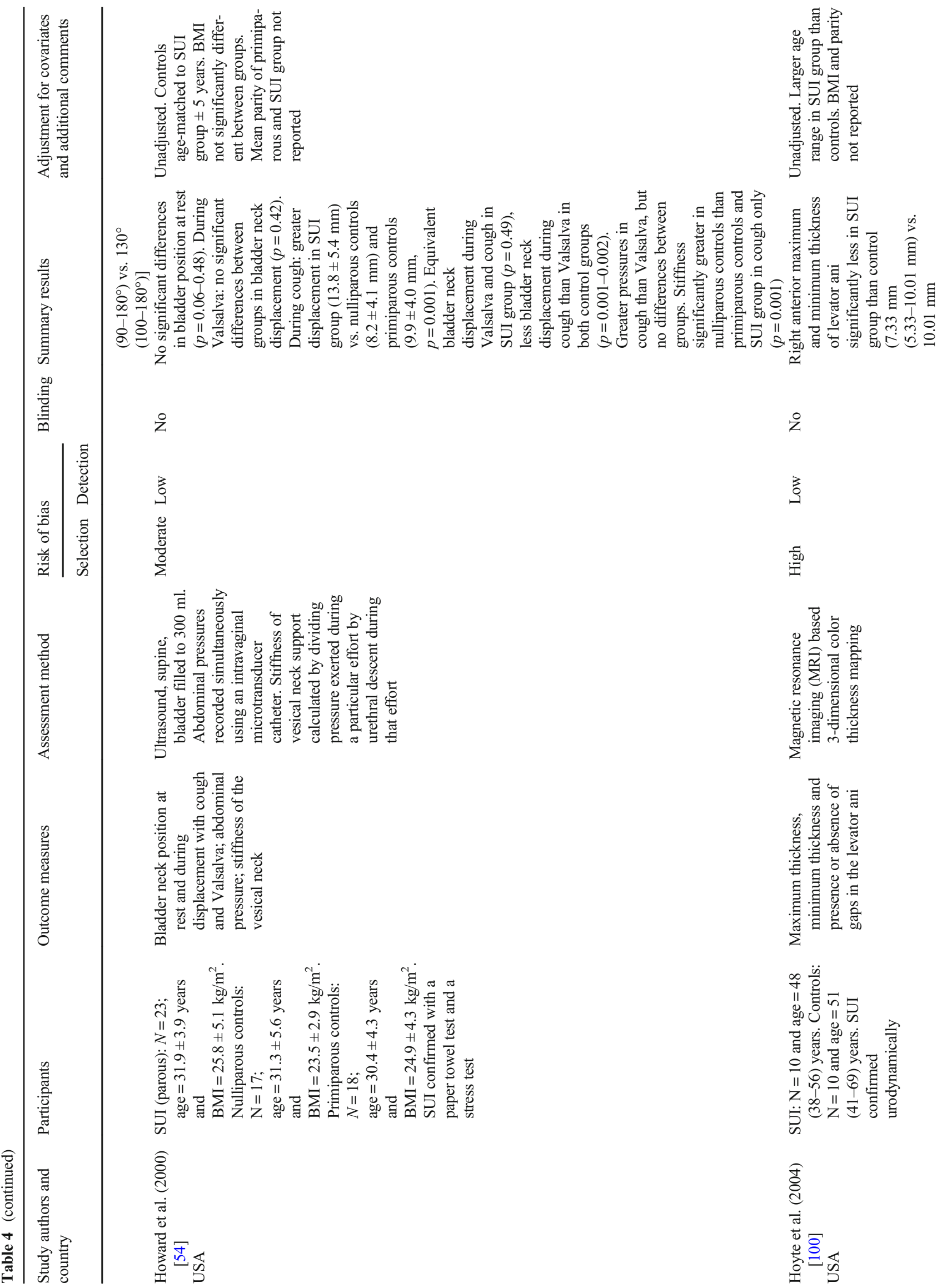




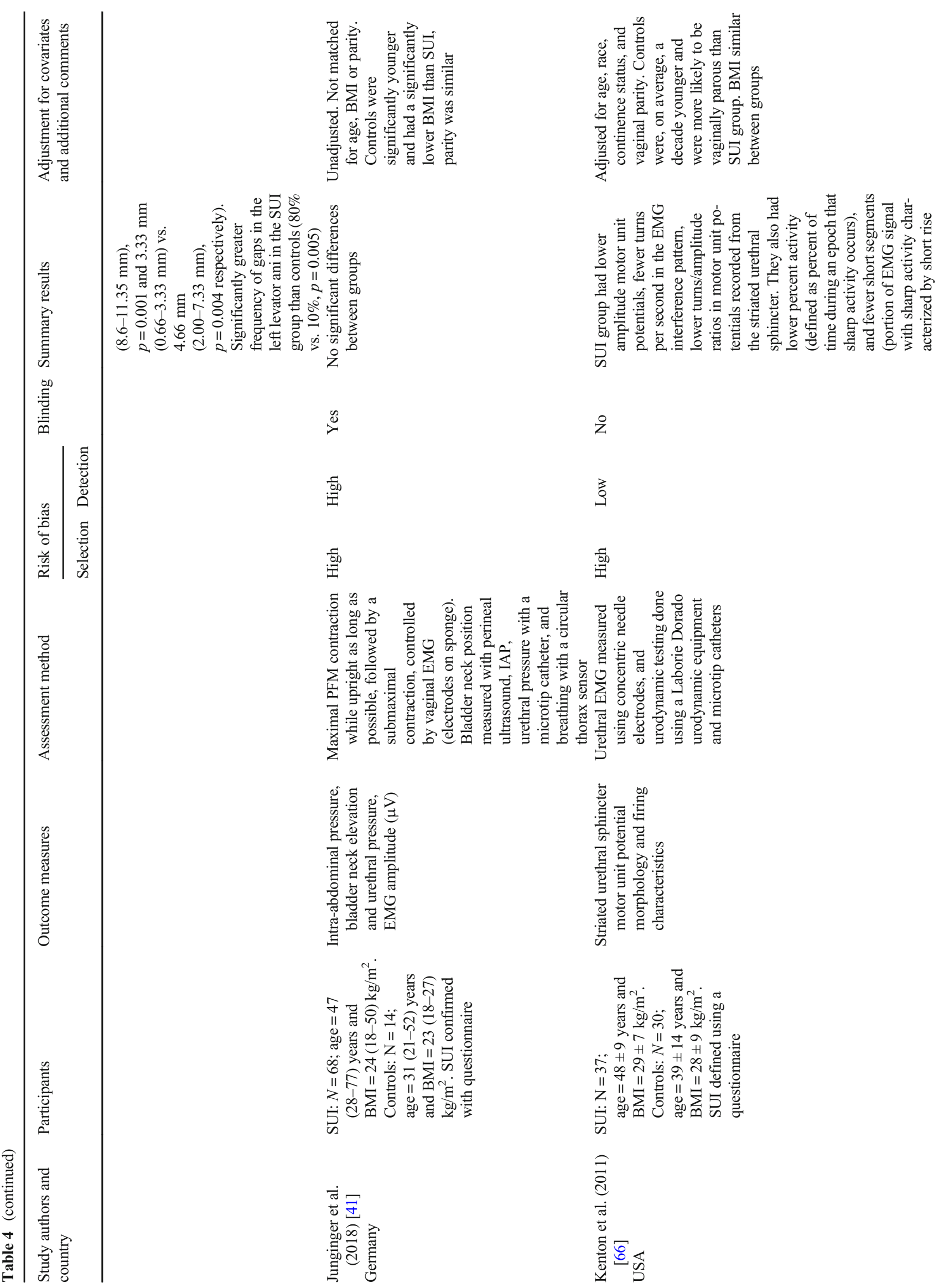




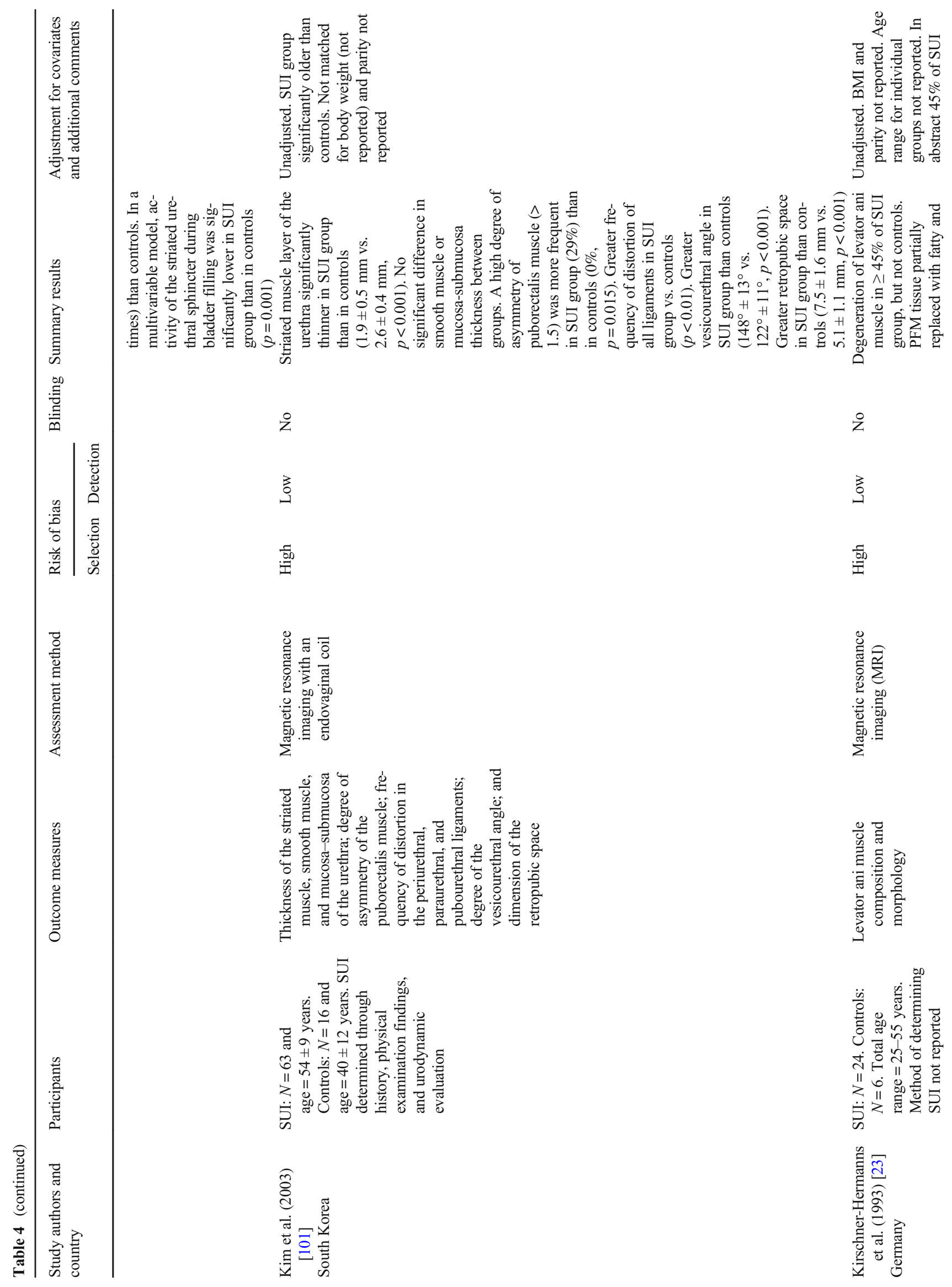




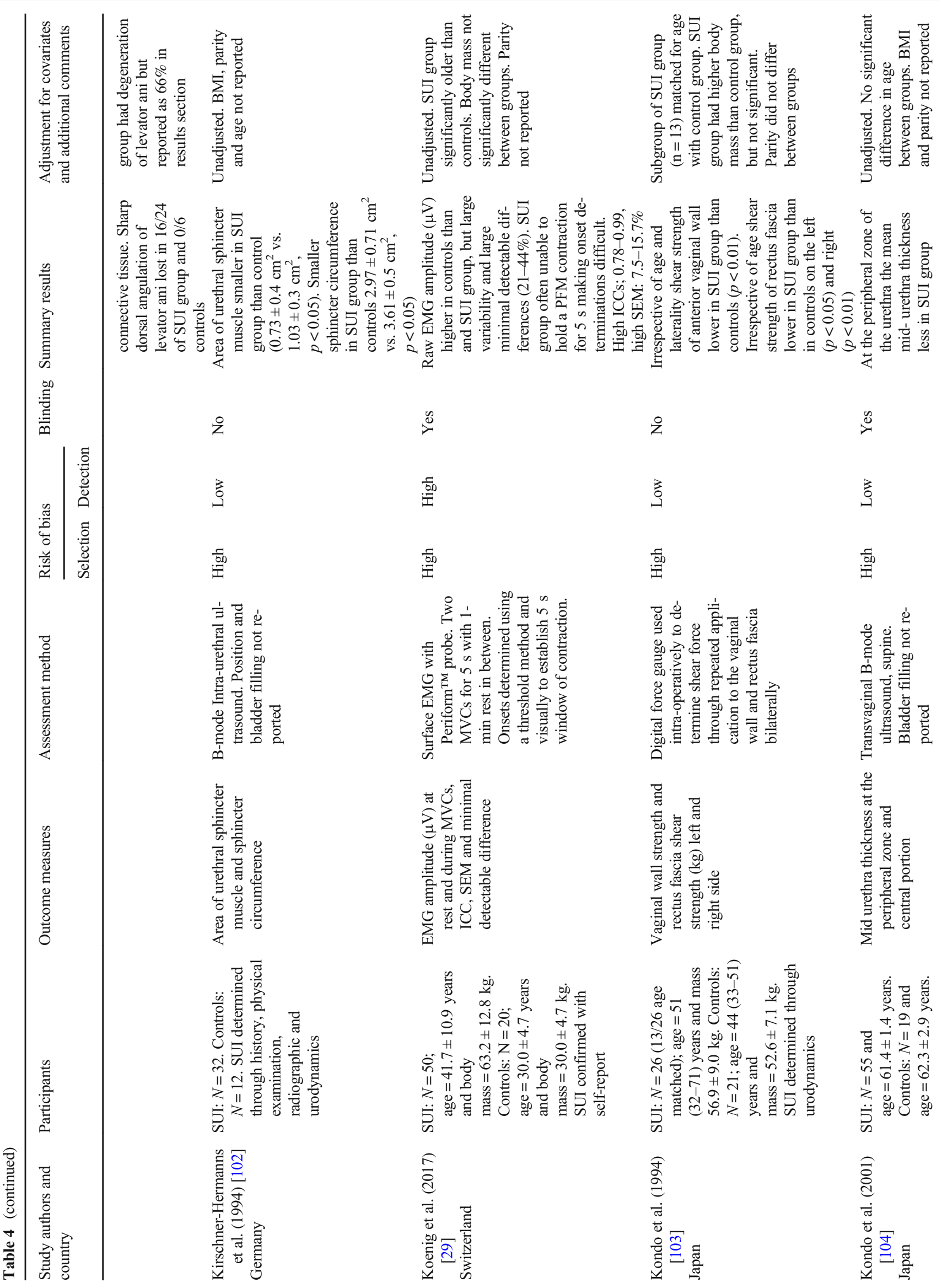




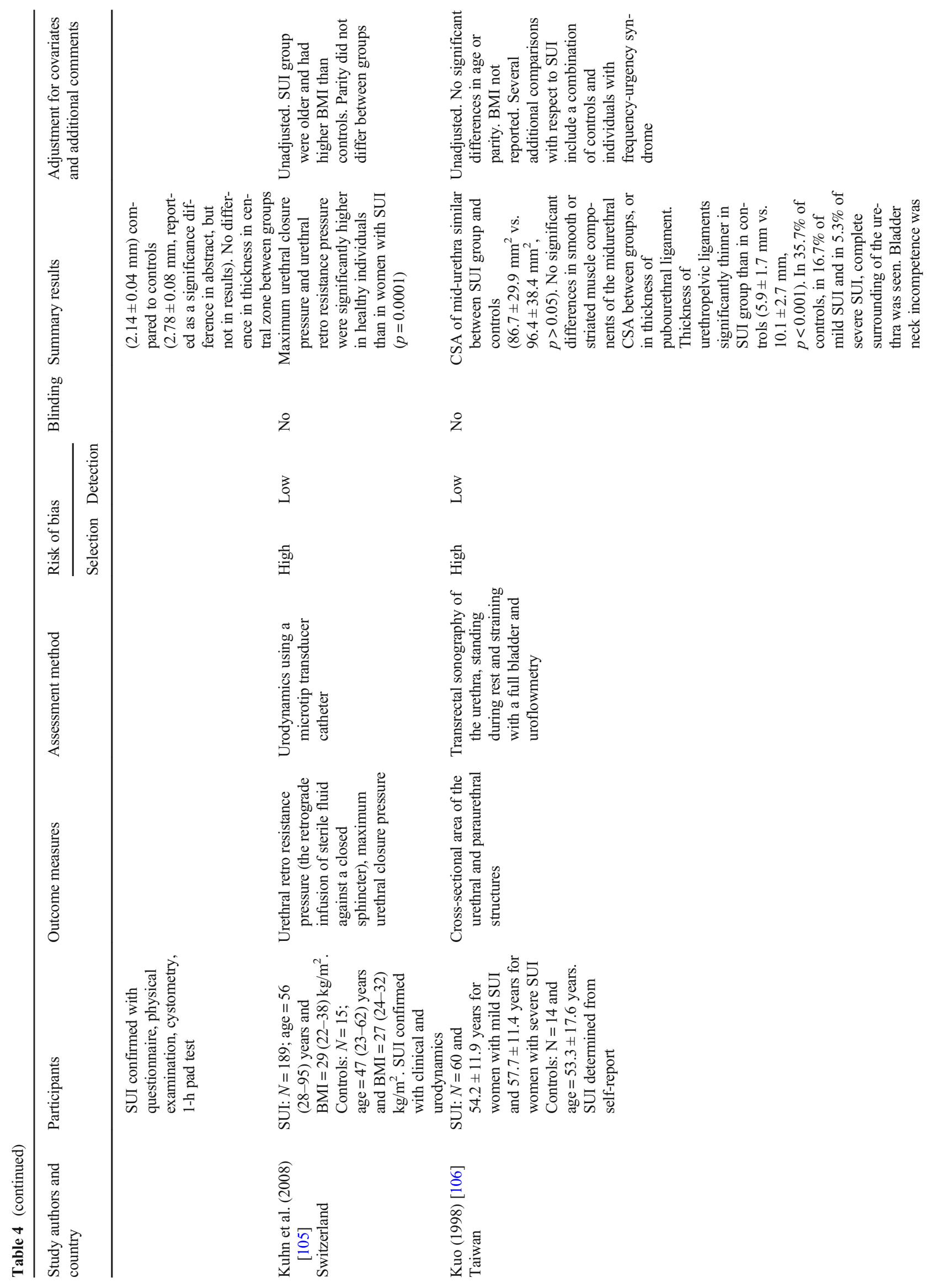




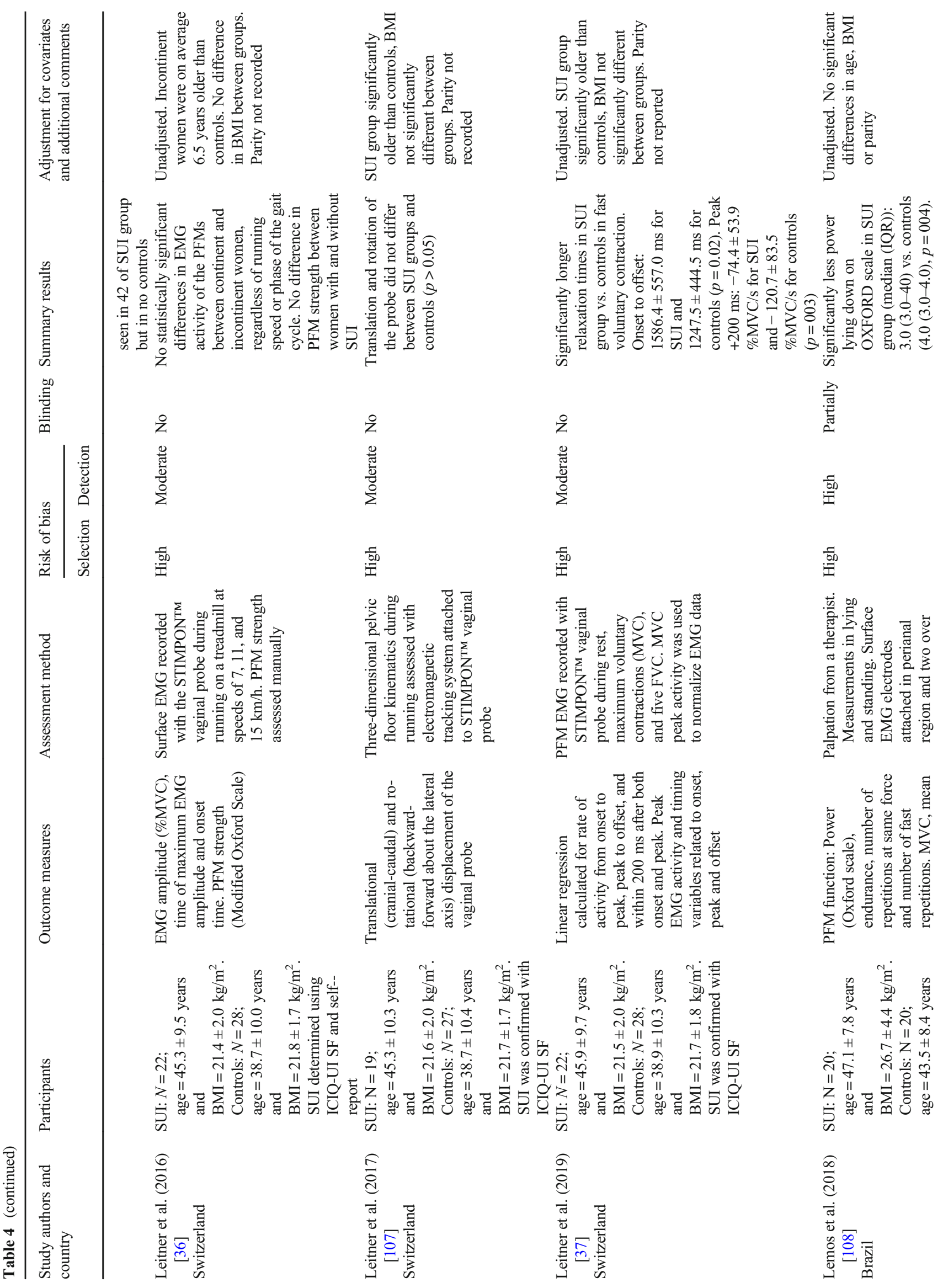




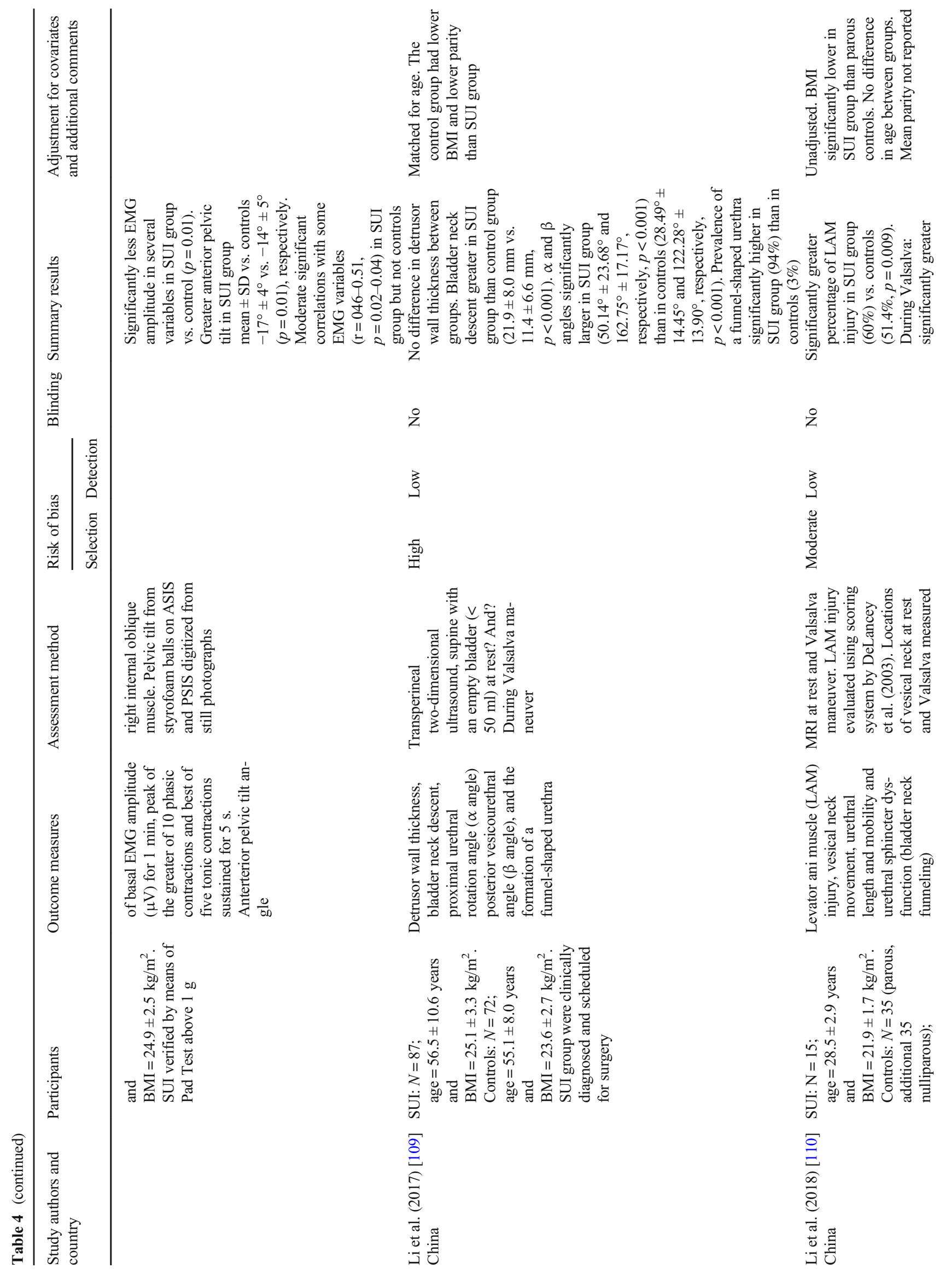




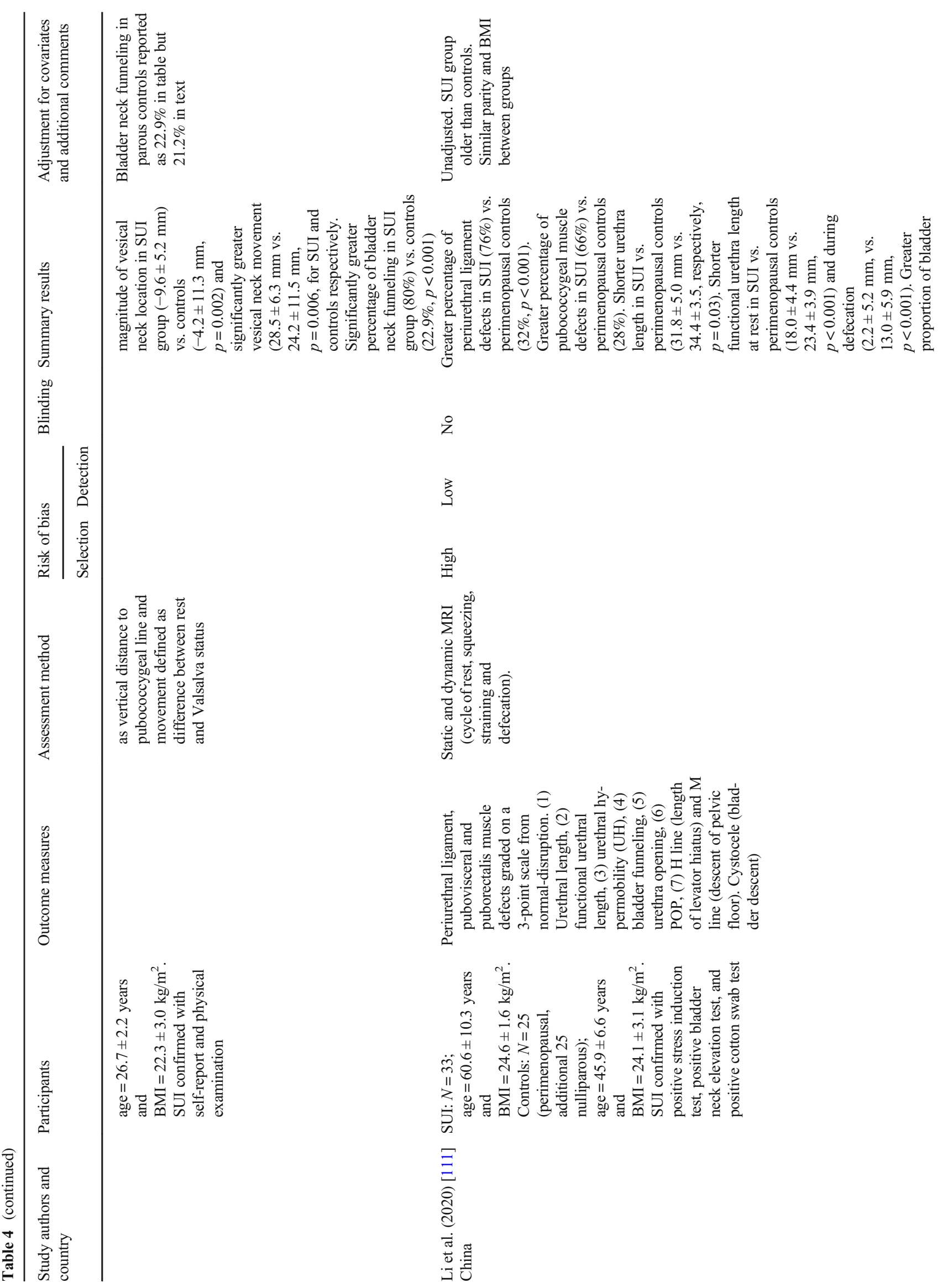




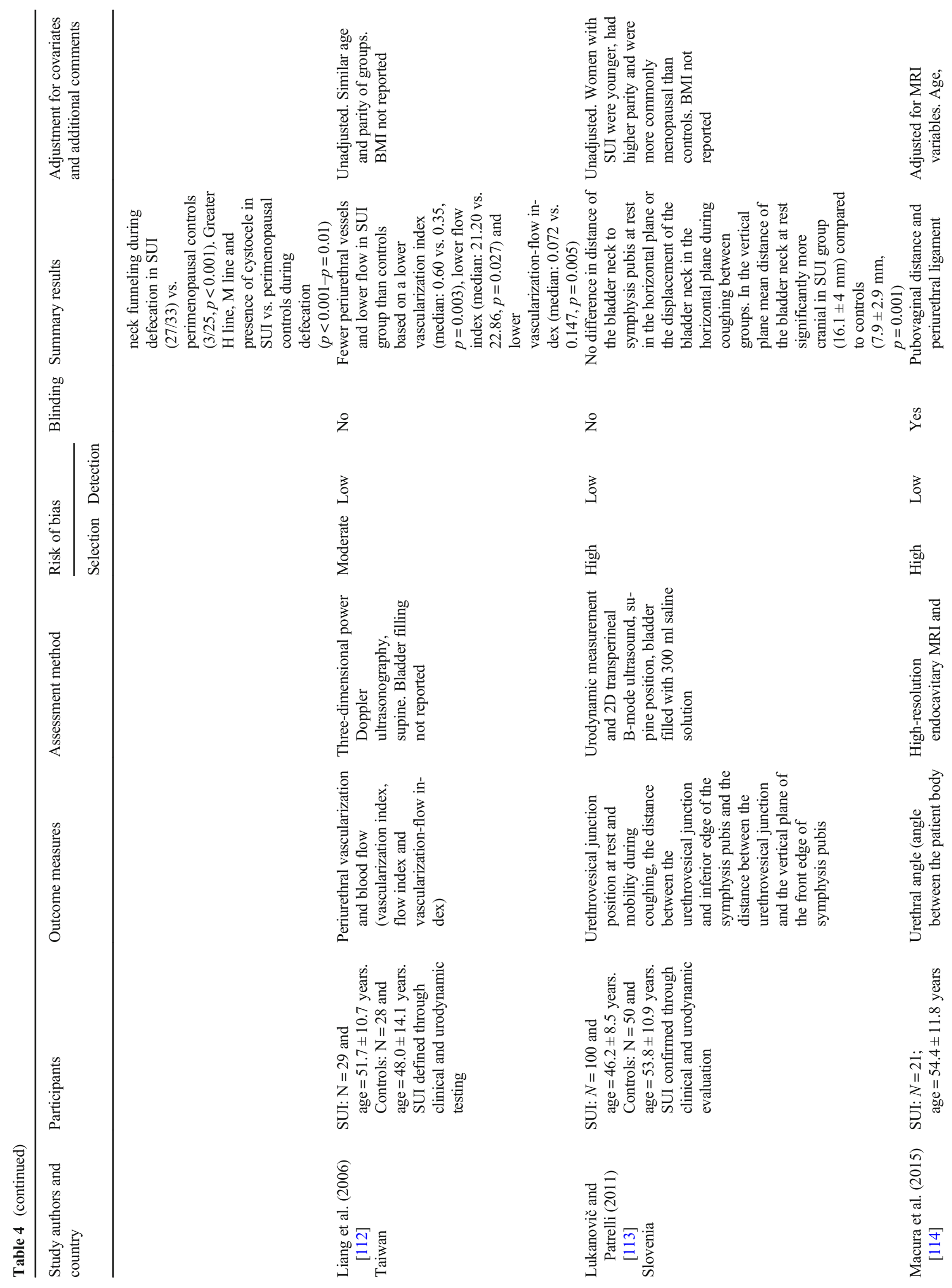




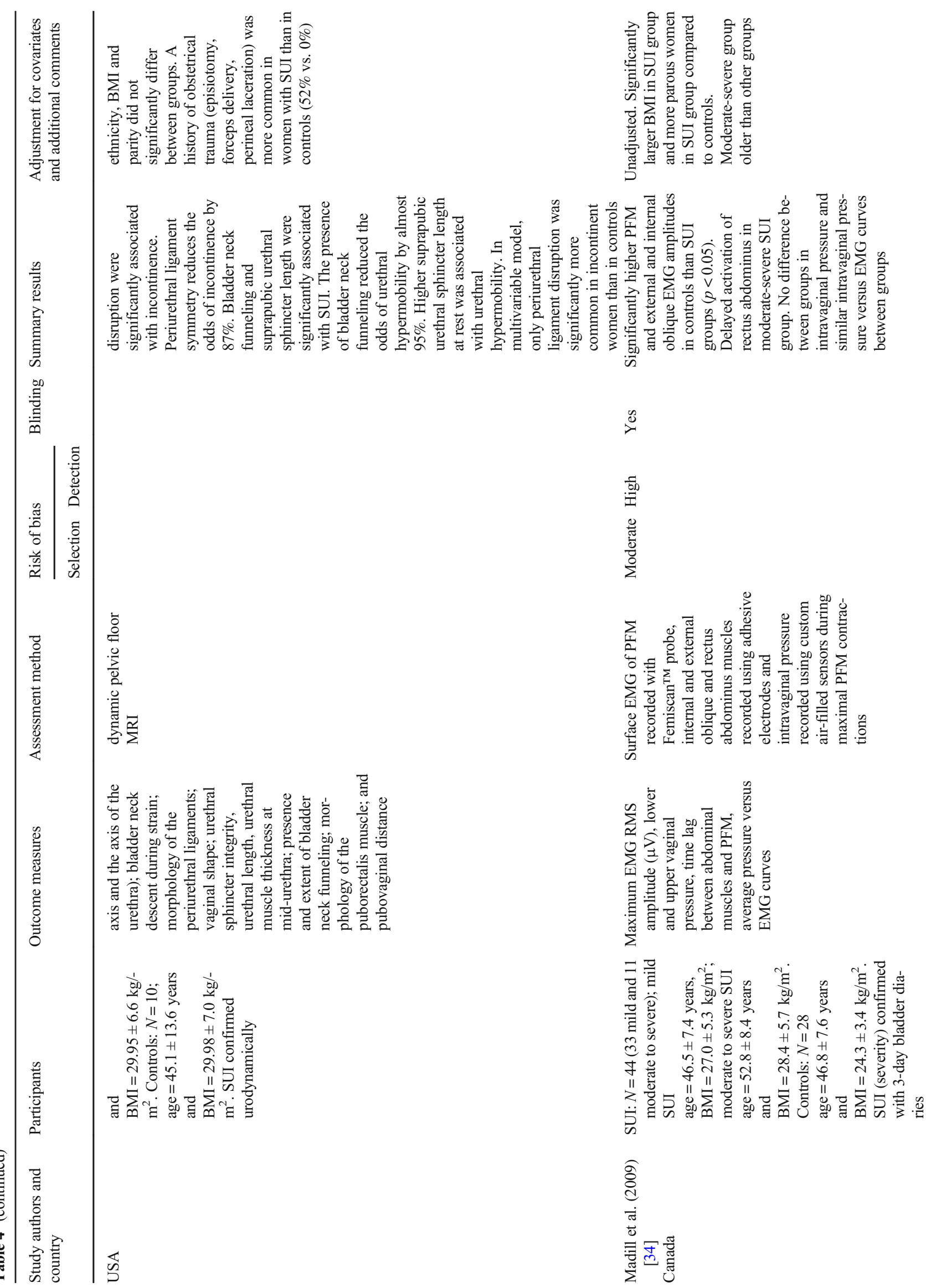




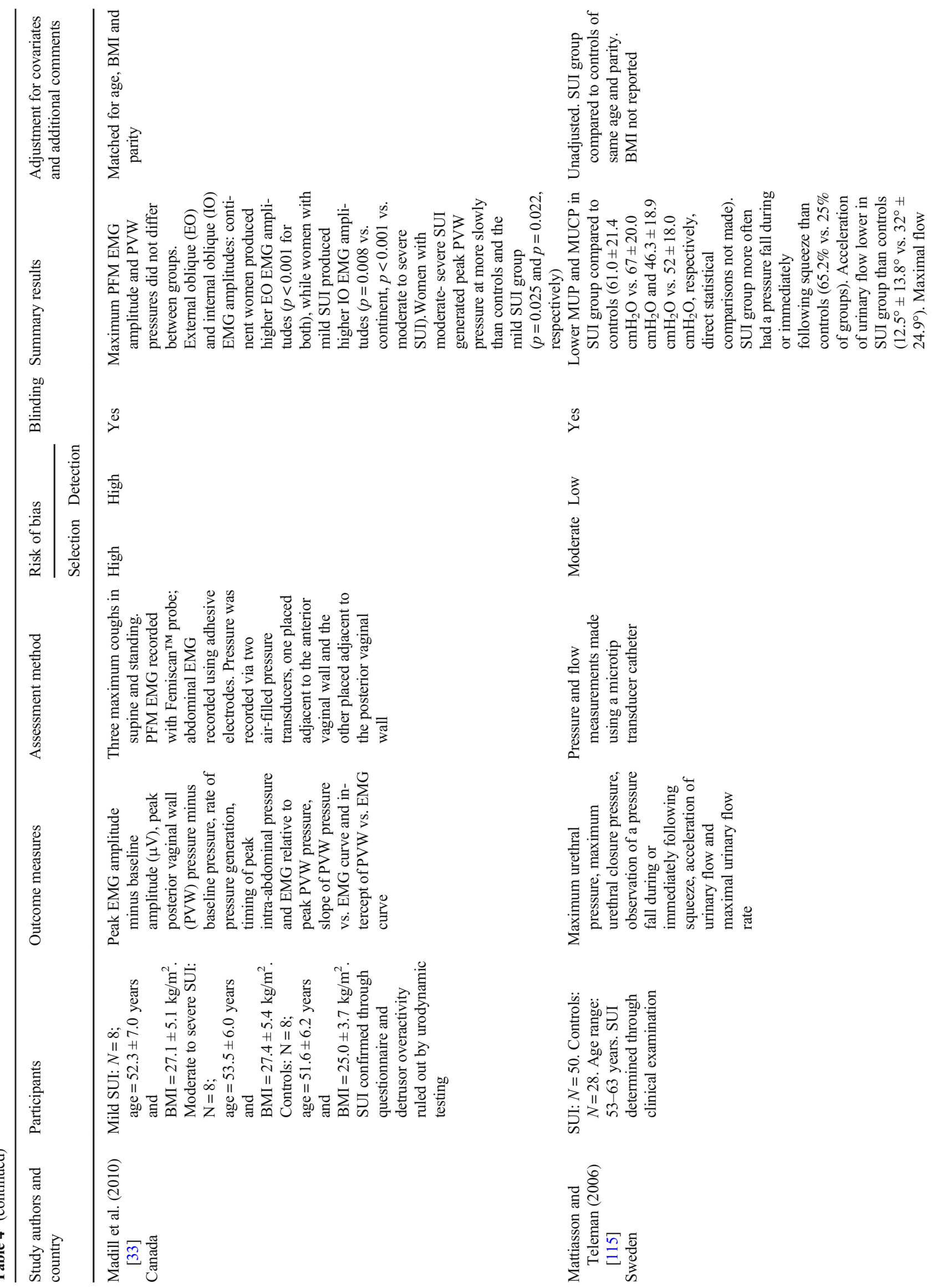




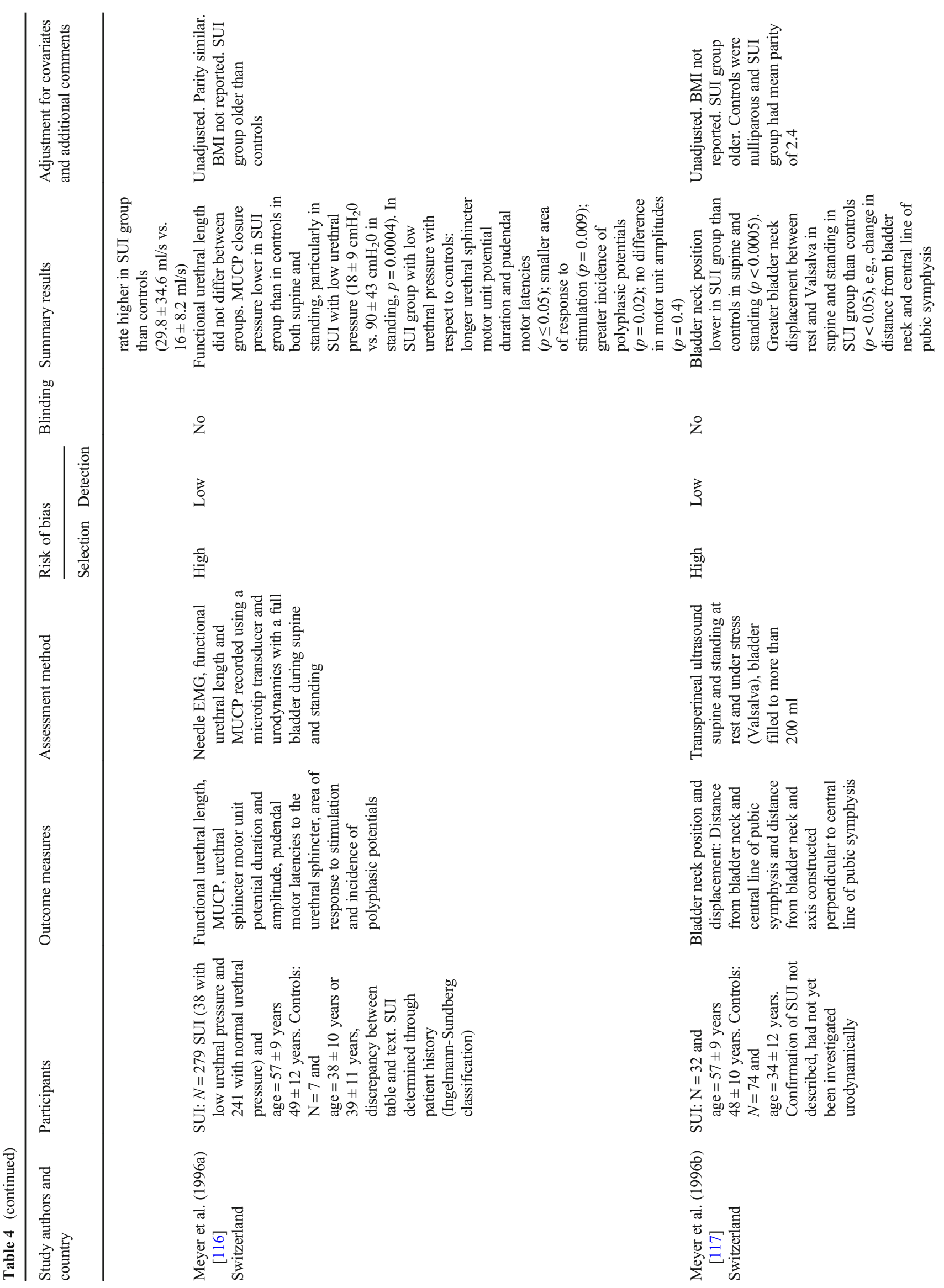




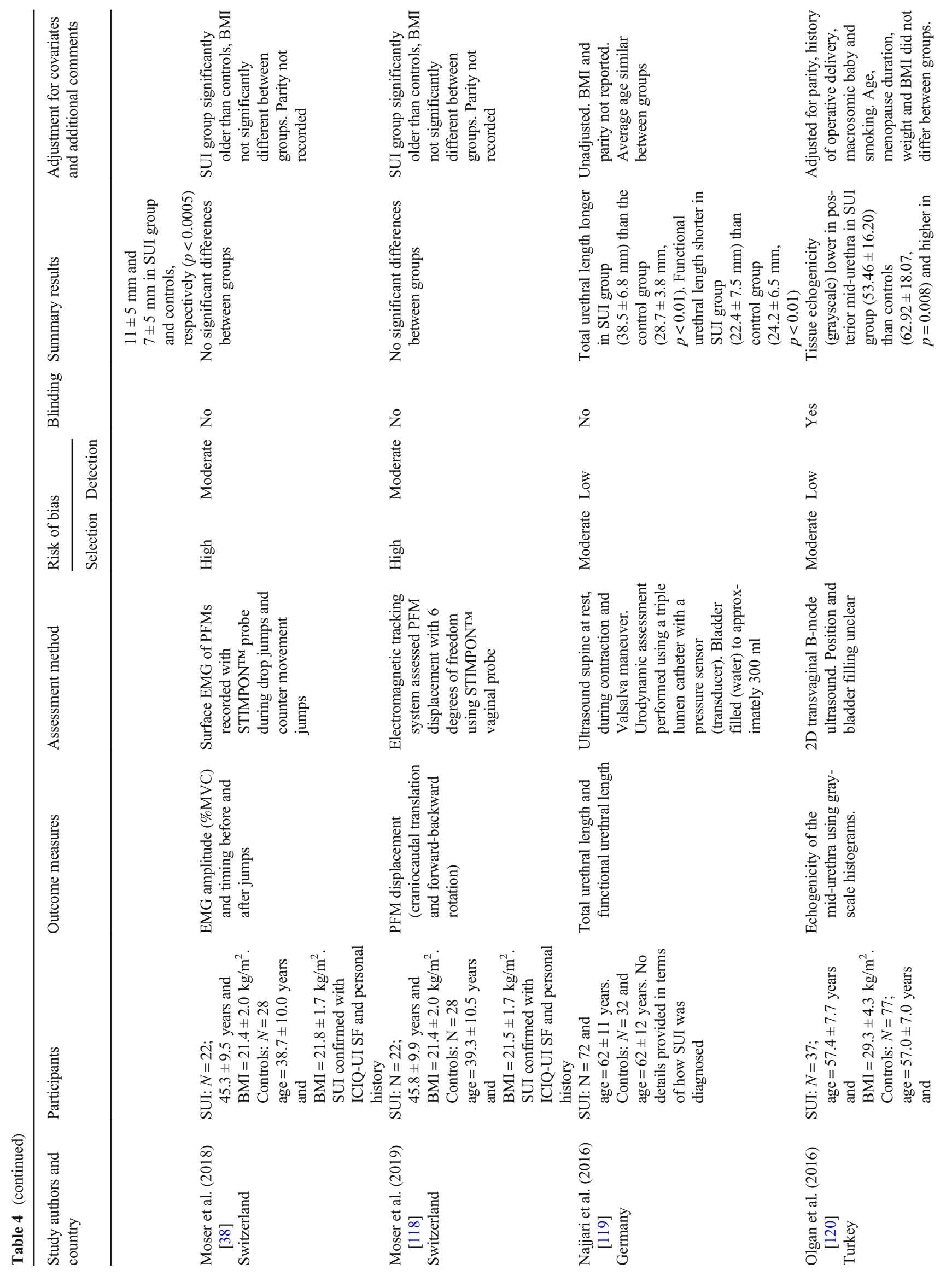




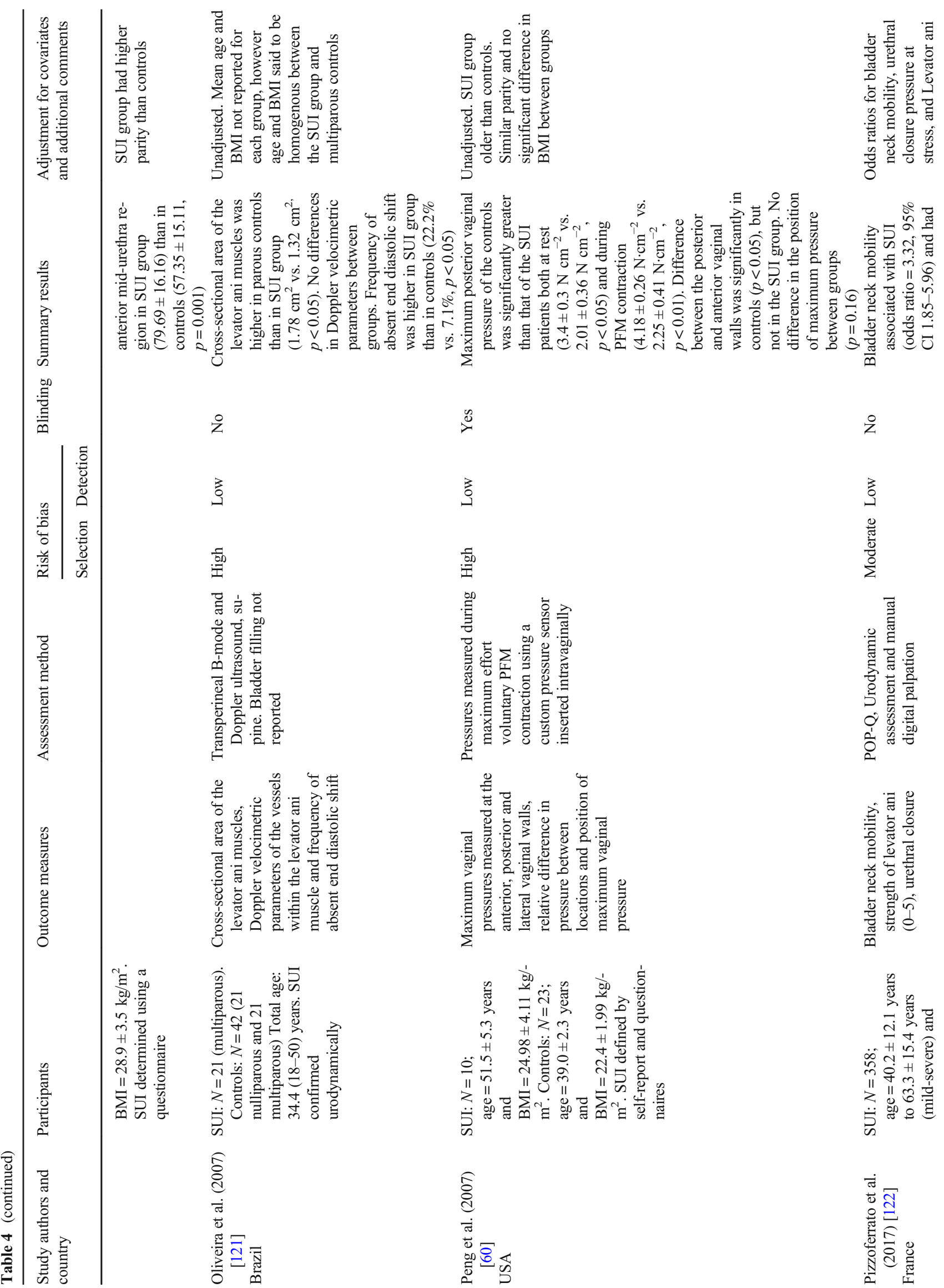




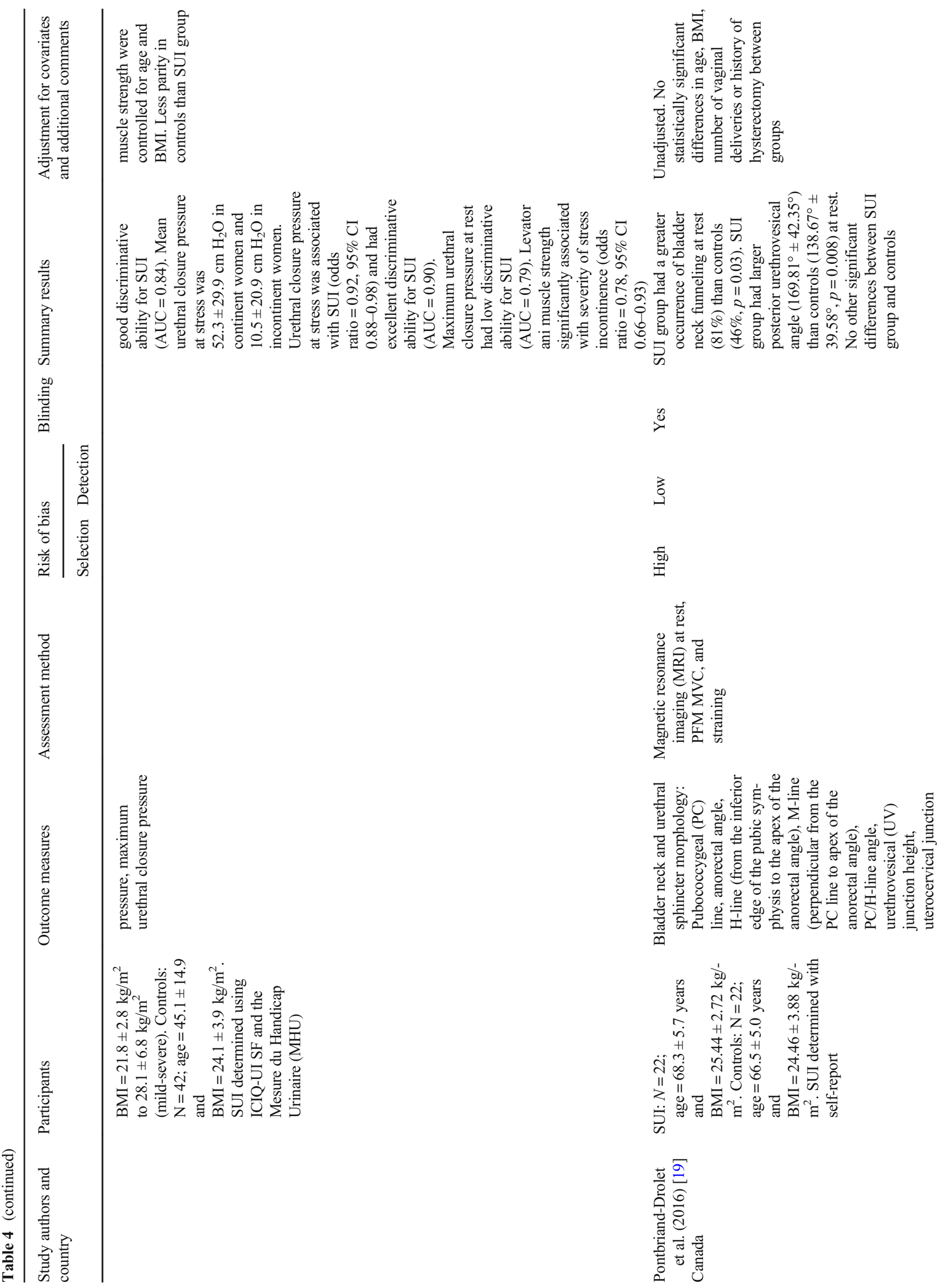




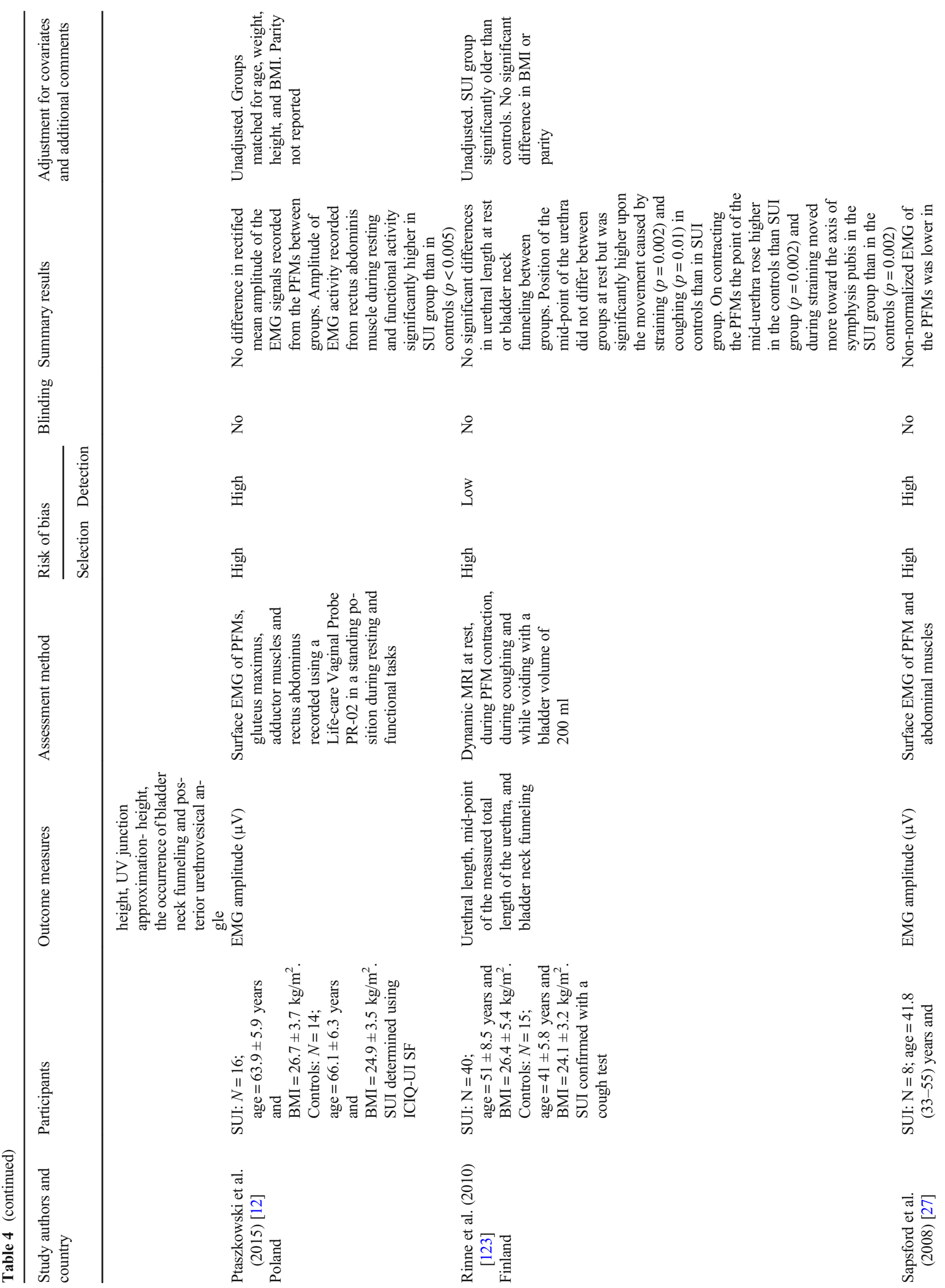




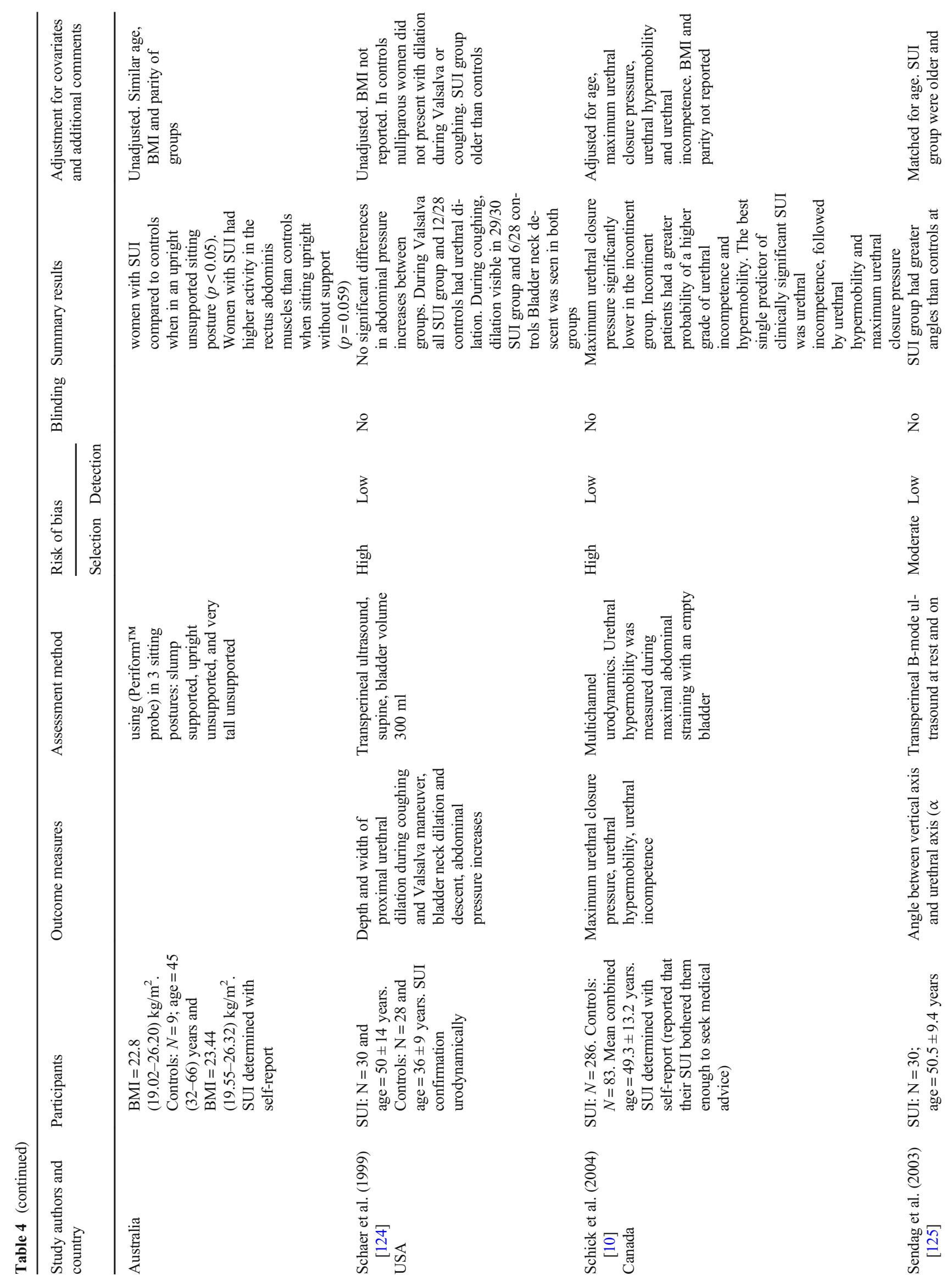




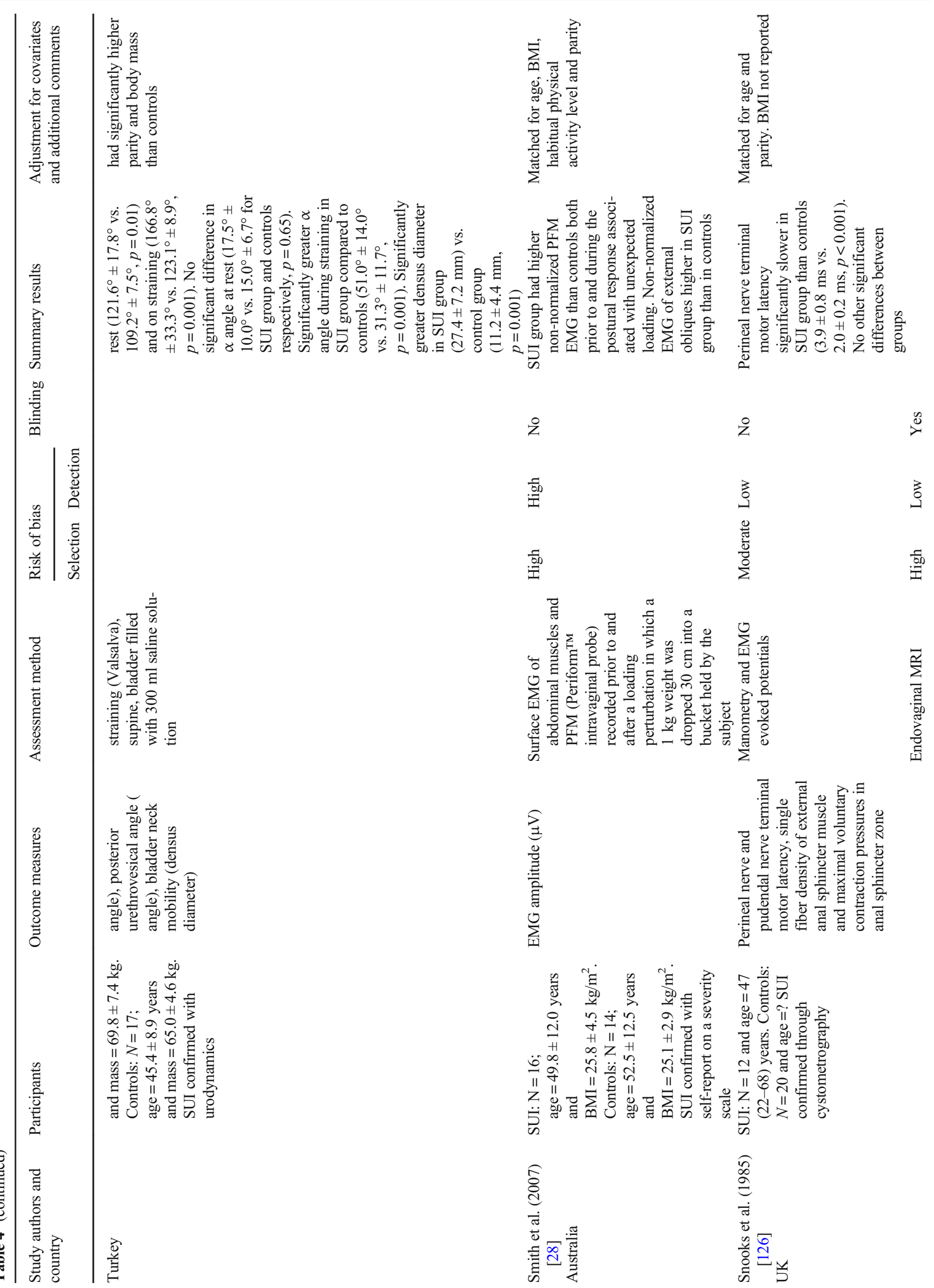




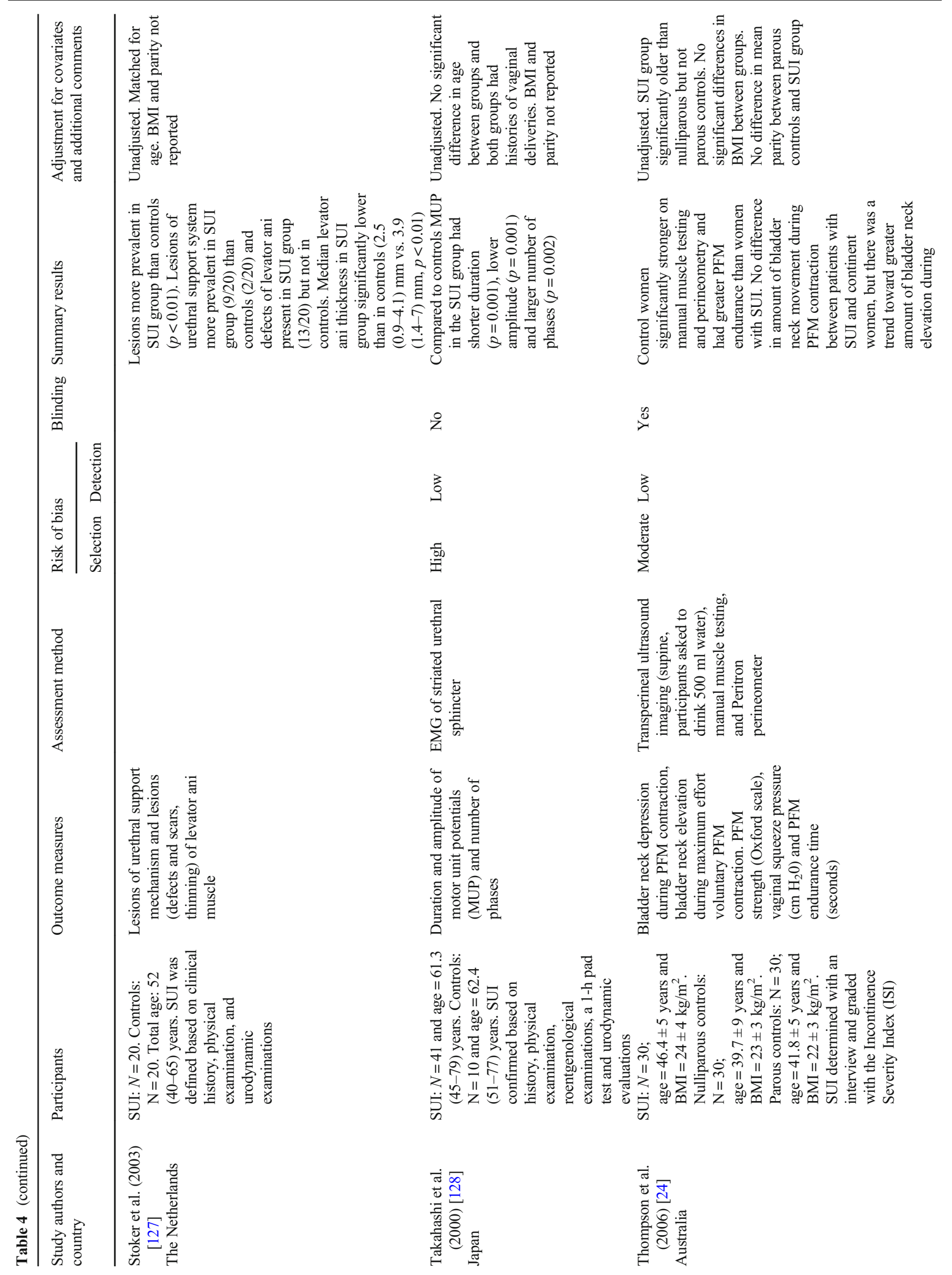




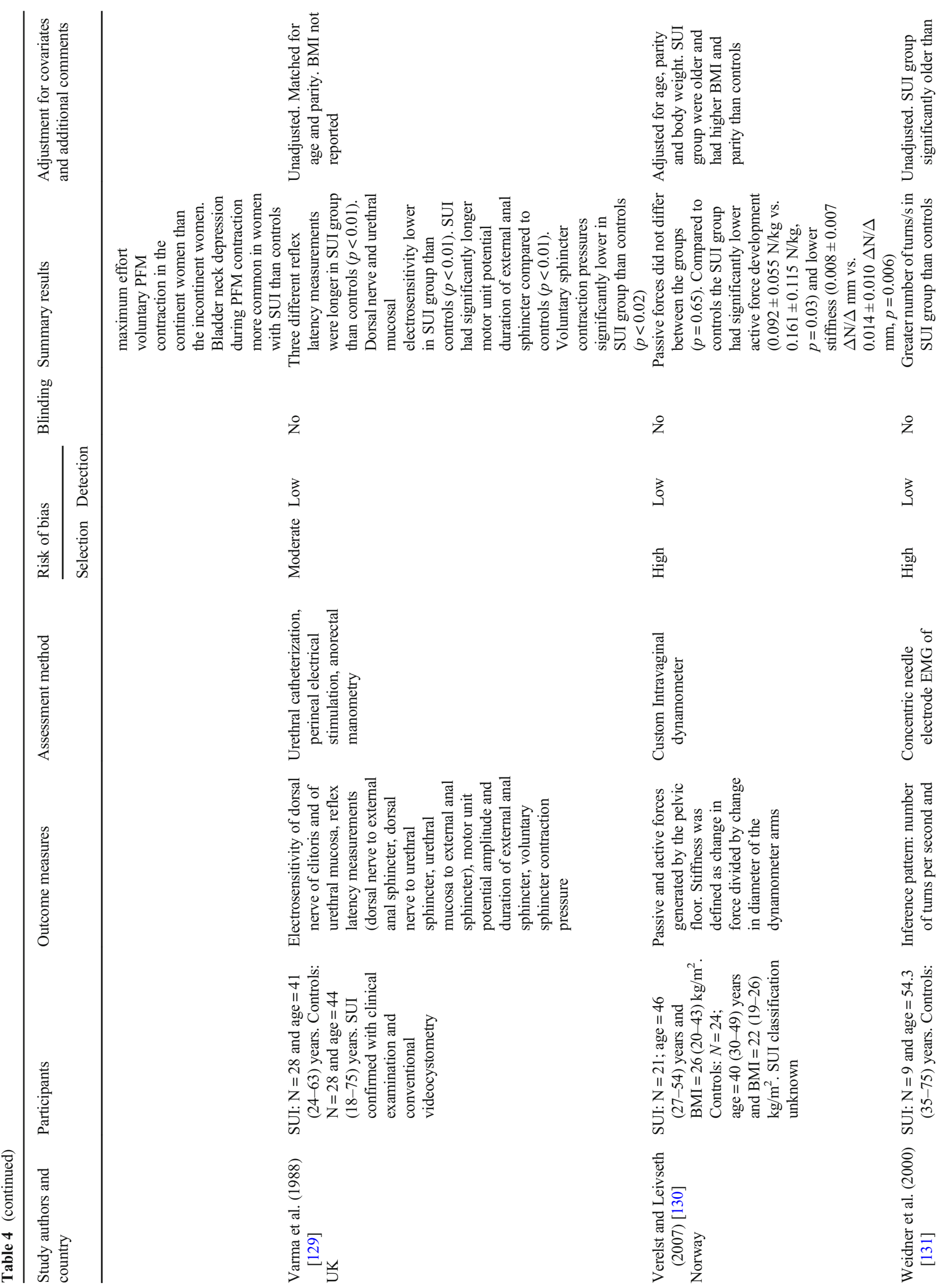




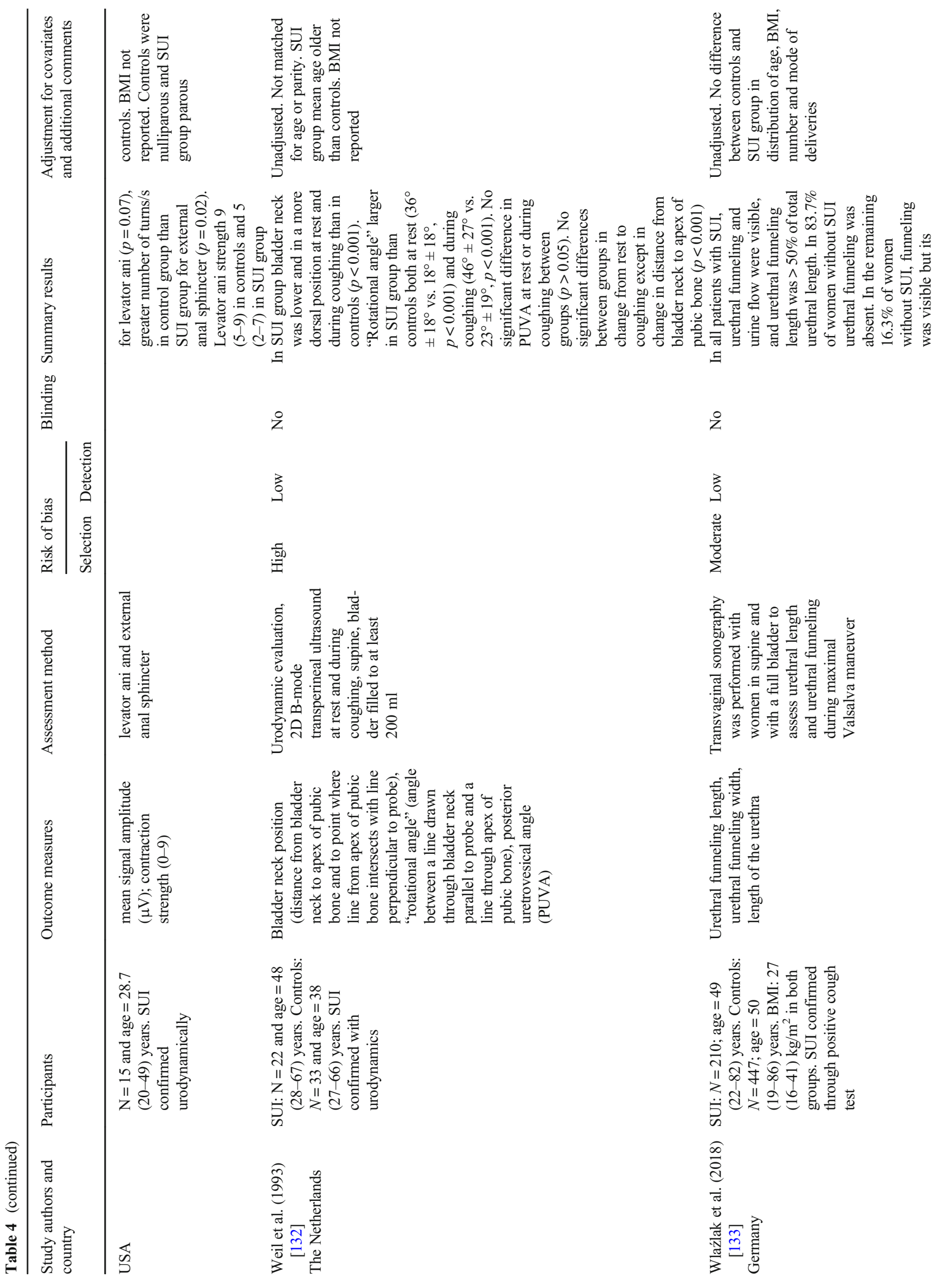




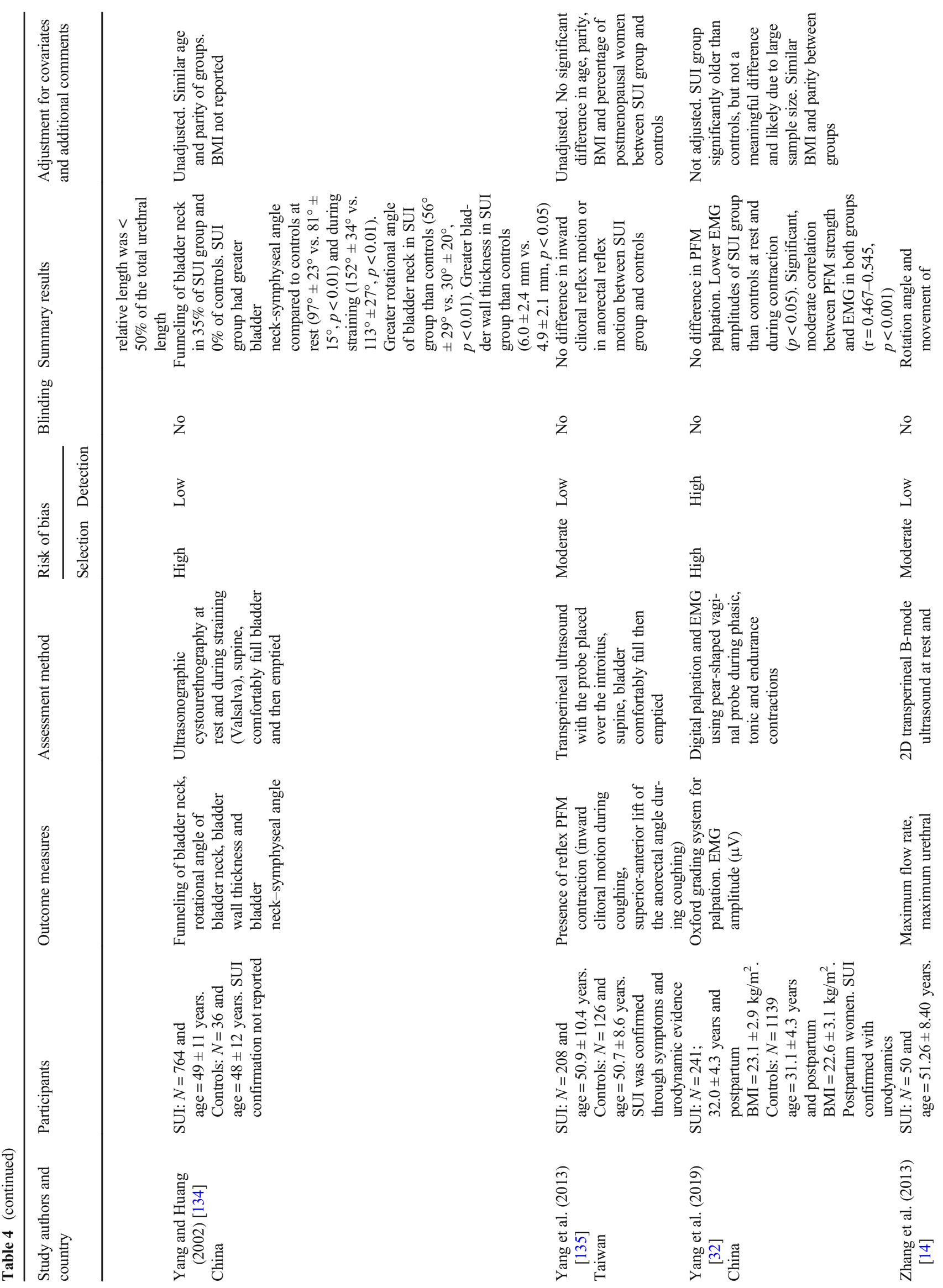




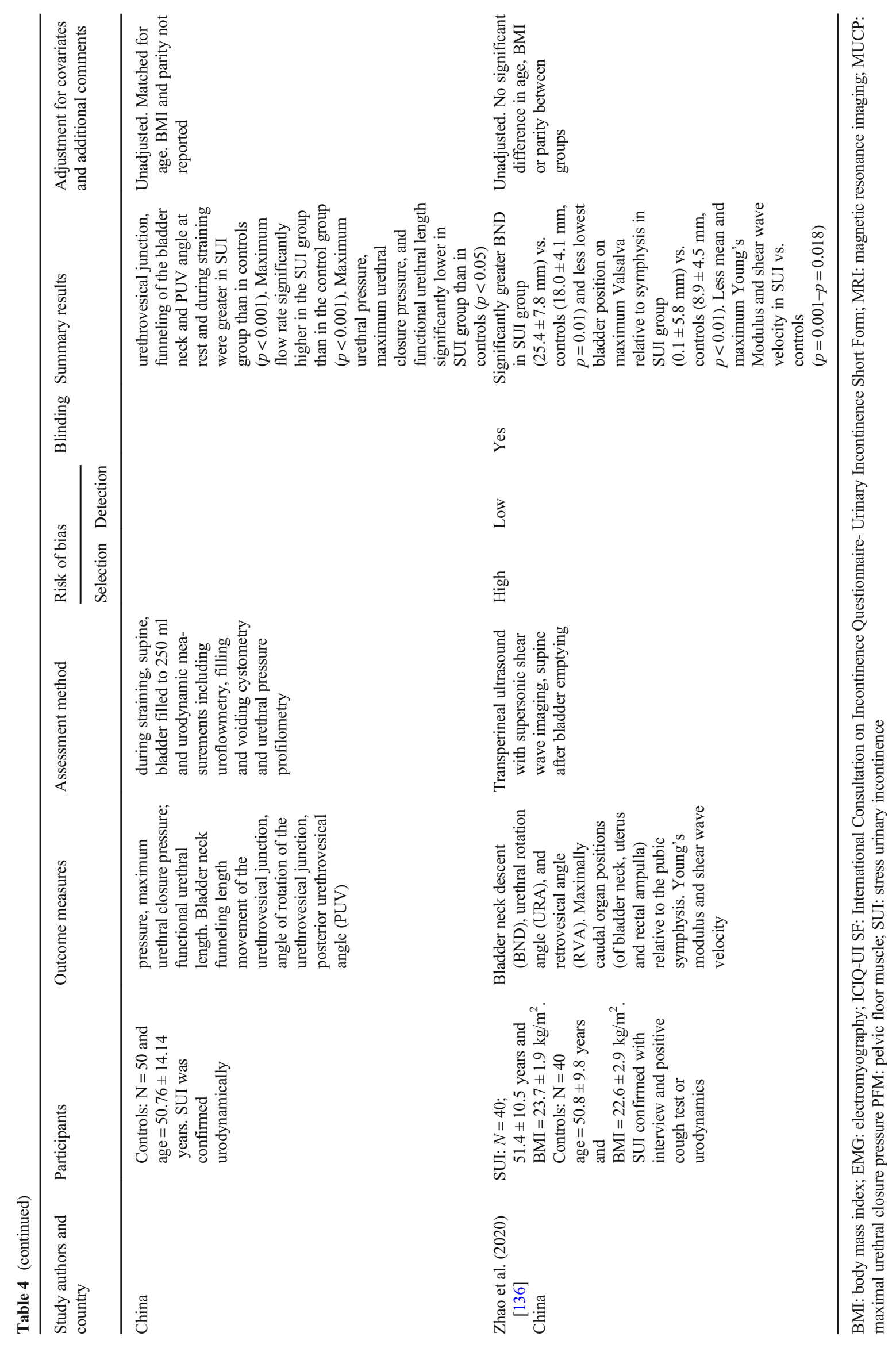


Open Access This article is licensed under a Creative Commons Attribution 4.0 International License, which permits use, sharing, adaptation, distribution and reproduction in any medium or format, as long as you give appropriate credit to the original author(s) and the source, provide a link to the Creative Commons licence, and indicate if changes were made. The images or other third party material in this article are included in the article's Creative Commons licence, unless indicated otherwise in a credit line to the material. If material is not included in the article's Creative Commons licence and your intended use is not permitted by statutory regulation or exceeds the permitted use, you will need to obtain permission directly from the copyright holder. To view a copy of this licence, visit http://creativecommons.org/licenses/by/4.0/.

\section{References}

1. Minassian VA, Drutz HP, Al-Badr A. Urinary incontinence as a worldwide problem. Int J Gynaecol Obstet. 2003;82(3):327-38.

2. D'Ancona C, Haylen B, Oelke M, Abranches-Monteiro L, Arnold E, Goldman H, et al. The international continence society (ICS) report on the terminology for adult male lower urinary tract and pelvic floor symptoms and dysfunction. Neurourol Urodyn. 2019;38(2):433-77. https://doi.org/10.1002/nau.23897.

3. Castro Diaz D, Robinson D, Bosch R, Constantini E, Cotterill N, Espuna-Pons M, Kocjancic E, Lemos N, Tarcan T, Yoshida M. Patient-Reported Outcome Assessment. In Incontinence, 6th Edition 2017: International Consultation on Incontinence, Tokyo, September 2016, P. Abrams, L. Cardozo, A. Wagg, and A. Wein, eds. (International Continence Society), pp. 541-599. 2017.

4. Wan J, McGuire EJ, Bloom DA, Ritchey ML. Stress leak point pressure: a diagnostic tool for incontinent children. J Urol. 1993;150(2 Pt 2):700-2. https://doi.org/10.1016/s0022-5347(17) 35590-8.

5. Burden $H$, Warren $K$, Abrams P. Leak point pressures: how useful are they? Curr Opin Urol. 2015;25(4):317-22. https://doi.org/10. 1097/MOU.0000000000000176.

6. McGuire EJ, Woodside JR, Borden TA, Weiss RM. Prognostic value of urodynamic testing in myelodysplastic patients. J Urol. 1981;126(2):205-9. https://doi.org/10.1016/s0022-5347(17) 54449-3.

7. Schäfer W. Some biomechanical aspects of continence function. Scand J Urol Nephrol Suppl. 2002;207:44-60.

8. Cooper MA, Fletter PC, Zaszczurynski PJ, Damaser MS. Comparison of air-charged and water-filled urodynamic pressure measurement catheters. Neurourol Urodyn. 2011;30(3):329-34. https://doi.org/10.1002/nau.20991.

9. Schick E, Tessier J, Bertrand PE, Dupont C, Jolivet-Tremblay M. Observations on the function of the female urethra: I: relation between maximum urethral closure pressure at rest and urethral hypermobility. Neurourol Urodyn. 2003;22(7):643-7. https://doi. org/10.1002/nau.10148.

10. Schick E, Dupont C, Bertrand PE, Jolivet-Tremblay M, Tessier J. Predictive value of maximum urethral closure pressure, urethral hypermobility and urethral incompetence in the diagnosis of clinically significant female genuine stress incontinence. J Urol. 2004;171(5):1871-5. https://doi.org/10.1097/01.ju.0000120224. 67012.39 .

11. Barbic M, Kralj B, Cor A. Compliance of the bladder neck supporting structures: importance of activity pattern of levator ani muscle and content of elastic fibers of endopelvic fascia. Neurourol Urodyn. 2003;22(4):269-76. https://doi.org/10.1002/ nau.10116.

12. Ptaszkowski K, Paprocka-Borowicz M, Slupska L, Bartnicki J, Dymarek R, Rosinczuk J, et al. Assessment of bioelectrical activity of synergistic muscles during pelvic floor muscles activation in postmenopausal women with and without stress urinary incontinence: a preliminary observational study. Clin Interv Aging. 2015;10:1521-8. https://doi.org/10.2147/CIA.S89852.

13. Kuo $\mathrm{H}$. The relationships of urethral and pelvic floor muscles and the urethral pressure measurements in women with stress urinary incontinence. Eur Urol. 2000;37(2):149-55. https://doi.org/10. $1159 / 000020132$.

14. Zhang X, Chen Z, Song X, Yuan X, Cai D, Chen J, et al. Application of perineal ultrasound measurement and urodynamic study in the diagnosis and typing of stress urinary incontinence ultrasound and urodynamic study. Urologia. 2013;80(3):233-8. https://doi.org/10.5301/urologia.5000027.

15. Hale DS, Benson JT, Brubaker L, Heidkamp MC, Russell B. Histologic analysis of needle biopsy of urethral sphincter from women with normal and stress incontinence with comparison of electromyographic findings. Am J Obstet Gynecol. 1999;180(2 Pt 1):342-8.

16. DeLancey JO. Structural aspects of the extrinsic continence mechanism. Obstet Gynecol. 1988;72(3 Pt 1):296-301.

17. Robinson BL, Geller EJ, Parnell BA, Crane AK, Jannelli ML, Wells EC, et al. Diagnostic accuracy of visual urethral mobility exam versus Q-tip test: a randomized crossover trial. Am J Obstet Gynecol. 2012;206(6):528 e521-526. https://doi.org/10.1016/j. ajog.2012.02.015.

18. Pirpiris A, Shek KL, Dietz HP. Urethral mobility and urinary incontinence. Ultrasound Obstet Gynecol. 2010;36(4):507-11. https://doi.org/10.1002/uog.7658.

19. Pontbriand-Drolet S, Tang A, Madill SJ, Tannenbaum C, Lemieux MC, Corcos J, et al. Differences in pelvic floor morphology between continent, stress urinary incontinent, and mixed urinary incontinent elderly women: an MRI study. Neurourol Urodyn. 2016;35(4):515-21. https://doi.org/10.1002/nau.22743.

20. Örnö A-K, Dietz H. Levator co-activation is a significant confounder of pelvic organ descent on Valsalva maneuver. Ultrasound Obstet Gynecol Off J Int Soc Ultrasound Obstet Gynecol. 2007;30(3):346-50.

21. Wei JT, De Lancey JO. Functional anatomy of the pelvic floor and lower urinary tract. Clin Obstet Gynecol. 2004;47(1):3-17.

22. Chamochumbi CC, Nunes FR, Guirro RR, Guirro EC. Comparison of active and passive forces of the pelvic floor muscles in women with and without stress urinary incontinence. Rev Bras Fisioter. 2012;16(4):314-9.

23. Kirschner-Hermanns R, Wein B, Niehaus S, Schaefer W, Jakse G. The contribution of magnetic resonance imaging of the pelvic floor to the understanding of urinary incontinence. Br J Urol. 1993;72(5 Pt 2):715-8.

24. Thompson JA, O'Sullivan PB, Briffa NK, Neumann P. Assessment of voluntary pelvic floor muscle contraction in continent and incontinent women using transperineal ultrasound, manual muscle testing and vaginal squeeze pressure measurements. Int Urogynecol J Pelvic Floor Dysfunct. 2006;17(6): 624-30. https://doi.org/10.1007/s00192-006-0081-2.

25. Gunnarsson M, Mattiasson A. Female stress, urge, and mixed urinary incontinence are associated with a chronic and progressive pelvic floor/vaginal neuromuscular disorder: an investigation of 317 healthy and incontinent women using vaginal surface electromyography. Neurourol Urodyn. 1999;18(6):613-21.

26. Pereira-Baldon VS, de Oliveira AB, Padilha JF, Degani AM, Avila MA, Driusso P. Reliability of different electromyographic normalization methods for pelvic floor muscles assessment. Neurourol Urodyn. 2020;39(4):1145-51. https://doi.org/10.1002/ nau. 24332

27. Sapsford RR, Richardson CA, Maher CF, Hodges PW. Pelvic floor muscle activity in different sitting postures in continent and 
incontinent women. Arch Phys Med Rehabil. 2008;89(9):1741-7. https://doi.org/10.1016/j.apmr.2008.01.029.

28. Smith MD, Coppieters MW, Hodges PW. Postural response of the pelvic floor and abdominal muscles in women with and without incontinence. Neurourol Urodyn. 2007;26(3):377-85. https://doi. org/10.1002/nau.20336.

29. Koenig I, Luginbuehl H, Radlinger L. Reliability of pelvic floor muscle electromyography tested on healthy women and women with pelvic floor muscle dysfunction. Ann Phys Rehab Med. 2017;60(6):382-6. https://doi.org/10.1016/j.rehab.2017.04.002.

30. Dornowski M, Sawicki P, Vereshchaka I, Piernicka M, Bludnicka $\mathrm{M}$, Worska A, et al. Training-related changes of EMG activity of the pelvic floor muscles in women with urinary incontinence problems. Neurophysiology. 2018;50(3):215-21. https://doi.org/10. 1007/s11062-018-9740-4.

31. Dornowski M, Sawicki P, Wilczynska D, Vereshchaka I, Piernicka M, Bludnicka M, et al. Six-week pelvic floor muscle activity (sEMG) training in pregnant women as prevention of stress urinary incontinence. Med Sci Monit Int Med J Exp Clin Res. 2018;24:5653-9. https://doi.org/10.12659/msm.911707.

32. Yang X, Zhu L, Li W, Sun X, Huang Q, Tong B, et al. Comparisons of electromyography and digital palpation measurement of pelvic floor muscle strength in postpartum women with stress urinary incontinence and asymptomatic Parturients: a crosssectional study. Gynecol Obstet Investig. 2019;84(6):599-605. https://doi.org/10.1159/000501825.

33. Madill SJ, Harvey MA, McLean L. Women with stress urinary incontinence demonstrate motor control differences during coughing. J Electromyogr Kinesiol. 2010;20(5):804-12. https:// doi.org/10.1016/j.jelekin.2009.10.006.

34. Madill SJ, Harvey M-A, McLean L. Women with SUI demonstrate motor control differences during voluntary pelvic floor muscle contractions. Int Urogynecol J. 2009;20(4):447-59.

35. Ballmer C, Eichelberger P, Leitner M, Moser H, Luginbuehl H, Kuhn A, et al. Electromyography of pelvic floor muscles with true differential versus faux differential electrode configuration. Int Urogynecol J. 2020. https://doi.org/10.1007/s00192-020-042254.

36. Leitner M, Moser H, Eichelberger P, Kuhn A, Radlinger L. Evaluation of pelvic floor muscle activity during running in continent and incontinent women: an exploratory study. Neurourol Urodyn. 2016;36(6):1570-6. https://doi.org/10.1002/nau.23151.

37. Leitner M, Moser H, Eichelberger P, Kuhn A, Radlinger L. Pelvic floor muscle activity during fast voluntary contractions in continent and incontinent women. Neurourol Urodyn. 2019;38(2):62531. https://doi.org/10.1002/nau.23911.

38. Moser H, Leitner M, Eichelberger P, Kuhn A, Baeyens JP, Radlinger L. Pelvic floor muscle activity during jumps in continent and incontinent women: an exploratory study. Arch Gynecol Obstet. 2018;297(6):1455-63. https://doi.org/10.1007/s00404$018-4734-4$.

39. Koenig I, Eichelberger P, Leitner M, Moser H, Kuhn A, Taeymans J, et al. Pelvic floor muscle activity patterns in women with and without stress urinary incontinence while running. Ann Phys Rehabil Med. 2019. https://doi.org/10.1016/j.rehab.2019. 09.013 .

40. Burti JS, Hacad CR, Zambon JP, Polessi EA, Almeida FG. Is there any difference in pelvic floor muscles performance between continent and incontinent women? Neurourol Urodyn. 2015;34(6): 544-8. https://doi.org/10.1002/nau.22613.

41. Junginger B, Vollhaber H, Baessler K. Submaximal pelvic floor muscle contractions: similar bladder-neck elevation, longer duration, less intra-abdominal pressure. Int Urogynecol J. 2018;29(11):1681-7. https://doi.org/10.1007/s00192-018-37250 .
42. Devreese A, Staes F, Janssens L, Penninckx F, Vereecken R, De Weerdt W. Incontinent women have altered pelvic floor muscle contraction patterns. J Urol. 2007;178(2):558-62. https://doi.org/ 10.1016/j.juro.2007.03.097.

43. Auchincloss CC, McLean L. The reliability of surface EMG recorded from the pelvic floor muscles. J Neurosci Methods. 2009; 182(1):85-96

44. Grape HH, Dedering A, Jonasson AF. Retest reliability of surface electromyography on the pelvic floor muscles. Neurourol Urodyn. 2009;28(5):395-9. https://doi.org/10.1002/nau.20648.

45. Keshwani N, McLean L. State of the art review: intravaginal probes for recording electromyography from the pelvic floor muscles. Neurourol Urodyn. 2015;34(2):104-12. https://doi.org/10. 1002/nau.22529.

46. Luginbuehl H, Greter C, Gruenenfelder D, Baeyens JP, Kuhn A, Radlinger L. Intra-session test-retest reliability of pelvic floor muscle electromyography during running. Int Urogynecol J. 2013;24(9):1515-22. https://doi.org/10.1007/s00192-012-20342.

47. Semciw AI, Freeman M, Kunstler BE, Mendis MD, Pizzari T. Quadratus femoris: an EMG investigation during walking and running. J Biomech. 2015;48(12):3433-9. https://doi.org/10. 1016/j.jbiomech.2015.05.029.

48. Constantinou CE, Omata S. Direction sensitive sensor probe for the evaluation of voluntary and reflex pelvic floor contractions. Neurourol Urodyn. 2007;26(3):386-91. https://doi.org/10.1002/ nau. 20263.

49. Guaderrama NM, Nager CW, Liu J, Pretorius DH, Mittal RK. The vaginal pressure profile. Neurourol Urodyn. 2005;24(3):243-7. https://doi.org/10.1002/nau.20112.

50. Kerschan-Schindl K, Uher E, Wiesinger G, Kaider A, Ebenbichler $\mathrm{G}$, Nicolakis $P$, et al. Reliability of pelvic floor muscle strength measurement in elderly incontinent women. Neurourol Urodyn. 2002;21(1):42-7.

51. Navarro Brazález B, Torres Lacomba M, de la Villa P, Sánchez Sánchez B, Prieto Gómez V, Asúnsolo del Barco Á, et al. The evaluation of pelvic floor muscle strength in women with pelvic floor dysfunction: a reliability and correlation study. Neurourol Urodyn. 2018;37(1):269-77.

52. Laycock J, Jerwood D. Pelvic floor muscle assessment: the PERFECT scheme. Physiotherapy. 2001;87(12):631-42. https:// doi.org/10.1016/S0031-9406(05)61108-X.

53. Talasz H, Kremser C, Kofler M, Kalchschmid E, Lechleitner M, Rudisch A. Proof of concept: differential effects of Valsalva and straining maneuvers on the pelvic floor. Eur J Obstet Gynecol Reprod Biol. 2012;164(2):227-33. https://doi.org/10.1016/j. ejogrb.2012.06.019.

54. Howard D, Miller JM, Delancey JOL, Ashton-Miller JA. Differential effects of cough, valsalva, and continence status on vesical neck movement. Obstet Gynecol. 2000;95(4):535-40. https://doi.org/10.1016/S0029-7844(99)00618-3.

55. Rett MT, Simoes JA, Herrmann V, Pinto CL, Marques AA, Morais SS. Management of stress urinary incontinence with surface electromyography-assisted biofeedback in women of reproductive age. Phys Ther. 2007;87(2):136-42. https://doi.org/10. 2522/ptj.20050318.

56. Peschers UM, Gingelmaier A, Jundt K, Leib B, Dimpfl T. Evaluation of pelvic floor muscle strength using four different techniques. Int Urogynecol J Pelvic Floor Dysfunct. 2001;12(1): 27-30.

57. Lammers K, Prokop M, Vierhout ME, Kluivers KB, Futterer JJ. A pictorial overview of pubovisceral muscle avulsions on pelvic floor magnetic resonance imaging. Insights Imaging. 2013;4(4): 431-41. https://doi.org/10.1007/s13244-013-0261-9.

58. Pineda M, Shek K, Wong V, Dietz HP. Can hiatal ballooning be determined by two-dimensional translabial ultrasound? Aust N Z J 
Obstet Gynaecol. 2013;53(5):489-93. https://doi.org/10.1111/ajo. 12111.

59. Kruger JA, Dietz HP, Budgett SC, Dumoulin CL. Comparison between transperineal ultrasound and digital detection of levator ani trauma. Can we improve the odds? Neurourol Urodyn. 2014;33(3):307-11. https://doi.org/10.1002/nau.22386.

60. Peng Q, Jones R, Shishido K, Omata S, Constantinou CE. Spatial distribution of vaginal closure pressures of continent and stress urinary incontinent women. Physiol Meas. 2007;28(11):1429 50. https://doi.org/10.1088/0967-3334/28/11/009.

61. Romero-Culleres G, Pena-Pitarch E, Jane-Feixas C, Arnau A, Montesinos J, Abenoza-Guardiola M. Intra-rater reliability and diagnostic accuracy of a new vaginal dynamometer to measure pelvic floor muscle strength in women with urinary incontinence. Neurourol Urodyn. 2017;36(2):333-7. https://doi.org/10.1002/ nau. 22924.

62. Tahan N, Arab AM, Arzani P, Rahimi F. Relationship between ultrasonography and electromyography measurement of abdominal muscles when activated with and without pelvis floor muscles contraction. Minerva Med. 2013;104(6):625-30.

63. Constantinou CE. Dynamics of female pelvic floor function using urodynamics, ultrasound and magnetic resonance imaging (MRI). Eur J Obstet Gynecol Reprod Biol. 2009;144(Suppl 1):S159-65. https://doi.org/10.1016/j.ejogrb.2009.02.021.

64. Thibault-Gagnon S, Auchincloss C, Graham R, McLean L. The temporal relationship between activity of the pelvic floor muscles and motion of selected urogenital landmarks in healthy nulliparous women. J Electromyogr Kinesiol. 2018;38:126-35. https:// doi.org/10.1016/j.jelekin.2017.11.012.

65. Juenemann KP, Lue TF, Schmidt RA, Tanagho EA. Clinical significance of sacral and pudendal nerve anatomy. J Urol. 1988;139(1):74-80.

66. Kenton K, Mueller E, Brubaker L. Continent women have better urethral neuromuscular function than those with stress incontinence. Int Urogynecol J. 2011;22(12):1479-84. https://doi.org/ 10.1007/s00192-011-1447-7.

67. Ashton-Miller JA, Delancey JOL. Functional anatomy of the female pelvic floor. In: Elad D, Young RC, editors. Reproductive biomechanics, vol 1101. Annals of the new York Academy of Sciences. Malden: Wiley-Blackwell; 2007. p. 266-96. https:// doi.org/10.1196/annals.1389.034.

68. Cundiff GW. The pathophysiology of stress urinary incontinence: a historical perspective. Rev Urol. 2004;6(Suppl 3):S10-8.

69. Rud T, Andersson KE, Asmussen M, Hunting A, Ulmsten U. Factors maintaining the intraurethral pressure in women. Investig Urol. 1980;17(4):343-7.

70. Moher D, Liberati A, Tetzlaff J, Altman DG, Group P. Preferred reporting items for systematic reviews and meta-analyses: the PRISMA statement. PLoS Med. 2009;6(7):e1000097. https:// doi.org/10.1371/journal.pmed.1000097.

71. Armijo-Olivo S, Stiles CR, Hagen NA, Biondo PD, Cummings GG. Assessment of study quality for systematic reviews: a comparison of the Cochrane collaboration risk of Bias tool and the effective public health practice project quality assessment tool: methodological research. J Eval Clin Pract. 2012;18(1):12-8. https://doi.org/10.1111/j.1365-2753.2010.01516.x.

72. Hunskaar S, Burgio K, Clark A, Lapitan M, Nelson R, Sillen U, et al. Epidemiology of urinary (UI) and faecal (FI) incontinence and pelvic organ prolapse (POP). Incontinence. 2005;1:255-312.

73. Higgins JP, Altman DG, Gøtzsche PC, Jüni P, Moher D, Oxman $\mathrm{AD}$, et al. The Cochrane Collaboration's tool for assessing risk of bias in randomised trials. Bmj. 2011;343:d5928.

74. Viechtbauer W. Conducting meta-analyses in R with the metafor package. J Stat Softw. 2010;36(3):1-48.

75. Hedges LV. Distribution theory for Glass's estimator of effect size and related estimators. J Educ Stat. 1981;6(2):107-28.
76. Higgins JP, Thompson SG. Quantifying heterogeneity in a metaanalysis. Stat Med. 2002;21(11):1539-58. https://doi.org/10. 1002/sim. 1186.

77. Deng S, Jiang Q, Wang Y, Zhou Q, Zhang Y. ROC analysis and significance of transperineal ultrasound in the diagnosis of stress urinary incontinence. J Med Imaging Health Inform. 2020;10(1): 113-7. https://doi.org/10.1166/jmihi.2020.2864.

78. Weng X, Yang J, Xin X, Weng G. The significance of UVJ-M and PUVA in diagnosing stress urinary incontinence in women. Biomed Res (India). 2017;28(3):1305-9.

79. Beall J (2015) Criteria for determining predatory open-access publishers. https://crescent.education/wp-content/uploads/2017/09/ Criteria.pdf.

80. Aanestad O, Flink R. Urinary stress incontinence. A urodynamic and quantitative electromyographic study of the perineal muscles. Acta Obstet Gynecol Scand. 1999;78(3):245-53.

81. Al-Saadi WI. Transperineal ultrasonography in stress urinary incontinence: the significance of urethral rotation angles. Arab J Urol. 2016;14(1):66-71. https://doi.org/10.1016/j.aju.2015.11.003.

82. Bergman A, Ballard CA, Platt LD. Ultrasonic evaluation of urethrovesical junction in women with stress urinary incontinence. J Clin Ultrasound. 1988;16(5):295-300.

83. Bø K, Stien R, Kulseng-Hanssen S, Kristofferson M. Clinical and urodynamic assessment of nulliparous young women with and without stress incontinence symptoms: a case-control study. Obstet Gynecol. 1994;84(6):1028-32.

84. Cacciari LP, Amorim AC, Passaro AC, Dumoulin C, Sacco ICN. Intravaginal pressure profile of continent and incontinent women. J Biomech. 2020;99:109572. https://doi.org/10.1016/j.jbiomech. 2019.109572.

85. Carafini A, Sacco IC, Vieira MF. Pelvic floor pressure distribution profile in urinary incontinence: a classification study with feature selection. PeerJ. 2019;7. https://doi.org/10.7717/peerj.8207.

86. Carvalhais A, Da Roza T, Vilela S, Jorge RN, Bo K. Association between physical activity level and pelvic floor muscle variables in women. Int J Sports Med. 2018;39(13):995-1000. https://doi. org/10.1055/a-0596-7531.

87. Cassado J, Pessarrodona A, Tulleuda R, Cabero L, Valls M, Quintana S, et al. Introital ultrasonography: a comparison of women with stress incontinence due to urethral hypermobility and continent women. BJU Int. 2006;98(4):822-8. https://doi.org/10. 1111/j.1464-410X.2006.06404.x.

88. Cassado Garriga J, Pessarrodona Isern A, Rodriguez Carballeira M, Pallarols Badia M, Moya Del Corral M, Valls Esteve M, et al. Three-dimensional translabial ultrasound assessment of urethral supports and the urethral sphincter complex in stress urinary incontinence. Neurourol Urodyn. 2017;36(7):1839-45. https://doi. org/10.1002/nau.23193.

89. Chang HC, Chang SC, Kuo HC, Tsai TC. Transrectal sonographic cystourethrography: studies in stress urinary incontinence. Urology. 1990;36(6):488-92.

90. Chen GD, Su TH, Lin LY. Applicability of perineal sonography in anatomical evaluation of bladder neck in women with and without genuine stress incontinence. J Clin Ultrasound. 1997;25(4):189-94.

91. de Aguiar Cavalcanti G, Manzano GM, Nunes KF, Giuliano LM, de Menezes TA, Bruschini H. Electrophysiological evaluation of the pudendal nerve and urethral innervation in female stress urinary incontinence. Int Urogynecol J. 2013;24(5):801-7. https:// doi.org/10.1007/s00192-012-1931-8.

92. de Melo Silva R, Rodrigues MES, Puga GM, Dionisio VC, Baldon VSP, Resende APM. The relationship between running kinematics and the pelvic floor muscle function of female runners. Int Urogynecol J. 2020;31(1):155-63. https://doi.org/10.1007/ s00192-019-03968-z.

93. DeLancey JO, Trowbridge ER, Miller JM, Morgan DM, Guire K, Fenner DE, et al. Stress urinary incontinence: relative importance 
of urethral support and urethral closure pressure. J Urol. 2008;179(6):2286-90; discussion 2290. https://doi.org/10.1016/j. juro.2008.01.098.

94. dos Santos KM, Da Roza T, Mochizuki L, Arbieto ERM, Tonon da Luz SC. Assessment of abdominal and pelvic floor muscle function among continent and incontinent athletes. Int Urogynecol J. 2019;30(5):693-9. https://doi.org/10.1007/s00192-018-3701-8.

95. Frauscher F, Helweg G, Strasser H, Enna B, Klauser A, Knapp R, et al. Intraurethral ultrasound: diagnostic evaluation of the striated urethral sphincter in incontinent females. Eur Radiol. 1998;8(1): 50-3. https://doi.org/10.1007/s003300050336.

96. Henriksson L, Andersson KE, Ulmsten U. The urethral pressure profiles in continent and stress-incontinent women. Scand J Urol Nephrol. 1979a;13(1):5-10.

97. Henriksson L, Aspelin P, Ulmsten U. Combined urethrocystometry and cinefluorography in continent and incontinent women. Radiology. 1979b;130(3):607-11. https://doi.org/10.1148/130.3.607.

98. Hilton P, Stanton SL. Urethral pressure measurement by microtransducer: the results in symptom-free women and in those with genuine stress incontinence. Br J Obstet Gynaecol. 1983;90(10):919-33.

99. Hoffmann J, Ulrich J. Cystourethrography and female urinary stress incontinence. Acta Radiol Diagn (Stockh). 1966;4(1):1-13.

100. Hoyte L, Jakab M, Warfield SK, Shott S, Flesh G, Fielding JR. Levator ani thickness variations in symptomatic and asymptomatic women using magnetic resonance-based 3-dimensional color mapping. Am J Obstet Gynecol. 2004;191(3):856-61. https:// doi.org/10.1016/j.ajog.2004.06.067.

101. Kim JK, Kim YJ, Choo MS, Cho KS. The urethra and its supporting structures in women with stress urinary incontinence: MR imaging using an endovaginal coil. AJR Am J Roentgenol. 2003;180(4):1037-44. https://doi.org/10.2214/ajr.180.4. 1801037.

102. Kirschner-Hermanns R, Klein HM, Muller U, Schafer W, Jakse G. Intra-urethral ultrasound in women with stress incontinence. $\mathrm{Br} \mathrm{J}$ Urol. 1994;74(3):315-8.

103. Kondo A, Narushima M, Yoshikawa Y, Hayashi H. Pelvic fascia strength in women with stress urinary incontinence in comparison with those who are continent. Neurourol Urodyn. 1994;13(5):507-13.

104. Kondo Y, Homma Y, Takahashi S, Kitamura T, Kawabe K. Transvaginal ultrasound of urethral sphincter at the mid urethra in continent and incontinent women. J Urol. 2001;165(1):149-52. https://doi.org/10.1097/00005392-200101000-00036.

105. Kuhn A, Kuhn P, Dreher E. The correlation of urethral resistance pressure with maximum urethral closure pressure and stress incontinence. Eur J Obstet Gynecol Reprod Biol. 2008;136(1):116-20. https://doi.org/10.1016/j.ejogrb.2007.04.002.

106. Kuo HC. Transrectal sonographic investigation of urethral and paraurethral structures in women with stress urinary incontinence. J Ultrasound Med. 1998;17(5):311-20.

107. Leitner M, Moser H, Eichelberger P, Kuhn A, Baeyens JP, Radlinger L. Evaluation of pelvic floor kinematics in continent and incontinent women during running: an exploratory study. Neurourol Urodyn. 2017;37(2):609-18.

108. Lemos AQ, Brasil CA, Alvares CM, Passos JCG, Lordelo P, Sa $\mathrm{KN}$. The relation of the pelvis and the perineal function in incontinent women: a neglected subject. Neurourol Urodyn. 2018;37(8):2799-809. https://doi.org/10.1002/nau.23772.

109. Li YQ, Geng J, Tan C, Tang J, Yang X. Diagnosis and classification of female stress urinary incontinence by transperineal twodimensional ultrasound. Technol Health Care. 2017;25(5):85966. https://doi.org/10.3233/THC-160786.

110. Li N, Cui C, Cheng Y, Wu Y, Yin J, Shen W. Association between magnetic resonance imaging findings of the pelvic floor and de novo stress urinary incontinence after vaginal delivery. Korean J Radiol. 2018;19(4):715-23. https://doi.org/10.3348/kjr.2018.19.4.715.
111. Li M, Wang B, Liu X, Qiao P, Jiao W, Jiang T. MR defecography in the assessment of anatomic and functional abnormalities in stress urinary incontinence before and after pelvic reconstruction. Eur J Radiol. 2020;126:108935. https://doi.org/10.1016/j.ejrad. 2020.108935.

112. Liang CC, Chang SD, Chang YL, Wei TY, Wu HM, Chao AS. Three-dimensional power Doppler measurement of perfusion of the periurethral tissue in incontinent women - a preliminary report. Acta Obstet Gynecol Scand. 2006;85(5):608-13. https://doi.org/ 10.1080/00016340500342920.

113. Lukanovic A, Patrelli TS. Validation of ultrasound scan in the diagnosis of female stress urinary incontinence. Clin Exp Obstet Gynecol. 2011;38(4):373-8.

114. Macura KJ, Thompson RE, Bluemke DA, Genadry R. Magnetic resonance imaging in assessment of stress urinary incontinence in women: parameters differentiating urethral hypermobility and intrinsic sphincter deficiency. World J Radiol. 2015;7(11):394-404. https://doi.org/10.4329/wjr.v7.i11.394.

115. Mattiasson A, Teleman P. Abnormal urethral motor function is common in female stress, mixed, and urge incontinence. Neurourol Urodyn. 2006;25(7):703-8. https://doi.org/10.1002/nau.20207.

116. Meyer S, Kuntzer T, Newsom N, de Grandi P. Stress urinary incontinence due to a low-pressure urethra: a socially invalidizing disease. Neurourol Urodyn. 1996a;15(3):177-86. https://doi.org/10.1002/ (SICI)1520-6777(1996)15:3<177::AID-NAU2>3.0.CO;2-C.

117. Meyer S, De Grandi P, Schreyer A, Caccia G. The assessment of bladder neck position and mobility in continent nullipara, mulitpara, forceps-delivered and incontinent women using perineal ultrasound: a future office procedure? Int Urogynecol J. 1996b;7(3):138-46.

118. Moser H, Leitner M, Eichelberger P, Kuhn A, Baeyens JP, Radlinger L. Pelvic floor muscle displacement during jumps in continent and incontinent women: an exploratory study. Neurourol Urodyn. 2019;38(8):2374-82. https://doi.org/10. 1002/nau.24161.

119. Najjari L, Janetzki N, Kennes L, Stickeler E, Serno J, Behrendt J. Comparison of perineal Sonographically measured and functional urodynamic urethral length in female urinary incontinence. Biomed Res Int. 2016;2016:4953091. https://doi.org/10.1155/ 2016/4953091.

120. Olgan S, Mantar OP, Okyay RE, Gulekli B. Quantitative sonographic differences in mid-urethra between postmenopausal women with and without stress urinary incontinence. Gynecol Obstet Investig. 2016;81(3):256-61. https://doi.org/10.1159/000445748.

121. Oliveira E, Castro RA, Takano CC, Bezerra LR, Sartori MG, Lima GR, et al. Ultrasonographic and Doppler velocimetric evaluation of the levator ani muscle in premenopausal women with and without urinary stress incontinence. Eur J Obstet Gynecol Reprod Biol. 2007;133(2):213-7. https://doi.org/10.1016/j.ejogrb.2006.04.042.

122. Pizzoferrato A-C, Fauconnier A, Fritel X, Bader G, Dompeyre P. Urethral closure pressure at stress: a predictive measure for the diagnosis and severity of urinary incontinence in women. Int Neurourol J. 2017;21(2):121.

123. Rinne KM, Kainulainen S, Aukee S, Heinonen S, Nilsson CG. Dynamic magnetic resonance imaging of the behavior of the midurethra in healthy and stress incontinent women. Acta Obstet Gynecol Scand. 2010;89(3):373-9. https://doi.org/10.3109/ 00016340903555982.

124. Schaer GN, Perucchini D, Munz E, Peschers U, Koechli OR, Delancey JO. Sonographic evaluation of the bladder neck in continent and stress-incontinent women. Obstet Gynecol. 1999;93(3): 412-6.

125. Sendag F, Vidinli H, Kazandi M, Itil IM, Askar N, Vidinli B, et al. Role of perineal sonography in the evaluation of patients with stress urinary incontinence. Aust N Z J Obstet Gynaecol. 2003;43(1):54-7. 
126. Snooks SJ, Badenoch DF, Tiptaft RC, Swash M. Perineal nerve damage in genuine stress urinary incontinence. An electrophysiological study. Br J Urol. 1985;57(4):422-6.

127. Stoker J, Rociu E, Bosch JL, Messelink EJ, van der Hulst VP, Groenendijk AG, et al. High-resolution endovaginal MR imaging in stress urinary incontinence. Eur Radiol. 2003;13(8):2031-7. https://doi.org/10.1007/s00330-003-1855-2.

128. Takahashi S, Homma Y, Fujishiro T, Hosaka Y, Kitamura T, Kawabe K. Electromyographic study of the striated urethral sphincter in type 3 stress incontinence: evidence of myogenicdominant damages. Urology. 2000;56(6):946-50.

129. Varma JS, Fidas A, McInnes A, Smith AN, Chisholm GD. Neurophysiological abnormalities in genuine female stress urinary incontinence. Br J Obstet Gynaecol. 1988;95(7):705-10.

130. Verelst M, Leivseth G. Force and stiffness of the pelvic floor as function of muscle length: a comparison between women with and without stress urinary incontinence. Neurourol Urodyn. 2007;26(6):852-7. https://doi.org/10.1002/nau.20415.

131. Weidner AC, Barber MD, Visco AG, Bump RC, Sanders DB. Pelvic muscle electromyography of levator ani and external anal sphincter in nulliparous women and women with pelvic floor dysfunction. Am J Obstet Gynecol. 2000;183(6):1390-9; discussion 1399-1401. https://doi.org/10.1067/mob.2000.111073.

132. Weil EH, van Waalwijk van Doorn ES, Heesakkers JP, Meguid T, Janknegt RA. Transvaginal ultrasonography: a study with healthy volunteers and women with genuine stress incontinence. Eur Urol. 1993;24(2):226-30.

133. Wlazlak E, Kluz T, Surkont G, Kociszewski J. Urethral funneling visualized during pelvic floor sonography - analysis of occurrence among urogynecological patients. Ginekol Pol. 2018;89(2):5561. https://doi.org/10.5603/GP.a2018.0010.

134. Yang JM, Huang WC. Discrimination of bladder disorders in female lower urinary tract symptoms on ultrasonographic cystourethrography. J Ultrasound Med. 2002;21(11):1249-55.

135. Yang JM, Yang SH, Huang WC, Tzeng CR. Impact of two reflex pelvic floor muscle contraction patterns on female stress urinary incontinence. Ultraschall Med. 2013;34(4):335-9. https://doi.org/ 10.1055/s-0032-1313206.

136. Zhao B, Wen L, Chen W, Qing Z, Liu D, Liu M. A preliminary study on quantitative quality measurements of the urethral Rhabdosphincter muscle by supersonic shear wave imaging in women with stress urinary incontinence. J Ultrasound Med. 2020. https://doi.org/10.1002/jum.15255.

137. Singla P, Long SS, Long CM, Genadry RR, Macura KJ. Imaging of the female urethral diverticulum. Clin Radiol. 2013;68(7): e418-25. https://doi.org/10.1016/j.crad.2013.02.006.

138. Tunn R, Goldammer K, Gauruder-Burmester A, Wildt B, Beyersdorff D. Pathogenesis of urethral funneling in women with stress urinary incontinence assessed by introital ultrasound. Ultrasound Obstet Gynecol. 2005;26(3):287-92. https://doi.org/ 10.1002/uog.1977.

139. Delancey JOL. Pubovesical ligament: a separate structure from the urethral supports ("Pubo-urethral ligaments"). Neurourol Urodyn. 1989;8:53-61.

140. Caputo RM, Benson JT. The Q-tip test and urethrovesical junction mobility. Obstet Gynecol. 1993;82(6):892-6.

141. Besomi M, Hodges PW, Clancy EA, Van Dieën J, Hug F, Lowery $\mathrm{M}$, et al. Consensus for experimental design in electromyography (CEDE) project: amplitude normalization matrix. J Electromyogr Kinesiol. 2020;53:102438. https://doi.org/10.1016/j.jelekin.2020. 102438

142. Konrad P. The ABC of EMG A practical introduction to kinesiological electromyography. 2005.

143. Delancey JO. Why do women have stress urinary incontinence? Neurourol Urodyn. 2010;29(Suppl 1):S13-7. https://doi.org/10. 1002/nau.20888.
144. Carlile A, Davies I, Rigby A, Brocklehurst JC. Age changes in the human female urethra: a morphometric study. J Urol. 1988;139(3):532-5.

145. Verelst M, Maltau JM, Orbo A. Computerised morphometric study of the paraurethral tissue in young and elderly women. Neurourol Urodyn. 2002;21(6):529-33. https://doi.org/10.1002/nau.10089.

146. Zhou HH, Shu B, Liu TZ, Wang XH, Yang ZH, Guo YL. Association between parity and the risk for urinary incontinence in women: a meta-analysis of case-control and cohort studies. Medicine (Baltimore). 2018;97(28):e11443. https://doi.org/10. 1097/MD.0000000000011443.

147. Subak LL, Richter HE, Hunskaar S. Obesity and urinary incontinence: epidemiology and clinical research update. J Urol. 2009;182(6 Suppl):S2-7. https://doi.org/10.1016/j.juro.2009.08.071.

148. Bump RC, McClish DK. Cigarette smoking and urinary incontinence in women. Am J Obstet Gynecol. 1992;167(5):1213-8.

149. Nygaard IE, Shaw JM. Physical activity and the pelvic floor. Am J Obstet Gynecol. 2016;214(2):164-71.

150. Thom DH, van den Eeden SK, Ragins AI, Wassel-Fyr C, Vittinghof E, Subak LL, et al. Differences in prevalence of urinary incontinence by race/ethnicity. J Urol. 2006;175(1):259-64. https://doi.org/10.1016/s0022-5347(05)00039-x.

151. Lose G, Griffiths D, Hosker G, Kulseng-Hanssen S, Perucchini D, Schafer W, et al. Standardisation of urethral pressure measurement: report from the standardisation sub-Committee of the International Continence Society. Neurourol Urodyn. 2002;21(3):258-60.

152. Saltiel F, Miranda-Gazzola APG, Vitória RO, Figueiredo EM. Terminology of pelvic floor muscle function in women with and without urinary incontinence: a systematic review. Phys Ther. 2018;98(10):876-90.

153. Daube JR, Sorenson EJ. Needle electromyography, vol 4. Handbook of Clinical Neurophysiology. Elsevier. 2004.

154. Daube JR, Rubin DI. Needle electromyography. Muscle Nerve. 2009;39(2):244-70. https://doi.org/10.1002/mus.21180.

155. Heesakkers J, Gerretsen R, Izeta A, Sievert KD, Farag F. Circumferential urinary sphincter surface electromyography: a novel diagnostic method for intrinsic sphincter deficiency. Neurourol Urodyn. 2016;35(2):186-91. https://doi.org/10.1002/nau.22711.

156. Stav K, Dwyer PL, Rosamilia A, Schierlitz L, Lim YN, Lee J. Risk factors of treatment failure of midurethral sling procedures for women with urinary stress incontinence. Int Urogynecol J. 2010;21(2):149-55. https://doi.org/10.1007/s00192-009-1020-9.

157. Garg N, Howells J, Yiannikas C, Vucic S, Krishnan AV, Spies J, et al. Motor unit remodelling in multifocal motor neuropathy: the importance of axonal loss. Clin Neurophysiol. 2017;128(10): 2022-8. https://doi.org/10.1016/j.clinph.2017.07.414.

158. Dumoulin C, Cacciari LP, Hay-Smith EJC (2018) Pelvic floor muscle training versus no treatment, or inactive control treatments, for urinary incontinence in women. Cochrane Database Syst Rev (10).

159. Madill SJ, Pontbriand-Drolet S, Tang A, Dumoulin C. Changes in urethral sphincter size following rehabilitation in older women with stress urinary incontinence. Int Urogynecol J. 2015;26(2): 277-83. https://doi.org/10.1007/s00192-014-2507-6.

160. Ribeiro AM, Mateus-Vasconcelos ECL, Silva TDD, Brito LGDO, Oliveira HFD. Functional assessment of the pelvic floor muscles by electromyography: is there a normalization in data analysis? A systematic review. Fisioterapia e Pesquisa. 2018;25(1):88-99.

161. Abitteboul Y, Leonard F, Mouly L, Riviere D, Oustric S. Urinary incontinence in non-professional female marathon runners. Progres en urologie: journal de l'Association francaise d'urologie et de la Societe francaise d'urologie. 2015;25(11):636-41.

Publisher's note Springer Nature remains neutral with regard to jurisdictional claims in published maps and institutional affiliations. 